\title{
TRATAMENTO INSETICIDA E QUALIDADE DE SEMENTES DE MILHO DURANTE O ARMAZENAMENTO
}

\author{
OSCAR JOSÉ SMIDERLE \\ Engenheiro Agrônomo
}

Orientador: Prof. Dr. SILVIO MOURE CICERO

Tese apresentada à Escola Superior de Agricultura "Luiz de Queiroz", da Universidade de São Paulo, para obtençäo do título de Doutor em Agronomia, Área de Concentração: Fitotecnia.

PIR A C ICABA

Estado de São Paulo - Brasil

Agosto - 1998 
Dados Internacionais de Catalogação na Publicação (CIP)

DIVISĀO DE BIBLIOTECA E DOCUMENTAÇĀO - Campus "Luiz de Queiroz"/USP

Smiderle, Oscar José

Tratamento inseticida e qualidade de sementes de milho durante o armazenamento / Oscar José Smiderle. - - Piracicaba, 1998

$81 \mathrm{p}$.

Tese (doutorado) - Escola Superior de Agricultura Luiz de Queiroz, 1998.

Bibliografia.

1. Armazenamento agricola 2. Inseticida 3. Inseto 4. Semente de milho 5 . Terra diatomácea 6. Tratamento I. Titulo

CDD 633.15 
Aos meus pais:

João Agostinho e Basilica Mafalda 


\section{AGRADECIMENTOS}

Ao Professor Silvio Moure Cicero pela amizade, apoio e orientação na realização da Tese.

Ao corpo docente da ESALQ/USP, especialmente aos Professores Doutores Walter Rodrigues da Silva, Francisco Ferraz de Toledo, Durval Dourado Neto, Keigo Minami, Maria Cristina Stolf Nogueira, Geraldo José Aparecido Dario, José Otávio Machado Menten, Paulo Roberto de Camargo Castro, Marcos Silveira Bernardes e Gil Miguel de Souza Câmara, pela constante assistência no transcorrer do Curso.

À Coordenação de Aperfeiçoamento do Pessoal de Ensino Superior (CAPES) pela concessão da Bolsa de Estudos e à Fundação de Amparo à Pesquisa do Estado de São Paulo (FAPESP) pelo suporte financeiro para a realização do projeto.

Ao corpo docente da FAEM/UFPel, especialmente aos Professores Doutores Alci Enimar Loeck, Francisco Amaral Villela, Elói Pauletto e Silmar Peske, pelo incentivo e formação profissional propiciada.

À EMBRAPA, Centro de Pesquisa Agroflorestal de Roraima, nas pessoas de seus Chefes, Daniel Gianluppi e Wellington Costa do Ó, pela oportunidade de conclusão do Curso.

Às Empresas Zeneca Agrícola, Sementes Agroceres e Sementes Fartura pela cessão das sementes para a pesquisa e às Empresas Keepdry, Casa Bernardo, AgrEvo e Prodelyn Química por fornecer os produtos para tratamento das sementes

Ao Professor Dr. Carlos Tadeu dos Santos Dias, do Departamento de Matemática e Estatística da ESALQ/USP, pela colaboração nas análises estatísticas. 
Aos Engenheiros Agrônomos Maria Heloísa Duarte de Moraes, Helena Maria P. Chamma e Edson Teramoto, pela coloração prestada e auvilio constante.

Aos colegas de curso, em especial aos amigos Marluce Cortez, Luciana Gusmão, Marcos Botton, Renata Waldemarin Maschietto, Cristina Maria Ribeiro, Pedro Abel Vieira Júnior, Leila Martins, Fernanda Caliari, Marcelo Miguel, Mariane Carvalho, Luiz Ferraro, João Kluthcouski, João Gadioli, Carlos Cicero, Mônica Martins, Maria Cristina Spinola, Maristela Panobianco, Clóvis Peixoto, Lídia e Renata Almeida, pelo apoio, incentivo e bons momentos compartilhados.

Aos funcionários da ESALQ/USP Antônio Arruda, Osvaldo Pelissari, Adilson Teixeira, Ananias Souza, Ilze Helena C.G. das Neves, Adriana Gimenes, Maria Aparecida Soledade, Edson Moraes, Celestino Ferreira, João Jabur, João Bigelli e em especial às bibliotecárias Eliana M.G. Sabino e Kátia M.A. Ferraz, pelo apoio e colaboração.

A todos que contribuíram para a realização deste trabalho. 


\section{SUMÁRIO}

Página

LISTA DE FIGURAS.................................................................................... vii

LISTA DE TABELAS................................................................................. viii

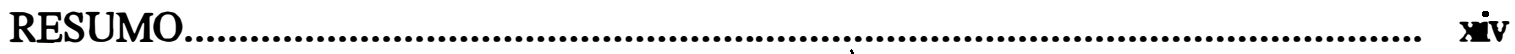

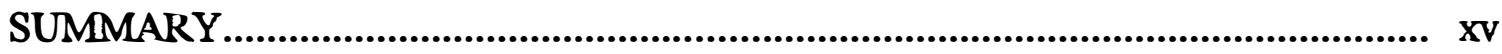

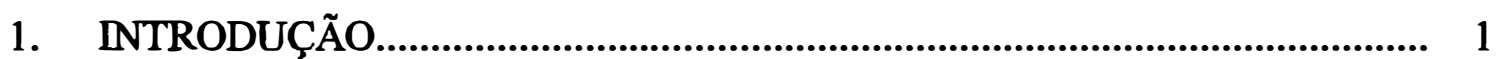

2. REVISÃO DE LITERATURA.............................................................. 3

3. MATERIAL E MÉTODOS.................................................................... 17

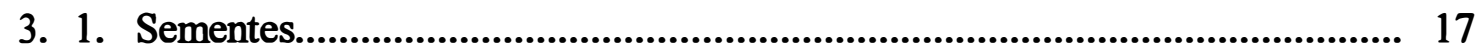

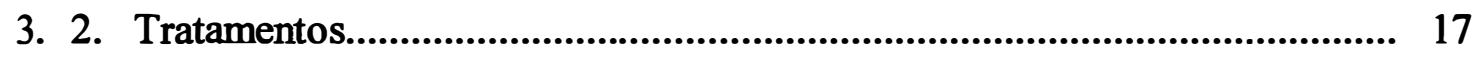

3. 3. Aplicação dos produtos nas sementes........................................................... 18

3. 4. Embalagem e armazenamento............................................................... 19

3. 5. Período experimental.............................................................................. 19

3. 6. Determinações de laboratório................................................................. 19

3. 6. 1. Determinação do teor de água................................................................ 19

3. 6. 2. Exame de sementes infestadas................................................................. 20

3. 6. 3. Massa de 100 sementes................................................................... 21

3. 6. 4. Teste de germinação................................................................................. 21

3. 6. 5. Teste de frio............................................................................... 21

3. 6. 6. Envelhecimento acelerado..................................................................... 21

3. 6. 7. Condutividade elétrica...................................................................... 22

3. 6. 8. Persistência dos produtos aplicados nas sementes...................................... 22

3. 7. Determinações de campo.......................................................................... 22

3. 7. 1. Emergência de plântulas em campo........................................................... 22

3. 7. 2. Velocidade de emergência de plântulas..................................................... 23

3. 8. Procedimento estatístico......................................................................... 24 


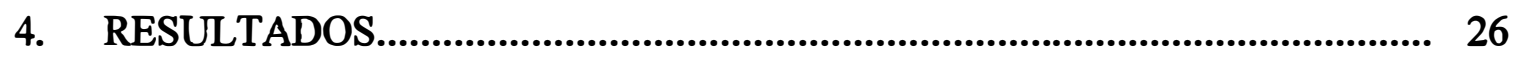

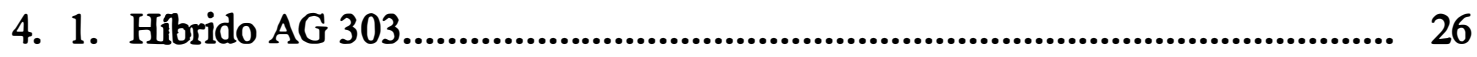

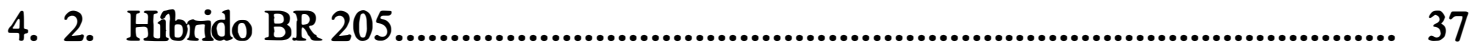

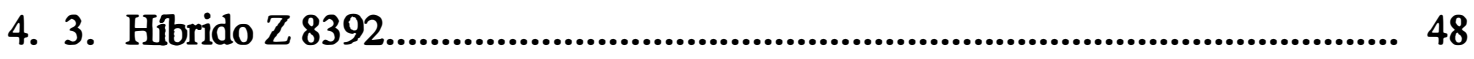

4. 4. Persistência dos produtos aplicados nas sementes.......................................... 58

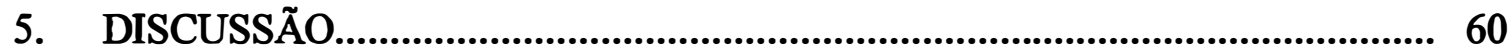

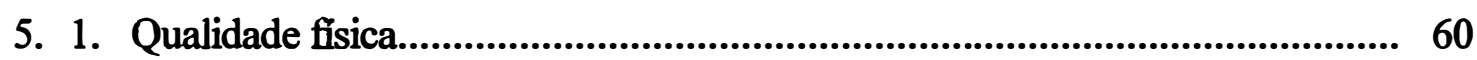

5. 2. Qualidade fisiológica................................................................................ 62

5. 3. Persistência dos produtos aplicados nas sementes......................................... 64

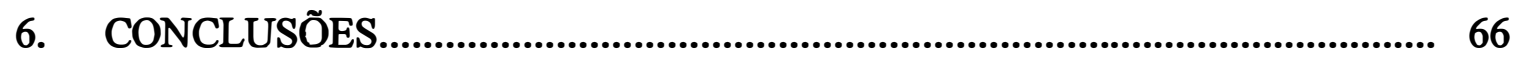

REFERÊNCIAS BIBLIOGRÁFICAS.............................................................67 


\section{LISTA DE FIGURAS}

Página

1. Dados climáticos registrados durante o período de armazenamento das sementes de milho no Laboratório de Análise de Sementes do LAG/ESALQ/USP, no município de Piracicaba-SP.............................................. 20

2. Dados climáticos coletados durante o período de realização do trabalho, no Posto Agrometeorológico do Departamento de Física e Meteorologia LFM/ESALQ/USP, coordenadas: latitude $22^{\circ} 42^{\prime} 30^{\prime \prime}$; longitude $47^{\circ} 38^{\prime} 30^{\prime \prime}$; altitude 546 metros, no município de Piracicaba-SP........................................... 


\section{LISTA DE TABELAS}

Página

1. Tratamentos realizados para cada híbrido, nomenclatura e doses utilizadas nos tratamentos

2. Esquema utilizado para análise de variância dos dados relativos à sementes infestadas- SI, massa de 100 sementes- M100S, teste de germinação- TG, teste de frio- TF, envelhecimento acelerado- EA e condutividade elétrica- CE, para cada híbrido e em cada época de avaliação

3. Esquema utilizado para análise de variância dos dados obtidos na avaliação de persistência dos produtos aplicados nas sementes, para cada híbrido.

4. Esquema utilizado para análise de variância dos dados obtidos nas determinações de campo, para cada híbrido e em cada época de avaliação

5. Híbrido AG 303: teores médios de água (\%) das sementes, observados nos tratamentos nas sete épocas de avaliação, durante 12 meses de armazenamento. 26

6. Híbrido AG 303: valores de F, para as determinações de laboratório (sementes infestadas-SI, massa de 100 sementes-M100S, teste de germinação-TG, teste de frio-TF, envelhecimento acelerado-EA e condutividade elétrica-CE) e de campo (emergência de plântulas em campo-EC e velocidade de emergência$\mathrm{VE})$, calculados para as sete épocas.

7. Hibrido AG 303- Primeira época: médias relativas ao exame de sementes infestadas (SI), massa de 100 sementes (M100S), teste de germinação (TG), teste de frio (TF), envelhecimento acelerado (EA), condutividade elétrica (CE), 
emergência de plântulas em campo (EC), velocidade de emergência (VE) e respectivos coeficientes de variação (C.V., \%)...................................................

8. Hibrido AG 303- Segunda época: médias relativas ao exame de sementes infestadas (SI), massa de 100 sementes (M100S), teste de germinação (TG), teste de frio (TF), envelhecimento acelerado (EA), condutividade elétrica (CE), emergência de plântulas em campo (EC), velocidade de emergência (VE) e respectivos coeficientes de variação (C.V., \%).....................................................

9. Hibrido AG 303- Terceira época: médias relativas ao exame de sementes infestadas (SI), massa de 100 sementes (M100S), teste de germinação (TG), teste de frio (TF), envelhecimento acelerado (EA), condutividade elétrica (CE), emergência de plântulas em campo (EC), velocidade de emergência (VE) e respectivos coeficientes de variação (C.V., \%).

10. Hibrido AG 303- Quarta época: médias relativas ao exame de sementes infestadas (SI), massa de 100 sementes (M100S), teste de germinação (TG), teste de frio (TF), envelhecimento acelerado (EA), condutividade elétrica (CE), emergência de plântulas em campo (EC), velocidade de emergência (VE) e respectivos coeficientes de variação (C.V., \%).....................................................

11. Híbrido AG 303- Quinta época: médias relativas ao exame de sementes infestadas (SI), massa de 100 sementes (M100S), teste de germinação (TG), teste de frio $(\mathrm{TF})$, envelhecimento acelerado (EA), condutividade elétrica ( $\mathrm{CE})$, emergência de plântulas em campo (EC), velocidade de emergência (VE) e respectivos coeficientes de variação (C.V., \%)

12. Híbrido AG 303- Sexta época: médias relativas ao exame de sementes infestadas (SI), massa de 100 sementes (M100S), teste de germinação (TG), 
teste de frio (TF), envelhecimento acelerado (EA), condutividade elétrica (CE), emergência de plântulas em campo (EC), velocidade de emergência (VE) e respectivos coeficientes de variação (C.V., \%)

13. Híbrido AG 303- Sétima época: médias relativas ao exame de sementes infestadas (SI), massa de 100 sementes (M100S), teste de germinação (TG), teste de frio (TF), envelhecimento acelerado (EA), condutividade elétrica (CE), emergência de plântulas em campo (EC), velocidade de emergência (VE) e respectivos coeficientes de variação (C.V. \%)..................................................... 36

14. Híbrido BR 205: teores médios de água (\%) das sementes, observados nos tratamentos nas sete épocas de avaliação, durante 12 meses de armazenamento.

15. Hibrido $B R$ 205: valores de F, para as determinações de laboratório (sementes infestadas-SI, massa de 100 sementes-M100S, teste de germinação-TG, teste de frio-TF, envelhecimento acelerado-EA e condutividade elétrica-CE) e de campo (emergência de plântulas em campo-EC e velocidade de emergência$\mathrm{VE})$, calculados para as sete épocas.

16. Hibrido BR 205- Primeira época: médias relativas ao exame de sementes infestadas (SI), massa de 100 sementes (M100S), teste de germinação (TG), teste de frio (TF), envelhecimento acelerado (EA), condutividade elétrica (CE), emergência de plântulas em campo (EC) e velocidade de emergência (VE) e respectivos coeficientes de variação (C.V., \%)...................................................... 39

17. Híbrido BR 205- Segunda época: médias relativas ao exame de sementes infestadas (SI), massa de 100 sementes (M100S), teste de germinação (TG), teste de frio $(\mathrm{TF})$, envelhecimento acelerado (EA), condutividade elétrica (CE), emergência de plântulas em campo (EC), velocidade de emergência (VE) e 
respectivos coeficientes de variação (C.V., \%).

18. Híbrido BR 205- Terceira época: médias relativas ao exame de sementes infestadas (SI), massa de 100 sementes (M100S), teste de germinafão (TG), teste de frio (TF), envelhecimento acelerado (EA), condutividade elétrica (CE), emergência de plântulas em campo (EC), velocidade de emergência (VE) e respectivos coeficientes de variação (C.V., \%).

19. Híbrido BR 205- Quarta época: médias relativas ao exame de sementes infestadas (SI), massa de 100 sementes (M100S), teste de germinação (TG), teste de frio (TF), envelhecimento acelerado (EA), condutividade elétrica (CE), emergência de plântulas em campo (EC), velocidade de emergência (VE) e respectivos coeficientes de variação (C.V., \%).

20. Híbrido BR 205- Quinta época: médias relativas ao exame de sementes infestadas (SI), massa de 100 sementes (M100S), teste de germinação (TG), teste de frio (TF), envelhecimento acelerado (EA), condutividade elétrica (CE), emergência de plântulas em campo (EC), velocidade de emergência (VE) e respectivos coeficientes de variação (C.V., \%)

21. Híbrido BR 205- Sexta época: médias relativas ao exame de sementes infestadas (SI), massa de 100 sementes (M100S), teste de germinação (TG), teste de frio (TF), envelhecimento acelerado (EA), condutividade elétrica (CE), emergência de plântulas em campo (EC), velocidade de emergência (VE) e respectivos coeficientes de variação (C.V., \%).

22. Híbrido BR 205- Sétima época: médias relativas ao exame de sementes infestadas (SI), massa de 100 sementes (M100S), teste de germinação (TG), teste de frio (TF), envelhecimento acelerado (EA), condutividade elétrica (CE), 
emergência de plântulas em campo (EC), velocidade de emergência (VE) e respectivos coeficientes de variação (C.V., \%).

23. Híbrido $Z$ 8392: teores médios de água (\%) das sementes, observados nos tratamentos nas sete épocas de avaliação, durante 12 meses de armazenamento. 48

24. Híbrido $Z$ 8392: valores de $F$, para as determinações de laboratório (sementes infestadas-SI, massa de 100 sementes-M100S, teste de genninação-TG, teste de frio-TF, envelhecimento acelerado-EA e condutividade elétrica-CE) e de campo (emergência de plântulas em campo-EC e velocidade de emergência$V E)$, calculados para as sete épocas.

25. Híbrido $Z$ 8392- Primeira época: médias relativas ao exame de sementes infestadas (SI), massa de 100 sementes (M100S), teste de germinação (TG), teste de frio (TF), envelhecimento acelerado (EA), condutividade elétrica (CE), emergência de plântulas em campo (EC), velocidade de emergência (VE) e respectivos coeficientes de variação (C.V., \%)

26. Híbrido Z 8392- Segunda época: médias relativas ao exame de sementes infestadas (SI), massa de 100 sementes (M100S), teste de germinação (TG), teste de frio (TF), envelhecimento acelerado (EA), condutividade elétrica (CE), emergência de plântulas em campo (EC), velocidade de emergência (VE) e respectivos coeficientes de variação (C.V., \%)

27. Híbrido Z 8392- Terceira época: médias relativas ao exame de sementes infestadas (SI), massa de 100 sementes (M100S), teste de germinação (TG), teste de frio (TF), envelhecimento acelerado (EA), condutividade elétrica (CE), emergência de plântulas em campo (EC), velocidade de emergência (VE) e respectivos coeficientes de variação (C.V., \%). 
28. Hibrido $\mathrm{Z}$ 8392- Quarta época: médias relativas ao exame de sementes infestadas (SI), massa de 100 sementes (M100S), teste de germinação (TG), teste de frio (TF), envelhecimento acelerado (EA), condutividade elétrica (CE), emergência de plântulas em campo (EC), velocidade de emergência (VE) e respectivos coeficientes de variação (C.V., \%)

29. Hibrido Z 8392- Quinta época: médias relativas ao exame de sementes infestadas (SI), massa de 100 sementes (M100S), teste de germinação (TG), teste de frio (TF), envelhecimento acelerado (EA), condutividade elétrica (CE), emergência de plântulas em campo (EC), velocidade de emergência (VE) e respectivos coeficientes de variação (C.V., \%)

30. Hibrido Z 8392- Sexta época: médias relativas ao exame de sementes infestadas (SI), massa de 100 sementes (M100S), teste de germinação (TG), teste de frio (TF), envelhecimento acelerado (EA), condutividade elétrica (CE), emergência de plântulas em campo (EC), velocidade de emergência (VE) e respectivos coeficientes de variação (C.V., \%)

31. Híbrido Z 8392- Sétima época: médias relativas ao exame de sementes infestadas (SI), massa de 100 sementes (M100S), teste de germinação (TG), teste de frio (TF), envelhecimento acelerado (EA), condutividade elétrica (CE), emergência de plântulas em campo (EC), velocidade de emergência (VE) e respectivos coeficientes de variação (C.V., \%).

32. Dados médios, em porcentagem, de controle de Sitophilus zeamais Motsch. proporcionado pelos produtos, 360 dias após a aplicação, em sementes de milho dos híbridos (AG 303, BR 205 e $Z$ 8392) e respectivos coeficientes de variação (C.V., \%) 


\title{
TRATAMENTO INSETICIDA E QUALIDADE DE SEMENTES DE MILHO DURANTE O ARMAZENAMENTO
}

\author{
Autor: Oscar José Smiderle \\ Orientador: Prof. Dr. Silvio Moure Cicero
}

\section{RESUMO}

A presente pesquisa, condurida no Laboratório de Análise de Sementes e no Campo Experimental do Departamento de Agricultura, da Escola Superior de Agriculturd "Luiz de Queiroz", da Universidade de São Paulo, em Piracicaba, Estado de São Paulo, objetivou verificar os efeitos dos inseticidas químicos deltamerina, chlorpirifos, fosfina e da terra diatomácea no controle de insetos e na qualidade de sementes de milho armazenadas visando oferecer alternativas de produtos inseticidas. As sementes dos híbridos AG 303, BR 205 e Z 8392, tratadas com deltametrina e chlorpirifos, aplicados na forma isolada ou em combinação, fosfina e terra diatomácea foram acondicionadas em sacos de papel multifoliado e armazenadas por até doze meses (maio/1997 a abril/1998) em condições normais de ambiente. Em intervalos bimestrais, sete épocas no total, as sementes foram submetidas às seguintes determinações: exame de sementes infestadas, massa de 100 sementes, teste de germinação, teste de frio, envelhecimento acelerado, condutividade elétrica, emergência de plântulas em campo e velocidade de emergência de plântulas. A análise dos dados e interpretação dos resultados permitiram concluir que: a) os inseticidas químicos deltametrina e chlorpirifos, isolados ou associados, fosfina e a terra diatomácea promovem, de maneira similar, o controle de insetos-praga que ocorrem no armazenamento e não causam toxicidade às sementes de milho; b) a qualidade fisiológica das sementes de milho é preservada pelos ratamentos com os inseticidas químicos e a terra diatomácea. 


\title{
INSECTICIDE TREATMENT AND SEEDS QUALITY OF CORN DURING STORAGE
}

\author{
Author: Oscar José Smiderle \\ Adviser: Prof. Dr. Silvio Moure Cicero
}

\section{SUMMARY}

With the purpose to study the effects of insecticides (deltamethrin, chlorpyrifos, and diatomaceous earth) on the insects control in stored corn seeds during 12 months, looking for an alternative products, a research was conducted at the Seeds Analysis Laboratory and at the Experimental Field of the Agricultural Department, ESALQ, University of São Paulo, Piracicaba, São Paulo State. Seeds of diferent hybrids (AG 303, BR 205, and Z 8392) were treated with either isolated or combined deltamethrin and chlorpyrifos, diatomaceous earth, and expurgates; and further arranged into multifoliated paper sacks and stored for up to twelve months (Mai/1997 through April/1998) under normal environmental condition. The seeds were submitted to infested seeds exam, mass of 100 seeds, germination test, cold test, accelerated aging, electric conductivity test, emergence of seedlings in field and seedling emergence speed seven times in bimonthly intervals. The data analysis and the interpretation of the results showed that: a) deltamethrin and chlorpyrifos insecticides, alone or combined, diatomaceous earth, and phosphin promoted the control (similar manner) of pest-insects occuring during storage without causing toxicity to corn seeds; b) the physiological quality of corn seeds in all three hybrids is effectively preserved by the insecticides and diatomaceous earth treatments. 


\section{INTRODUÇÃO}

Dentre os diversos problemas enfrentados na produção e conservação de sementes de milho, um dos maiores refere-se às pragas durante o armazenamento, onde as perdas devido ao ataque situam-se em torno de $20 \%$ do produto armazenado, sendo que o adequado ammazenamento impediria a destruição, no Brasil, de três milhões de toneladas (Carvalho, 1978). Além dos prejuízos qualitativos (contaminação, degradação do valor nutricional, propagação e desenvolvimento de fungos) e quantitativos (redução do massa), o ataque de pragas às sementes pode causar perdas do poder germinativo e do vigor (Padilha \& Faroni, 1993).

Durante o período de armazenamento a preservação da qualidade das sementes não é absoluta. A medida mais eficaz e melhor para um bom armazenamento consiste inicialmente, em armazenar sementes de elevados atributos genéticos, fisicos, fisiológicos e sanitários (Popinigis, 1985). A velocidade de deterioração das sementes de milho pode também ser influenciada pelas condições e tempo de armazenamento (Christensen, 1966). O tratamento de sementes com inseticidas e fungicidas pode favorecer a manutenção da qualidade das sementes durante o armazenamento (Machado, 1988).

O estabelecimento das plântulas em campo, permitindo a obtenção de população adequada de plantas por unidade de área, constitui-se na base para atingir altos rendimentos agrícolas em culturas de expressão econômica. Desta maneira, o sucesso da emergência de plântulas representa uma meta prioritária dentro do processo de produção.

A emergência das plântulas em campo, de maneira geral, é o reflexo da qualidade fisiológica das sementes. Assim sendo, a responsabilidade pelas falhas na emergência, ou mesmo a redução de sua velocidade, freqüentemente é atribuída ao baixo vigor, associado ao processo de deterioração. 
Os trabalhos realizados para controle de insetos em sementes armazenadas, em sua maioria, são conduzidos com produtos químicos. Assim, considerando-se a importância econômica do milho, as características fisiológicas das sementes e seus problemas, o presente trabalho objetivou estudar os efeitos dos produtos deltametrina, chlorpirifos, fosfina e da terra diatomácea no controle de insetos e na qualidade de sementes de milho armazenadas visando oferecer alternativas de produtos inseticidas. 


\section{REVISĀO DE LITERATURA}

Atualmente o Brasil convive com perdas muito elevadas durante o armazenamento, devido a insetos que atacam sementes e grãos nesta fase (Santos et al., 1988a e 1988b; Barney et al., 1991; Santos, 1993). Apesar das vultuosas perdas, o setor armazenista do país ainda não se encontra em condições de reduzí-las a despeito do montante de conhecimentos acumulados sobre o assunto (Simpósio..., 1993).

A crise econômica e a lacuna existente entre o conhecimento teórico e sua aplicação prática são alguns dos empecilhos para redução de perdas. As causas de perdas podem ser devidas a fatores que antecedem a colheita, na própria colheita e na secagem e armazenamento. Vários fatores, tais como a qualidade inicial e condições fisicas das sementes, tratamento e embalagem podem afetar a viabilidade das sementes durante $o$ armazenamento (Carvalho \& Nakagawa, 1988).

O objetivo básico do armazenamento é manter o nível de qualidade das sementes até que sejam comercializadas e/ou utilizadas para semeadura. A capacidade de armazenamento de sementes em um ambiente é determinada por herança genética e pelo nível de deterioração das sementes no início do armazenamento (Delouche \& Baskin, 1973).

A deterioração é toda transformação degenerativa da semente, podendo ser de origem bioquímica, fisica, fisiológica ou genética. Trata-se de processo contínuo e com direção progressiva rumo à perda da viabilidade e mudanças nas propriedades fisicas e bioquímicas das sementes armazenadas. A velocidade do processo deteriorativo pode, até certo ponto, ser controlada pela adoção de técnicas adequadas de colheita, secagem, beneficiamento, manuseio e armazenamento (Popinigis, 1985). Para Anderson 
\& Baker (1983) a alta umidade relativa do ar e o teor de água das sementes acima de $12 \%$ aceleram a deterioração das sementes.

A deterioração de sementes durante o armazenamento pode ser afetada por diversos agentes tendo destaque os microorganismos e os insetos (Faroni, 1988). Delouche \& Baskin (1973) entendem a deterioração como uma seqüência de eventos, que inicia com a desorganização de membranas e perda de sua integridade e culmina com a redução do poder germinativo e morte da semente. Também nessa seqüência, são considerados a queda do potencial de armazenamento, o decréscimo da velocidade de germinação e da porcentagem de emergência e a ocorrência de anormalidades nas plântulas.

A qualidade da semente é fator a ser considerado em qualquer programa de produção agrícola, visto que as características agronômicas dos cultivares obtidos pela pesquisa chegam aos agricultores através da semente (Barros, 1986). A semente para expressar toda sua potencialidade deve possuir certos atributos de qualidade, estar presente em quantidade suficiente à disposição do agricultor e no momento apropriado. Entretanto, sementes de alta qualidade submetidas a práticas culturais inadequadas não terão condições de corresponder ao esperado e levam ao insucesso (Peske, 1988).

Qualidade de semente é o somatório de todos os atributos genéticos, fisicos, fisiológicos e sanitários que afetam sua capacidade de originar plantas e lavouras de alta produtividade (Popinigis, 1985). A qualidade fisica consiste na pureza fisica e na condição fisica da semente, caracterizada por aspectos relacionados com o teor de água, danos mecânicos, textura superficial, perda de massa, massa de mil sementes. A qualidade fisiológica está relacionada com a capacidade da semente em desempenhar funções vitais, caracterizada pela germinação, vigor e longevidade, ao passo que a qualidade sanitária compreende a condição da semente quanto à presença e grau de ocorrência de microorganismos e insetos (Mills, 1983).

A qualidade inicial das sementes é afetada por diversos fatores como: a) vigor das plantas que lhe deram origem; b) condições climáticas durante a maturação; c) estádio de maturação no momento da colheita; d) grau de dano mecânico; e) secagem (Carvalho \& Nakagawa, 1988). Muitos cuidados são requeridos para evitar a redução do 
potencial das sementes durante o armazenamento. As sementes ao serem armazenadas, apresentam níveis variáveis de qualidade, em função do que aconteceu durante o desenvolvimento no campo (Yamada, 1989).

Um lote de sementes armazenado é um ecossistema sujeito a transformações, deterioração e perdas devido a interações entre os fenômenos físicos, químicos e biológicos determinando a taxa de deterioração bioquímica e física durante o armazenamento (Mills, 1983; Sinha \& Sinha, 1992). Exercem grande influência nesse sistema os fatores temperatura, umidade, disponibilidade de oxigênio, microorganismos, insetos, roedores, tipos de unidades armazenadoras, localização geográfica e pássaros (Puzzi, 1986; Carvalho \& Nakagawa, 1988; Sinha \& Sinha, 1990; Santos, 1993; Wrigley et al., 1994).

Os fungos de armazenamento, principalmente Aspergillus sp. e Penicillium sp., são adaptados a ambiente com baixa umidade, podendo se desenvolver em materiais com teores de água em equilíbrio com a umidade relativa do ar de $65 \%$ a 90\% (Wetzel, 1987). Novembre \& Marcos Filho (1991) relataram que as condições de armazenagem de sementes, em baixa umidade e baixa temperatura não eliminam os "fungos de armazenamento", como Aspergillus sp. e Penicillium sp. Estes fungos são disseminados pela presença de insetos (Barney et al., 1995; Beti et al., 1995) e podem causar grandes danos à qualidade da semente armazenada (Harman, 1983).

Diversos são os danos causados por insetos às sementes, destacando-se as perdas de massa, da pureza física e da qualidade fisiológica. Estes danos podem iniciarse com o simples dano do tegumento, provocar um aumento na intensidade respiratória da semente e conseqüente redução do vigor (Carvalho \& Nakagawa, 1988). As sementes de milho, como as de outros cereais, podem trazer do campo infestação inicial de insetos, que é dependente do local (Sinha \& Sinha, 1990); durante o armazenamento a população de insetos cresce, proporcionando perdas consideráveis, incluindo a redução da porcentagem de germinação das sementes (Barney et al., 1991).

A qualidade da semente armazenada pode ser prejudicada pela presença de insetos que contribuem para aumento da temperatura, de $\mathrm{CO}_{2}$ no ambiente e pela redução do teor de oxigênio. Os embriões das sementes podem ser danificados ou mortos 
pela alimentação dos insetos ou oviposição (Howe, 1973; Barney et al., 1991). Os insetos, ainda, podem introduzir fungos na semente reduzindo a germinação, a emergência e debilitando a plântula (Howe, 1973; Caldwell et al., 1981; Bamey et al., 1991; Sinha \& Sinha, 1992).Os efeitos sobre a qualidade fisiológica, segundo Puzzi (1986), geralmente são raduzidos pelo decréscimo na porcentagem de germinação, no aumento de plântulas anormais e por redução de vigor das plântulas. Trabalhos desenvolvidos por Matioli \& Almeida (1979) e Santos \& Oliveira (1991), com Sitophilus oryzae, em sementes de milho, e Smiderle \& Belarmino (1993) e Smiderle et al. (1997), em sementes de arroz, ilustram os efeitos causados pelos insetos às sementes.

A ação de insetos sobre as sementes constitui-se problema para o armazenamento, acarretando perda de qualidade (Howe, 1973). Segundo Carvalho \& Nakagawa (1988), destacam-se entre as espécies de insetos de armazenamento aquelas das ordens Coleoptera e Lepidoptera, sendo a temperatura e umidade relativa do ar condicionantes da severidade dos danos. Segundo Faroni (1988) e Sedlacek et al. (1991), as faixas de temperatura ambiente de 23 a $35^{\circ} \mathrm{C}$ e teor de água das sementes de 12 a $15 \%$, são favoráveis ao desenvolvimento dos insetos. A temperatura tem relação direta com o desenvolvimento dos insetos. Temperaturas baixas provocam desenvolvimento lento após a oviposição e grande redução nas taxas de desenvolvimento e crescimento dos insetos (Gilbert \& Raworth, 1996). Os insetos mais encontrados danificando sementes de milho são o Sitophilus zeamais, Sitotroga cerealella, Rhizopertha dominica, Prostephanus truncatus, Plodia interpunctella, Tribolium castaneum, Tribolium confusum e Criptolestes ferrugineus (Santos, 1993).

As pragas em sementes armazenadas estão adaptadas a uma dieta a base de material vegetal seco (Faroni, 1992), e muitas delas possuem características especiais que lhes permitem a sobrevivência em condições de baixa disponibilidade de água, a exemplo do complexo criptonicfridal de Tenebrio (Mordue et al., 1980).

A aplicação das informações disponíveis sobre a manutenção da qualidade sanitária durante o armazenamento é feita principalmente por meio da redução/controle de insetos-praga em grãos/sementes (Braga et al., 1992). É dado enfoque ao manejo integrado de pragas, entendendo-se como tal a seleção, integração e uso adequado de 
métodos de controle (Sinclair \& Alder, 1984; Puzzi, 1986; Ibarra et al., 1990; Faroni, 1992). O método de controle atualmente mais utilizado é o químico, com suas implicações e limitações. O emprego de substâncias químicas no controle de insetos em grãos armazenados deve complementar, mais do que suplantar outras medidas de controle. Métodos alternativos de controle são importantes, visando sedimentar o manejo integrado, cuja aplicação é incipiente no setor armazenista.

Machado (1988) relatou que o tratamento de sementes com fungicidas e inseticidas pode assegurar a qualidade das sementes durante o período de armazenamento, porque a qualidade sanitária influencia diretamente o processo de deterioração durante o armazenamento. Por outro lado, o efeito de fungicidas em algumas ocasiões pode ser negativo às sementes, causando redução na germinação e aparecimento de plântulas anormais ou raquíticas (Dhingra et al., 1980).

No caso de sementes, é imprescindível o controle das pragas durante o armazenamento, pois a comercialização de sementes de milho permite, no máximo, 5\% de sementes infestadas e germinação mínima de 85\% (Brasil, 1991).

A viabilidade de se executar o controle químico das pragas no milho em armazém, fica condicionada a fatores de ordem econômica e restrita a um pequeno número de agricultores (Carvalho, 1978; Bitran, 1989; Santos, 1992 e 1993). Em relação aos produtores de sementes de milho, existe um consenso sobre a importância de medidas preventivas visando a melhor proteção das sementes durante o armazenamento e, para tanto, são utilizados produtos químicos para oferecer ação protetora às sementes, conservando-as durante o período de armazenamento até a semeadura (Matioli, 1978; Santos et al., 1990).

A aplicação de um inseticida ou da mistura de inseticidas é indispensável para evitar a infestação por gorgulhos e traças, que se constitui em grande problema durante a armazenagem de sementes de milho (Santos et al., 1990; Santos, 1993). O tratamento das sementes com produtos químicos, dependendo das condições, é importante na preservação do vigor, por evitar a ação negativa dos insetos, bem como por atenuar os efeitos de outros fatores que prejudicam o vigor (Carvalho \& Nakagawa, 1988). 
Referente às perdas causadas pelos insetos durante o armazenamento, há que se considerar a armazenagem em silos, graneleiros, sacarias e paióis, principalmente para milho (Santos et al., 1988a e 1988b). Nas três primeiras modalidades de armazenagem, as perdas causadas por insetos são relativamente pequenas, porque há tecnologia adequada para ser utilizada no combate às pragas. Porém, no armazenamento de milho em espiga, utilizando estruturas rústicas, como os paióis, as perdas causadas por insetos têm sido enormes. Apenas mais recentemente é que foram desenvolvidas tecnologias apropriadas para uso pelos pequenos e médios produtores.

Quanto ao tipo de ataque, os insetos são divididos em pragas primárias e secundárias. Os primários são aqueles que tem capacidade de atacar as sementes íntegras, rompendo a cobertura das sementes, enquanto os secundários somente se alimentam de sementes já danificadas, resultantes de danos mecânicos ou da ação dos insetos primánios (Smiderle, 1994).

Os insetos que ocorrem nos grãos armazenados são polífagos e caracterizam-se pelo alto potencial biótico e infestação cruzada. Deve-se também levar em consideração a localização geográfica, a temperatura, a umidade relativa do ar (ambiente de conservação) e a disponibilidade de alimentação como fatores importantes para a multiplicação desses insetos (Vernalha et al., 1966). Ao descrever os insetos que atacam sementes armazenadas, Puzzi (1986) mencionou suas características, os fatores que afetam as populações de insetos (temperatura, grãos quebrados, composição da atmosfera de armazenamento e teor de água dos grãos) e os prejuízos causados. Agrupou os danos em quatro itens: a) criação de bolsas de calor na massa de grãos; b) poluição da massa de grãos; c) disseminação de fungos na massa de grãos; e d) desvalorização do produto. Na fase inicial, os insetos se alimentam quase que exclusivamente do endosperma e, posteriormente do embrião, o que acarreta considerável perda de massa e do poder germinativo.

Os efeitos dos níveis de infestação inicial dos grãos de cereais por Sitophilus zeamais em períodos de armazenamento foram determinados por Floyd (1971), quando observou que os grãos infestados relacionaram-se diretamente com o período de armazenamento e com a porcentagem de infestação inicial. Grãos com $1,2 \%$, 
$3,5 \%$ e $6,3 \%$ de infestação inicial apresentaram $34,7 \%, 43 \%$ e $63 \%$ de danificações, respectivamente, após sete meses de armazenamento. Resultados mais severos foram obtidos por Takarashi (1985) em sementes de milho com infestação inicial de $1,7 \%$, atingindo $41,7 \%$ aos três meses de armazenamento e aos seis meses, $98,2 \%$ de infestação.

Sementes atacadas por insetos ou microorganismos normalmente apresentam menor vigor. Esta incidência e o efeito podem ter início já no campo, nos períodos de desenvolvimento e maturação das sementes ou durante e após a colheita e o armazenamento, quando as condições são favoráveis ou quando não se realiza controle dos insetos (Carvalho \& Nakagawa, 1988). As espécies que surgem nos armazéns reduzem o vigor das sementes devido ao consumo de materiais de reserva e à intensa atividade respiratória, que pode desencadear outros processos, como fermentação e desenvolvimento de fungos, podendo deteriorar por completo as sementes (Lazzari, 1993).

Em sementes de arroz BR-IRGA 410 infestadas artificialmente por insetos e armazenadas por 180 dias em laboratório, Smiderle et al. (1995) observaram perda de massa de 100 sementes, aumento na perda de massa durante o armazenamento e aumento na porcentagem de sementes infestadas quando estavam presentes, pelo menos, 20 insetos por 100 gramas de sementes.

Noutro trabalho realizado em sementes de arroz, infestadas artificialmente por populações de insetos das espécies Sitophilus sp. e Rhizopertha dominica, isolados e em associação e armazenadas por seis meses, Smiderle et al. (1997) verificaram que as sementes sofreram redução na massa, na porcentagem de germinação, na emergência e índice de velocidade de emergência de plântulas em casa de vegetação, com aumento na lixiviação de eletrólitos (solutos), quando infestadas por, pelo menos, 20 insetos adultos por 100 gramas de sementes.

Poucos inseticidas estão registrados para utilização em grãos armazenados, pois deles são exigidas uma série de vantagens e padrões. Quanto às vantagens, os produtos devem persistir por longos períodos em concentrações letais para as pragas; devem ser de aplicação mais segura que os fumigantes e não devem requerer 
para isso, equipamentos especiais ou metodologia sofisticada. Com relação à padrões de segurança, os inseticidas devem ser eficientes contra as pragas por longo período de tempo, devem apresentar seletividade, de baixa toxicidade para os mamíferos, não deixar resíduos tóxicos acima dos limites admitidos pelas fontes legais e nem reduzir a viabilidade das sementes (Harein \& Las Casas, 1974).

A maioria dos produtos protetores são aplicados nas sementes/grãos para evitar a infestação por insetos, não se esperando que eliminem a população já existente. O tratamento dos grãos deve ser efetuado antes de que sejam ammazenados (Harein \& Las Casas, 1974), ou durante a transferência para o local de armazenamento, antes que ocorra a infestação. Os protetores são usados na forma de pó, na forma líquida ou em formulações destinadas a nebulização.

Em sementes de cereais, La Hue (1976) avaliou a ação dos inseticidas pirimiphos-metil, chlorpirifos-metil, fenitrotion e malathion contra a infestação de traças e verificou que os produtos não afetaram a germinação.

Bitran et al. (1980) conduziram trabalho testando a persistência residual dos piretróides deltamethrin e bioresmethrin, concluindo que o deltamethrin, nas condições experimentais, se destacou com ação residual persistente e altamente eficaz no controle de gorgulhos.

Avaliando os efeitos da aplicação de inseticidas, fungicidas e suas associações na qualidade das sementes de milho, Takahashi (1986) observou que os inseticidas deltametrina 2,5\% CE + butóxido de piperonila e de avermectim 0,36\% SL apresentaram eficiência na proteção das sementes durante 12 meses de armazenamento.

Godoy et al. (1990) estudando o efeito do amazenamento sobre a qualidade fisiológica de sementes tratadas com os inseticidas sistêmicos Thiodicarb e Carbofuram, ambos na dose de $700 \mathrm{~g}$ i.a./ $100 \mathrm{~kg}$ de sementes, verificaram que as sementes de milho, quando armazenadas, apresentaram menor porcentagem e velocidade de emergência de plântulas em relação à testemunha não tratada, sendo tais diferenças mais marcantes após 15 dias de armazenamento.

Arthur et al. (1990) tratando sementes de milho com 6 ppm de chlorpirifos-metil, $6 \mathrm{ppm}$ de chlorpirifos-metil $+1 \mathrm{ppm}$ de methoprene e posterior 
infestação artificial, observaram controle por 12 meses. Resultados semelhantes foram obtidos por Giga \& Zvoutete (1990), que avaliaram a proteção de diferentes inseticidas na proteção contra algumas pragas de produtos armazenados, infestados de forma artificial com Sitophilus zeamais e Tribolium castaneum por 1, 7 e 14 dias, e posterior armazenamento por quatro meses. Os autores constataram a eficácia do chlorpirifosmetil, pirimiphos-metil e fenitrotion na preservação por quatro meses.

Pinto (1991) afirmou que os insetos prejudicam diretamente a semente de milho, pois ao se alimentarem podem destnuir total ou parcialmente o embrião, comprometendo o desenvolvimento normal da plântula. Recomendou o uso de: expurgo com fosfina nas dosagens de 2 pastilhas de $3 g$ / tonelada ou 2 comprimidos de $0,4 \mathrm{~g} / 200$ $\mathrm{kg}$ de sementes, à temperaturas não inferiores a $15^{\circ} \mathrm{C}$ por 7 dias; tratamento com os inseticidas líquidos misturados às sementes: fenitrotion $\mathrm{CE}$, malathion $\mathrm{CE}$, pirimiphosmetil $\mathrm{CE}$ nas doses de 10 e $20 \mathrm{~g}$ i.a./t e deltamethrin $\mathrm{CE}$ nas doses 1 e $2 \mathrm{~g}$ i.a./t, cuja proteção esperada é duas vezes superior na dose mais alta em relação à mais baixa. Citou ainda que, das 38 localidades onde os experimentos foram conduzidos, em apenas 4 (Capinópolis- MG, $\mathrm{St}^{\circ}$ Antonio da Platina- PR, $\mathrm{St}^{\mathrm{a}}$ Helena- GO e Inhumas- GO), Deltametrina não foi eficiente no controle de Sitophilus sp., devido ao surgimento de novas raças do inseto. Concluiu que, nas doses testadas, os inseticidas não apresentaram efeitos fitotóxicos às sementes e são compatíveis em mistura com os fungicidas Captan, Thiram, Metalaxyl e Thiabendazole.

$\mathrm{Na}$ avaliação da eficiência de inseticidas organofosforados e piretróides contra insetos-praga de grãos de milho, rigo e arroz armazenados, Bitran et al. (1991) observaram eficiência de $1 \mathrm{ppm}$ de deltametrina no controle de Rhizopertha dominica em trigo por 12 meses e de 6 meses para Sitophilus zeamais. Já para Arthur (1992), chlorpirifos-metil aplicado em sementes de milho foi eficiente no controle de Sitophilus zeamais durante 10 meses. A aplicação superficial não se mostrou eficiente e o tratamento das sementes propiciou 6 meses de proteção contra Sitophilus zeamais. Em outro trabalho, Arthur (1994) observou que $1 \mathrm{ppm}$ de deltametrina e a mistura de deltametrina com chlorpirifos-metil foram eficientes no controle de Rhizopertha dominica em trigo e de chlorpirifos-metil, no controle de Sitophilus oryzae em milho. 
Ao estudar a influência do tamanho das sementes e do tratamento fungicida e inseticida (Captan 7,5\%; deltametrina 2,5\% + pirimiphos-metil 50\%) em sementes de milho na preservação da qualidade durante o armazenamento e posterior comportamento no campo, Von Pinho et al. (1995) verificaram que as sementes tratadas proporcionaram maiores estandes inicial e final.

Estudando a aeração a baixa temperatura e a aplicação de $6 \mathrm{ppm}$ de chlorpirifos-metil em trigo armazenado, na Georgia, Arthur (1995a) observou após a infestação artificial com Rhizopertha dominica e Sitophilus oryzae a preservação por 4 meses. O mesmo autor, Arthur (1995b) estudou a degradação e eficácia de deltametrina + chlorpirifos-metil e ciflutrina + chlorpirifos-metil como protetores em trigo armazenado no sudeste da Georgia, verificou que a infestação artificial com Rhizopertha dominica e Sitophilus oryzae em trigo armazenado foi controlada por 9 meses com $0,25 \mathrm{ppm}$ de deltametrina $+6 \mathrm{ppm}$ de chlorpirifos-metil $+4 \mathrm{ppm}$ de butóxido de piperonila. Em outro trabalho, Arthur (1995c) estudou a eficácia de inseticidas no controle de insetos em sementes de milho armazenadas e, dois meses após o tratamento, as sementes foram infestadas artificialmente com Tribolium castaneum, Sitophilus zeamais e Plodia interpunctela, constatou eficiência de proteção do chlorpirifos e do pirimiphos-metil por 10 meses.

Através da aplicação de chlorpirifos-metil + methoprene e phenotrin + butóxido de piperonila para controle de coleópteros em milho, Deglish et al. (1995) observaram eficiência por 7 meses e não constataram a presença de coleópteros após os tratamentos.

Avaliando o efeito dos inseticidas chlorpirifos, carbossulfam e thiodicarb aplicados nas sementes de milho 15 dias antes e no momento da semeadura, Silva et al. (1996) concluíram que o armazenamento das sementes tratadas reduziu a porcentagem de emergência em campo e este efeito foi mais pronunciado no vigor e na porcentagem de germinação.

Guedes et al. (1994) constataram resistência a deltametrina de raças de Sitophilus zeamais Motsch. coletadas em Jacarezinho no Estado do Paraná e concluúram que a resistência é controlada por um gen simples recessivo ligado ao sexo. 
Utilizando combinações de inseticidas organofosforados e piretróides formulados na forma de pó, aplicados para controle de insetos em milho armazenado no Togo (África), Richter et al. (1998) observaram que deltametrina isolada ou em combinação com pirimifos-metil foi igualmente efetiva contra Prostephanus truncatus. Entretanto, verificaram que permetrina associada com pirimifos-metil foi pouco efetiva e que Sitophilus zeamais não foi controlado satisfatoriamente por nenhum dos tratamentos. Por outro lado, as perdas e danos nos tratamentos com inseticida foram significativamente menores que as observadas na testemunha.

Há muito tempo é conhecido o emprego de inseticidas fumigantes. Bitran \& Mello (1972) recomendaram o expurgo com hidróxido de alumínio, mesmo para casos de pequenas infestações. Os fumigantes são produtos que exercem ação tóxica no estado gasoso, podendo apresentar-se sob a forma de fumigantes gasosos, líquidos, sólidos e cristalinos (Oliveira et al, 1979). Destacando-se o fosfeto de alumínio (sólido) que libera gás fosfina, como o mais utilizado em silos e armazéns (Puzzi, 1986; Gallo et al., 1988).

$\mathrm{O}$ gás difunde-se na forma de moléculas isoladas e penetra em toda a massa de grãos agindo sobre a fauna existente. No inseto, penetra pelos espiráculos e por meio das traquéias é conduzido até as células onde atua sobre as enzimas, provocando sua morte. Em temperaturas mais elevadas, o ritmo respiratório do inseto é mais intenso havendo maior absorção de gases, além de favorecer a expansibilidade do fumigante (Gallo et al., 1988).

Diferenças de sensibilidade entre cultivares de milho quando submetidas à fumigação, foram observadas por Yadav \& Mookherjee (1975), porém a porcentagem de germinação não foi afetada. Popinigis (1985) afirmou ser a fosfina empregada no expurgo de sementes por oferecer menores riscos. Puzzi (1986) relatou que a aplicação de fosfina não altera as qualidades organolépticas dos produtos e a capacidade germinativa das sementes. Gallo et al. (1988) acrescentaram que mesmo em dosagens elevadas, o poder germinativo não é alterado.

Em relação ao emprego da fosfina em sementes visando o controle de insetos, alguns pesquisadores observaram que o expurgo feito com diferentes doses e tempos de exposição não tem causado prejuízos à qualidade da semente. $O$ efeito da 
fosfina na germinação tem sido observado, sendo que autores relatam resultados satisfatórios. Vários autores, em seus trabalhos a respeito da aplicação de fosfina em sementes, referem-se à capacidade germinativa sem, no entanto considerar o vigor das sementes. Fumigação em dosagem dupla e tripla foi estudada por Coelho et al. (1980) e Andrade \& Nascimento (1984) os quais não constataram efeitos prejudiciais à qualidade das sementes.

A fumigação com fosfina, por 48 horas de exposição, em sementes de milho, não causou variações significativas no poder germinativo e no vigor das sementes medido pelos testes de envelhecimento acelerado, de Hoope e índice de emergência (Andrade \& Nascimento, 1984). Komatsu (1985) aplicou Gastoxin na base de $12 \mathrm{~g} / \mathrm{m}^{3}$ por 72 horas de exposição sem constatar perdas de qualidade fisiológica em sementes de milho e feijão.

A aplicação de inseticidas com ação residual em grãos tem sido recomendada após o expurgo, visando prevenir reinfestações, sendo para esse fim aplicados diversos inseticidas, entre eles os piretróides e os organofosforados. Assim, Komatsu (1985) observou que a aplicação de fosfina e deltametrina sinergizada, associados ou isolados, promoveu o controle das pragas que ocorrem no armazenamento do milho e do feijão, além de não revelar fitotoxicidade às sementes.

As pragas ocorrentes durante o armazenamento causam severos problemas, por essa razão diversos trabalhos vem sendo realizados com inseticidas, incluindo alguns não convencionais, para reduzir a pressão de seleção e evitar o surgimento de populações resistentes aos inseticidas (Subramanyam, 1995), evidenciando a importância do tratamento das sementes armazenadas.

A utilização de pós inertes e abrasivos, como a sílica amorfa, tem sido indicada como uma forma de controle alternativo simples, barato e de boa eficiência na redução de pragas em grãos armazenados. Este substrato inerte apresenta a capacidade de remover a camada cerosa da cutícula dos insetos, resultando na morte por dessecação (Braccini \& Picanço, 1995).

A terra diatomácea é um depósito geológico que consiste de esqueletos petrificados de numerosas espécies de silícios e organismos unicelulares marinhos e 
outras algas. É um produto natural e extremamente estável, não produz resíduos químicos tóxicos às sementes e aos mamíferos e não reage com outras substâncias (Korunic, 1998). O produto não é inflamável, não apresenta riscos de explosão é de fácil aplicação, dispensando o uso de equipamentos sofisticados ou a vedação das estruturas de armazenamento. A terra diatomácea tem sido estudada para proteção de grãos armazenados (Kats, 1991; Quarles, 1992; Banks \& Fields, 1994; Bridgeman, 1994; McLaughlin, 1994; Subramanyam et al., 1994; Korunic et al., 1996; Quarles \& Winn, 1996; Korunic et al., 1998) sendo que a primeira formulação comercial foi obtida em 1950.

Diversos trabalhos indicam que o efeito dos pós inertes nos insetos depende de sua habilidade em absorver lipídeos da camada protetora que recobre a cutícula dos insetos e também de propriedades abrasivas. Os insetos perdem água por danos provocados por abrasão na cutícula causando a morte por dessecação após certo tempo (Ebeling, 1971; Golob, 1997; Korunic, 1998). Este tempo depende da umidade relativa do ar e, no caso de insetos de grãos armazenados, do teor de água dos grãos (Korunic, 1997). Outro modo de ação da terra diatomácea é a ação repelente causada pela presença física do pó. Além disso, uma terra diatomácea com alta capacidade de absorver óleo é um inseticida potencial (Korunic, 1998). Vários trabalhos têm sido realizados mostrando a eficácia de dessecantes contra insetos-praga de grãos armazenados (La Hue, 1970; Le Patourel, 1986; Desmarchelier \& Dines, 1987; Aldrym, 1990, 1993; Korunic et al., 1998; Nielsen, 1998). Entretanto, os resultados de pesquisas mostram que a eficácia da terra diatomácea contra insetos depende bastante das diferentes características físicas e morfológicas e da sua origem (Korunic, 1998). Porém, o número de produtos testados é limitado, sendo observadas variações nas condições de teste, espécie de inseto e períodos de exposição, tomando dificil as comparações de eficácia dos diferentes produtos encontrados no mercado.

Nos últimos anos, na Austrália, tem sido realizadas pesquisas com pós dessecantes para o tratamento estrutural de armazéns de grãos e de usinas de beneficiamento de grãos. Este método recebeu aceitação geral pelas indústrias australianas de grãos e tem contribuído para preservação da qualidade do grão da 
Austrália e a diminuição dos resíduos nos grãos. Também pode oferecer redução considerável de custos sobre os tratamentos químicos e prover proteção mais efetiva, a longo prazo (Desmarchelier et al., 1993).

Ao avaliar a eficácia de pó inerte, (terra diatomácea) no controle de Sitophilus spp. e Rhizopertha dominica em sementes de sorgo e seu efeito sobre a germinação, Rupp et al. (1996) observaram que os pós inertes foram eficazes no controle dos insetos, não deixaram resíduos tóxicos no produto e não provocaram fitotoxicidade. Além disso, houve redução na germinação das sementes sem tratamento inseticida e das tratadas com $20 \mathrm{ml} / \mathrm{t}$ de K-Obiol $25 \mathrm{CE}$.

Lazzari et al. (1996) trabalhando com grãos de milho hibrido C-855, tratado com K-Obiol $25 \mathrm{CE}$ e terra diatomácea, infestados artificialmente com Rhizopertha dominica e Sitophilus spp., observaram que os produtos foram eficazes no controle dos insetos e na manutenção da qualidade das sementes ao longo das avaliações. Resultados semelhantes foram obtidos por Dupchak et al. (1996) em milho híbrido C-701 e por Gionédis et al. (1996) com o híbrido C-805.

Pinto Junior et al. (1996) estudaram a manutenção da qualidade de milho, com umidade de $13 \%$, armazenado a temperatura de $25^{\circ} \mathrm{C} \pm 2^{\circ} \mathrm{C}$, por nove meses pela aplicação de terra diatomácea (750, 1000 e $1250 \mathrm{~g} / \mathrm{t})$. A terra diatomácea foi eficaz no controle de Sitophilus zeamais, tendo sido observado maior massa de 100 sementes e menor teor de água em relação à testemunha. 


\section{MATERIAL E MÉTODOS}

O presente trabalho foi conduzido no Laboratório de Análise de Sementes (LAS) e no Campo Experimental do Departamento de Agricultura (LAG), da Escola Superior de Agricultura "Luiz de Queiroz" (ESALQ), da Universidade de São Paulo (USP), em Piracicaba, durante os anos de 1997 e 1998.

\subsection{Sementes}

Foram utilizadas sementes de milho, sem qualquer tratamento químico, obtidas junto às Unidades de Produção de Sementes Fartura (Híbrido BR 205, da safra 95/96), Sementes Agroceres (Híbrido AG 303, da safra 96/97) e Zeneca Sementes (Híbrido Z 8392, da safra 96/97).

Os lotes de sementes foram divididos em frações de aproximadamente 5 $\mathrm{kg}$ (repetições dos diferentes tratamentos) e submetidas à aplicação dos produtos.

\subsection{Tratamentos}

Os tratamentos consistiram da aplicação ou não de produtos inseticidas nas sementes (Tabela 1).

$\mathrm{O}$ insecto ${ }^{\circledast}$ é uma terra diatomácea, registrada nos Estados Unidos da América, que apresenta as seguintes características: contém $87 \%$ de sílica amorfa (dióxido de silício); $3 \%$ de sílica cristalina; diâmetro médio das partículas de $6,89 \mu \mathrm{m}$; capacidade de absorção de óleo de $175 \%$ em relação ao peso; $\mathrm{pH} 7,0$; massa específica de $0,128 \mathrm{~g} / \mathrm{cm}^{3}$; gravidade específica de 0,23 (Subramanyam et al., 1994; Korunic et al., 1996). 
Tabela 1. Tratamentos realizados para cada híbrido, nomenclatura e doses utilizadas nos tratamentos.

\begin{tabular}{lll}
\hline Tratamentos & Nomenclatura & Doses $^{1}$ \\
\hline 1. Deltametrina 2,5 CE sinergizada & DELT & $14 \mathrm{ml}$ \\
2. Chlorpirifos, dosagem 1 & CLOR1 & $14 \mathrm{ml}$ \\
3. Chlorpirifos, dosagem 2 & CLOR2 & $28 \mathrm{ml}$ \\
4. Deltametrina + Chlorpirifos, dosagem 1 & DELT + CLOR1 & $14+14 \mathrm{ml}$ \\
5. Deltametrina + Chlorpirifos, dosagem 2 & DELT + CLOR2 & $14+28 \mathrm{ml}$ \\
6. Terra diatomácea- Insecto & INSECTO & $1000 \mathrm{~g}$ \\
7. Terra diatomácea- Keepdry & KEEPDRY & $1000 \mathrm{~g}$ \\
8. Testemunha & TEST & - \\
9. Expurgo- Gastoxin & EXPURGO & $3 \mathrm{~g}$
\end{tabular}

'Produto Comercialton de sementes

O keepdry- FEF 2000 é uma terra diatomácea, que apresenta as seguintes características: produto natural; mineral; não tóxico; contém $90 \%$ de sílica amorfa; $10 \%$ de outros silicatos; pó uniforme; ligeiramente bege; fino e sem odor; 200-300 g/l de massa específica; $\mathrm{pH} 7,5$.

O principal modo de ação da terra diatomácea é físico; provoca abrasão, removendo a camada de cera da cutícula dos insetos, ocasionando perda de água e morte por dessecação (Golob, 1997). Os produtos tem a capacidade de reter várias vezes seu massa em água.

\subsection{Aplicação dos produtos nas sementes}

Para a aplicação dos produtos líquidos (tratamentos 1, 2, 3, 4 e 5), as sementes foram dispostas em uma camada uniforme sobre filme plástico, possibilitando uma adequada distribuição dos produtos na superfície das sementes. Em seguida, as sementes foram agitadas, por dois minutos, prendendo-se as extremidades do filme plástico, de maneira que o recobrimento fosse uniforme. 
A aplicação do pó inerte (terra diatomácea) foi feita colocando as sementes e o produto em sacos plásticos, agitando-se por dois minutos para homogeneização.

Por outro lado, o expurgo foi realizado com produto à base de fosfeto de alumínio (Gastoxin), na forma de pastilhas, conforme o recomendado pelo fabricante ( $2 \mathrm{~g}$ i.a. $/ \mathrm{m}^{3}$ ). As aplicações foram realizadas em abril e novembro de 1997, na Unidade de Beneficiamento de Sementes do LAG/ESALQ/USP, sendo as amostras colocadas no interior de tambor metálico (200 l) e mantidas por 72 horas.

\subsection{Embalagem e armazenamento}

Após a aplicação dos produtos, as sementes de cada tratamento foram divididas em 4 frações e acondicionadas em sacos de papel multifoliado e, posteriormente armazenadas em condições de ambiente não controlado do LAG/ESALQ/USP.

\subsection{Período experimental}

As sementes permaneceram armazenadas por um período de 12 meses (maio de 1997 a abril de 1998), sendo as avaliações efetuadas em sete épocas bimestrais. No local de armazenamento, as condições de temperatura e de umidade relativa do ar do ambiente foram registradas em higrotermógrafo durante o referido período (Figura 1).

\subsection{Determinações de laboratório}

\subsubsection{Determinação do teor de água}

Durante o desenvolvimento do trabalho, foi determinado o teor de água das sementes em cada época de avaliação. Foi utilizado o método da estufa a $105^{\circ} \mathrm{C} \pm$ $3^{\circ} \mathrm{C}$ durante 24 horas, segundo as Regras para Análise de Sementes - RAS (Brasil, 1992). 


\subsubsection{Exame de sementes infestadas}

Foram utilizadas quatro repetições de 100 sementes. As sementes foram imersas em água por um período de 48 horas e posteriormente seccionadas, ao meio para expor a maior face interior, para a avaliação. Para a determinação da porcentagem de sementes infestadas por insetos durante o período de armazenamento, foram consideradas atacadas as sementes em que foram constatados a presença de ovo, larva, pupa, inseto adulto ou ainda orifício de saída do inseto, conforme as RAS (Brasil, 1992).

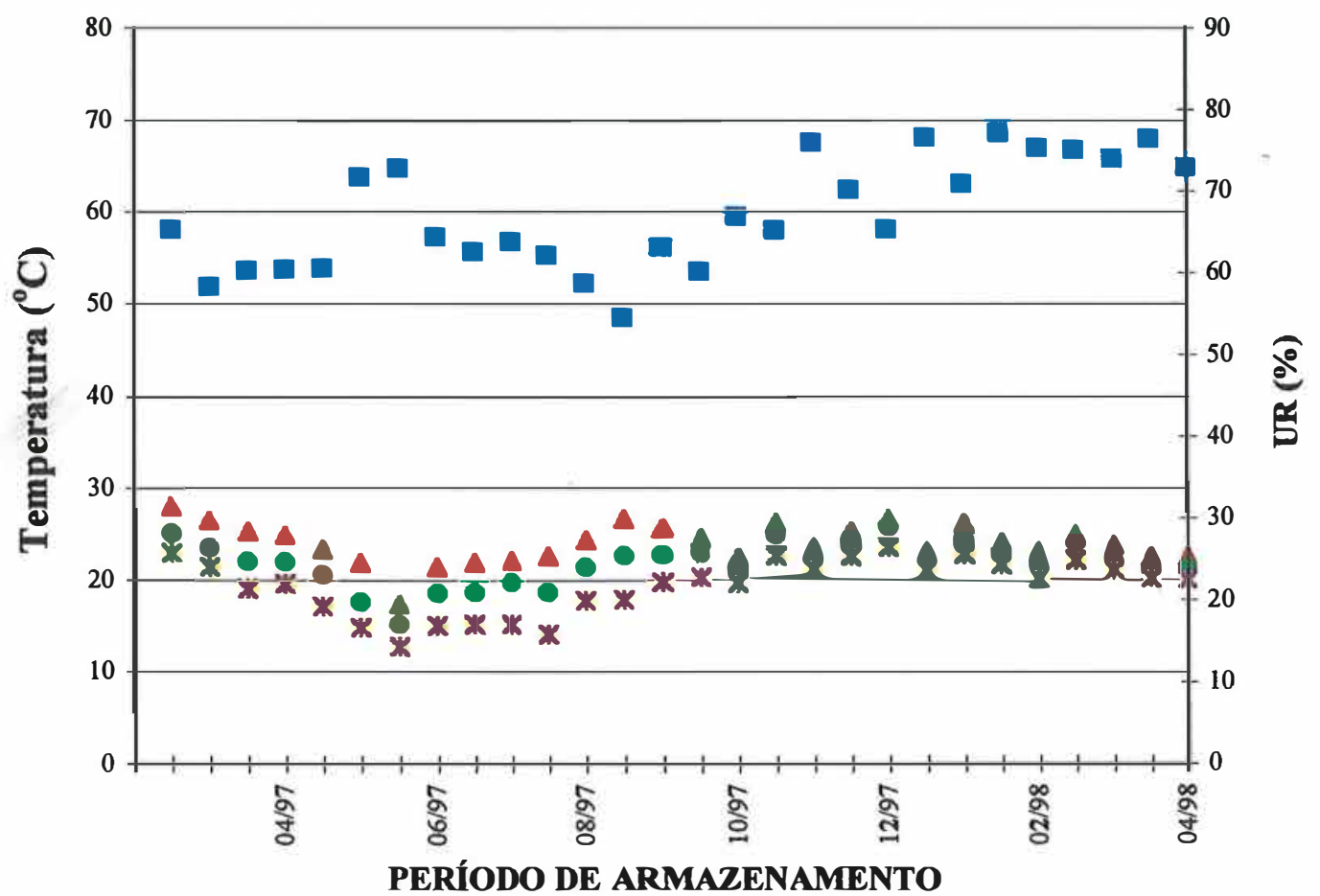

$\triangle$ Tmáxima $\bullet$ Tmédia $\times$ Tminima $\square$ UR

Figura 1. Dados climáticos registrados durante o período de armazenamento das sementes de milho no Laboratório de Análise de Sementes do LAG/ESALQ/USP, no município de Piracicaba-SP. 


\subsubsection{Massa de 100 sementes}

Foram pesadas 16 repetições de 100 sementes, separadas manualmente e, a seguir, foi calculado a massa média de 100 sementes. Os resultados foram expressos em gramas.

\subsubsection{Teste de germinação}

Foi realizado com 4 repetições de 100 sementes, utilizando-se como substrato rolos de papel Germitest, umedecidos com quantidade de água equivalente a 2,5 vezes a massa do papel seco e mantidas à temperatura de $25^{\circ} \mathrm{C}$. As avaliações foram efetuadas aos quatro e sete dias após a semeadura, conforme as RAS (Brasil, 1992). Os resultados foram expressos em porcentagem de plântulas normais.

\subsubsection{Teste de frio}

O substrato utilizado foi uma mistura de $2 / 3$ de areia e $1 / 3$ de terra, proveniente de uma área cultivada com milho há vários anos, colocada em caixa plástica com dimensões de $47 \mathrm{~cm} \times 30 \mathrm{~cm} \times 11 \mathrm{~cm}$. A semeadura foi realizada com 4 repetições de 100 sementes. A irrigação foi realizada ajustando a umidade para $60 \%$ da capacidade de retenção de água da mistura.

Os recipientes, cobertos com material plástico (as próprias caixas) para reduzir as perdas de água por evaporação, foram mantidos em uma câmara fria regulada a $10^{\circ} \mathrm{C}$, durante sete dias. Após esse período, as caixas foram retiradas e colocadas em condições de ambiente do LAS/LAG/ESALQ/USP, onde permaneceram por mais sete dias, quando foi procedida a contagem das plântulas emergidas.

\subsubsection{Envelhecimento acelerado}

Foi adotada a metodologia recomendada pelo Comitê de Vigor da "Association of Official Seed Analysts" (AOSA, 1983). Assim, uma camada única de sementes foi colocada sobre a tela metálica interna de uma caixa tipo gerbox. As caixas contendo $40 \mathrm{ml}$ de água, foram tampadas e mantidas em incubadora, a $41^{\circ} \mathrm{C}$, durante 96 horas. Após esse período de envelhecimento, foi determinado o teor de água das 
sementes, conforme descrito no item 3.6.1., e conduzido o teste de germinação, conforme o item 3.6.4., com avaliação única aos 4 dias, computando-se a porcentagem média de plântulas normais.

\subsubsection{Condutividade elétrica}

Foi conduzido através do sistema de massa; quatro repetições de 50 sementes foram pesadas, colocadas em copos plásticos de $200 \mathrm{ml}$, com $75 \mathrm{ml}$ de água destilada e mantidas em germinador à temperahrra constante de $20^{\circ} \mathrm{C}$. Após 24 horas de embebição, foi realizada a leitura da condutividade elétrica em um condutivímetro marca Digimed CD-20, de acordo com metodologia descrita por Krzyzanowski et al. (1991). Os resultados foram expressos em micromho por centímetro ( $\mu \mathrm{mho} / \mathrm{cm})$.

\subsubsection{Persistência dos produtos aplicados nas sementes}

Foi avaliada aos 360 dias após a aplicação dos produtos. Para esse fim, quatro repetições de 50 gramas de sementes dos tratamentos 1 a 7 e 9 foram acondicionadas no interior de vidros com capacidade para 150 gramas e após procedida a infestação com 20 insetos adultos em cada repetição foram vedados com tela. Os insetos adultos com 2 a 3 semanas de idade foram obtidos de criação, em sementes de trigo, realizada no local de armazenamento das sementes. A avaliação da mortalidade dos insetos foi realizada 15 dias após a infestação artificial.

\subsection{Determinações de campo}

\subsubsection{Emergência de plântulas em campo}

Foi instalado em canteiros, no campo experimental do LAG/ESALQ/USP, nas épocas de avaliações (maio/97, julho/97, setembro/97, novembro/97, janeiro/98, março/98 e maio/98). Os dados de umidade relativa do ar e temperatura estão apresentados na Figura 2. Para cada tratamento foram semeadas, manualmente, 100 sementes na profundidade de $3-5 \mathrm{~cm}$, em quatro linhas de quatro metros, espaçadas de 20 $\mathrm{cm}$. A contagem foi realizada aos 21 dias após a semeadura. 


\subsubsection{Velocidade de emergência de plântulas}

Foi conduzida juntamente com o teste de emergência de plântulas em campo; assim, a velocidade de emergência (VE) foi obtida a partir dos dados das contagens diárias das plântulas emergidas, de comprimento superior a $1,5 \mathrm{~cm}$ (da parte emersa), até o vigésimo primeiro dia após a semeadura, conforme descrito em 3.7.1. O cálculo do índice de velocidade de emergência foi obtido pela soma dos dados diários, dividida pelo número de dias após a semeadura, conforme Popinigis (1985).

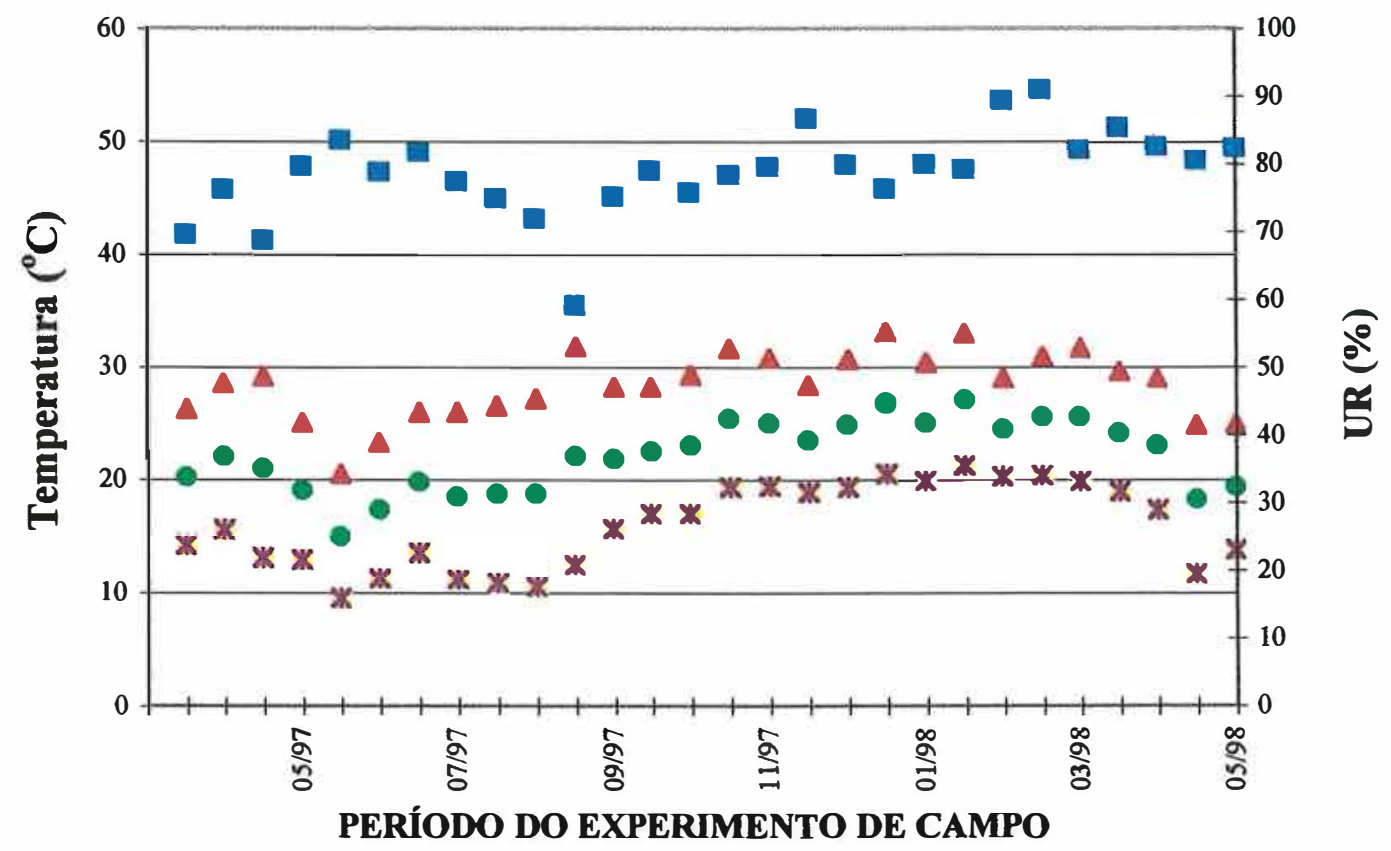

\Tmáxima $\bullet$ Tmédia $*$ Tmínima $₫$ UR

Figura 2. Dados climáticos coletados durante o período de realização do trabalho, no Posto Agrometeorológico do Departamento de Física e Meteorologia- LFM/ESALQ/USP, coordenadas: latitude $22^{\circ} 42^{\prime} 30^{\prime \prime}$; longitude 47 38' 30"; altitude 546 m, no município de Piracicaba-SP. 


\subsection{Procedimento estatístico}

O delineamento experimental utilizado nas determinações de laboratório (Tabelas 2 e 3) foi o inteiramente casualizado e nas determinações de campo o de blocos ao acaso (Tabela 4).

A análise de variância dos dados obtidos, foi realizada para cada determinação, época e híbrido; as médias foram comparadas pelo teste de Tukey ao nível de 5\% de probabilidade, utilizando-se o Sistema de Análise Estatística- SANEST (Zonta \& Machado, 1984). Os dados obtidos nos testes de germinação, primeira contagem de germinação, teste de frio, envelhecimento acelerado e emergência de plântulas em campo foram transformados em arco seno $(\% / 100)^{0,5}$ e, para sementes infestadas foram transformados em $(\%+0,5)^{0,5}$. A transformação dos dados foi necessária pelo fato da diferença entre a maior e a menor média em cada teste ter sido superior a 20\% (Banzatto \& Kronka, 1992).

Tabela 2. Esquema utilizado para análise de variância dos dados relativos à sementes infestadas- SI, massa de 100 sementes- M100S, teste de germinação- TG, teste de frio- TF, envelhecimento acelerado- EA e condutividade elétrica$\mathrm{CE}$, para cada híbrido e em cada época de avaliação.

\begin{tabular}{lc}
\hline Causas da Variação & G.L. \\
\hline Tratamentos & 8 \\
Resíduo & 27 \\
\hline Total & 35 \\
\hline
\end{tabular}

Tabela 3. Esquema utilizado para análise de variância dos dados obtidos na avaliação de persistência dos produtos aplicados nas sementes, para cada híbrido.

\begin{tabular}{lc}
\hline Causas da Variação & G.L. \\
\hline Tratamentos & 7 \\
Resíduo & 24 \\
\hline Total & 31 \\
\hline
\end{tabular}


Tabela 4. Esquema utilizado para análise de variância dos dados obtidos nas determinações de campo, para cada híbrido e em cada época de avaliação.

\begin{tabular}{lc}
\hline Causas da Variação & G.L. \\
\hline Tratamentos & 8 \\
Blocos (B) & 3 \\
Resíduo & 24 \\
\hline Total & 35 \\
\hline
\end{tabular}




\section{RESULTADOS}

\subsection{Hibrido AG 303}

Os dados relativos aos teores de água das sementes (Tabela 5), permitem verificar que os valores obtidos para os tratamentos nas diferentes épocas, ficaram entre $9,9 \%$ e $12,1 \%$, valores esses considerados como normais para o armazenamento de sementes de milho em ambiente não controlado na região de Piracicaba- SP (Figura 1).

Tabela 5. Híbrido AG 303: teores médios de água (\%) das sementes, observados nos tratamentos nas sete épocas de avaliação, durante 12 meses de armazenamento.

\begin{tabular}{lccccccc}
\hline & \multicolumn{7}{c}{ PERIODO DE ARMAZENAMENTO (MESES) } \\
\cline { 2 - 8 } TRATAMENTOS & 0 & 2 & 4 & 6 & 8 & 10 & 12 \\
\cline { 2 - 7 } & & & & & & & \\
1. DELT & 10,1 & 11,8 & 10,4 & 10,8 & 10,9 & 11,3 & 11,5 \\
2. CLOR1 & 10,2 & 11,8 & 10,4 & 10,7 & 10,5 & 11,1 & 11,3 \\
3. CLOR2 & 10,1 & 11,6 & 10,3 & 10,7 & 10,8 & 11,0 & 11,3 \\
4. DELT + CLOR1 & 10,0 & 11,5 & 10,3 & 10,7 & 10,5 & 11,0 & 11,2 \\
5. DELT + CLOR2 & 10,3 & 11,6 & 10,6 & 10,8 & 11,0 & 11,2 & 11,4 \\
6. INSECTO & 9,9 & 11,5 & 10,5 & 10,8 & 10,8 & 11,1 & 11,2 \\
7. KEEPDRY & 10,1 & 11,6 & 10,6 & 10,7 & 10,8 & 11,0 & 11,3 \\
8. TESTEMUNHA & 10,0 & 11,4 & 10,6 & 11,0 & 11,3 & 11,7 & 12,1 \\
9. EXPURGO & 10,0 & 11,2 & 10,3 & 10,8 & 10,6 & 11,0 & 11,1 \\
\hline
\end{tabular}

Por outro lado, os valores de $\mathrm{F}$ para as demais determinações de laboratório e de campo, calculados para as sete épocas, estão contidos na Tabela 6. 
Tabela 6. Híbrido AG 303: valores de F, para as determinações de laboratório (sementes infestadas-SI, massa de 100 sementes-M100S, teste de germinação-TG, teste de frio- $\mathrm{TF}$, envelhecimento acelerado-EA e condutividade elétrica-CE) e de campo (emergência de plântulas em campo-EC e velocidade de emergênciaVE), calculados para as sete épocas.

\begin{tabular}{|c|c|c|c|c|c|c|c|}
\hline \multirow{2}{*}{$\begin{array}{l}\text { DETERMI- } \\
\text { NAÇÓES }\end{array}$} & \multicolumn{7}{|c|}{ PERIODO DE ARMAZENAMENTO (MESES) } \\
\hline & 0 & 2 & 4 & 6 & 8 & 10 & 12 \\
\hline SI & 7,24 & 6,98 & 7,11 & $4,52^{\star \star}$ & $110,74^{\star \star}$ & $107,39^{\star \star}$ & $103,75^{\star \star}$ \\
\hline M100S & 26,23 & 20,17 & $14,71^{\text {** }}$ & $20,10^{* * *}$ & $17,82^{\text {** }}$ & $3,70^{\star *}$ & $205,41^{\text {t* }}$ \\
\hline TG & $6,32^{\text {*t }}$ & $2,15^{\star \star *}$ & $6,81^{\text {t**}}$ & 2,05 & $21,26^{\star \star}$ & $62,83^{\star *}$ & $193,93^{* \star}$ \\
\hline TF & 1,05 & 1,14 & $2,79^{*}$ & $3,00^{*}$ & $10,36^{\star \star}$ & $28,87^{\star \star}$ & $23,91^{\text {** }}$ \\
\hline EA & 2,53 & $2,85^{\star \star \star}$ & 1,37 & 3,252 & $31,91^{\star \star}$ & $18,27^{\text {** }}$ & $60,74^{* \star}$ \\
\hline CE & $5,79^{\text {t* }}$ & 2,58 & $5,33^{* *}$ & $14,02^{\text {t* }}$ & $78,75^{\star * *}$ & $51,18^{* *}$ & $449,86^{\text {t* }}$ \\
\hline EC & 2,01 & 0,55 & 1,30 & 14,92 & $9,35^{\star *}$ & $182,63^{* \star}$ & $344,62^{\star \star}$ \\
\hline VE & 0,57 & 0,56 & 7,42 & 12,01 & $11,92^{* *}$ & $87,77^{* *}$ & $129,31^{* \star}$ \\
\hline
\end{tabular}

* Significativo ao nivel de $5 \%$ de probabilidade

** Significativo ao nivel de $1 \%$ de probabilidade

Na Tabela 7 são apresentadas as médias relativas ao exame de sementes infestadas, massa de 100 sementes, teste de germinação, teste de frio, envelhecimento acelerado, condutividade elétrica, emergência de plântulas em campo, velocidade de emergência e seus respectivos coeficientes de variação, observados na primeira época. Como se pode observar, as sementes, dos nove tratamentos apresentaram porcentagem de infestação semelhantes. A maior infestação observada, em termos numéricos, foi de $3 \%$ (sementes expurgadas); o referido valor é admitido nos padrões de Sementes Certificadas e de Sementes Fiscalizadas (Brasil, 1991). Em relação à massa de 100 sementes, também foram observados resultados semelhantes entre os tratamentos.

Com relação ao teste de germinação observou-se para o tratamento testemunha maior porcentagem de plântulas normais em relação aos tratamentos 1 (DELT), 2 (CLOR1), 3 (CLOR2), 4 (DELT + CLOR2) e 9 (EXPURGO), havendo comportamento semelhante ao das sementes dos demais tratamentos. 
Por outro lado, no teste de condutividade elétrica as sementes do tratamento 4 (DELT + CLORl) apresentaram menor qualidade fisiológica em relação à maioria dos demais tratamentos.

Tabela 7. Híbrido AG 303- Primeira época: médias relativas ao exame de sementes infestadas (SI), massa de 100 sementes (M100S), teste de germinação (TG), teste de frio (TF), envelhecimento acelerado (EA), condutividade elétrica (CE), emergência de plântulas em campo (EC), velocidade de emergência (VE) e respectivos coeficientes de variação (C.V., \%).

\begin{tabular}{|c|c|c|c|c|c|c|c|c|}
\hline TRATAMENTOS & $\mathrm{SI}^{1}$ & $\mathrm{M}_{100 \mathrm{~S}^{2}}$ & $\mathrm{TG}^{1}$ & $\mathrm{TF}^{1}$ & $E A^{1}$ & $C E^{3}$ & $E C^{1}$ & $V E^{4}$ \\
\hline 1. DELT & $1,0 a^{*}$ & $28,3 a$ & $95 b$ & $86,5 a$ & $76,3 a$ & $12,1 a b$ & $91,3 a$ & $15,75 a$ \\
\hline 2. CLOR1 & $1,5 a$ & $28,4 a$ & $97 \mathrm{~b}$ & $89,8 a$ & $75,0 a$ & $12,0 b$ & $93,8 \mathrm{a}$ & $15,76 a$ \\
\hline 3. CLOR2 & $1,5 a$ & $28,2 a$ & $96 b$ & $83,8 a$ & $83,3 a$ & $11,4 b$ & $94,3 a$ & $15,82 a$ \\
\hline 4. DELT + CLOR1 & $0,5 a$ & $28,3 a$ & $96 b$ & $86,3 a$ & $82,0 a$ & $13,0 a$ & $95,5 a$ & $15,96 a$ \\
\hline 5. DELT + CLOR2 & $1,5 a$ & $28,5 a$ & $98 a b$ & $87,5 a$ & $73,3 a$ & $12,1 a b$ & $94,3 a$ & $15,66 a$ \\
\hline 6. INSECTO & $2,0 a$ & $28,4 a$ & $98 a b$ & $84,0 a$ & $80,5 a$ & $12,0 b$ & $96,3 a$ & $16,18 a$ \\
\hline 7. KEEPDRY & $2,0 a$ & $28,6 a$ & $98 a b$ & $87,8 a$ & $79,5 a$ & $12,0 b$ & $95,8 a$ & $16,05 a$ \\
\hline 8. TESTEMUNHA & $1,5 a$ & $28,7 a$ & $100 a$ & $87,5 a$ & $76,8 a$ & $11,4 b$ & $95,3 a$ & $15,90 a$ \\
\hline 9. EXPURGO & $3,0 a$ & $30,1 a$ & $97 b$ & $82,8 a$ & $79,8 a$ & $11,8 b$ & $96,0 a$ & $15,98 a$ \\
\hline č.v. & 17,7 & 1,9 & 3,7 & 5,3 & 4,7 & 3,2 & 2,5 & 3,5 \\
\hline
\end{tabular}

Na coluna médias seguidas por letras distintas diferem entre si pelo teste de Tukey ao nível de $5 \%$ de probabilidade ${ }^{1}$ Dados em porcentagem

${ }^{2}$ Dados em gramas

${ }^{3}$ Dados em $\mu \mathrm{mho} / \mathrm{cm}$

${ }^{4}$ Dados na forma de índice

Nos demais parâmetros utilizados para avaliação de vigor das sementes (teste de frio, envelhecimento acelerado, emergência de plântulas em campo e velocidade de emergência de plântulas em campo) não houve diferenças significativas entre os nove tratamentos aplicados às sementes. 
Na Tabela 8 são apresentadas as médias relativas ao exame de sementes infestadas, massa de 100 sementes, teste de germinação, teste de frio, envelhecimento acelerado, condutividade elétrica, emergência de plântulas em campo, velocidade de emergência e seus respectivos coeficientes de variação, obtidos 60 dias após a aplicação dos produtos (segunda época). Como se pode observar, no exame de sementes infestadas, massa de 100 sementes, teste de frio, condutividade elétrica, emergência de plântulas em campo e velocidade de emergência não foram constatadas diferenças significativas entre os nove tratamentos.

Tabela 8. Híbrido AG 303- Segunda época: médias relativas ao exame de sementes infestadas (SI), massa de 100 sementes (M100S), teste de germinação (TG), teste de frio (TF), envelhecimento acelerado (EA), condutividade elétrica (CE), emergência de plântulas em campo (EC), velocidade de emergência (VE) e respectivos coeficientes de variação (C.V., \%).

TRATAMENTOS $\quad \mathrm{SI}^{1} \quad \mathrm{M}_{100 \mathrm{~S}^{2}} \quad \mathrm{TG}^{1} \quad \mathrm{TF}^{1} \quad \mathrm{EA}^{1} \quad \mathrm{CE}^{3} \quad \mathrm{EC}^{1} \quad \mathrm{VE}^{4}$

$\begin{array}{lcccccccc}\text { 1. DELT } & 2,3 a^{*} & 29,0 a & 98 a b & 92,5 a & 48,5 b & 13,9 a & 93,3 a & 13,30 a \\ \text { 2. CLOR1 } & 3,0 a & 28,8 a & 97 a b & 92,5 a & 58,3 a b & 14,5 a & 93,5 a & 13,32 a \\ \text { 3. CLOR2 } & 3,5 a & 28,7 a & 96 a b & 90,3 a & 52,0 a b & 14,0 a & 93,8 a & 13,23 a \\ \text { 4. DELT + CLOR1 } & 2,0 a & 28,7 a & 97 a b & 92,0 a & 59,0 a b & 13,9 a & 93,5 a & 13,12 a \\ \text { 5. DELT + CLOR2 } & 3,5 a & 29,0 a & 95 b & 92,5 a & 56,3 a b & 14,7 a & 92,5 a & 12,77 a \\ \text { 6. INSECTO } & 1,5 a & 28,8 a & 98 a b & 91,8 a & 62,0 a & 13,3 a & 93,0 a & 13,15 a \\ \text { 7. KEEPDRY } & 0,8 a & 28,9 a & 99 a & 93,0 a & 63,0 a & 13,0 a & 93,8 a & 13,12 a \\ \text { 8. TESTEMUNHA } & 6,0 a & 29,1 a & 97 a b & 90,8 a & 60,5 a b & 14,3 a & 92,8 a & 12,78 a \\ \text { 9. EXPURGO } & 1,5 a & 30,4 a & 98 a b & 94,5 a & 56,5 a b & 13,0 a & 90,3 a & 12,51 a \\ \text { C.V. } & 28,8 & 1,8 & 3,5 & 3,7 & 6,6 & 5,8 & 3,2 & 5,8\end{array}$

$\mathrm{Na}$ coluna, médias seguidas por letras distintas diferem entre si pelo teste de Tukey ao nível de $5 \%$ de probabilidade

' Dados em porcentagem

${ }^{2}$ Dados em gramas

${ }^{3}$ Dados em $\mu \mathrm{mho} / \mathrm{cm}$

${ }^{4}$ Dados na forma de indice

No teste de germinação foi observado para o tratamento 7 (KEEPDRY) 
maior porcentagem de germinação em relação ao tratamento 5 (DELT + CLOR2), não sendo constatadas diferenças estatística em relação aos demais tratamentos.

No envelhecimento acelerado, as sementes dos tratamentos 6 (INSECTO) e 7 (KEEPDRY) apresentaram valores superiores ao das sementes do tratamento 1 (DELT).

$\mathrm{Na}$ terceira época (Tabela 9), são apresentadas as médias relativas ao exame de sementes infestadas, massa de 100 sementes, teste de germinação, teste de frio, envelhecimento acelerado, condutividade elétrica, emergência de plântulas em campo, velocidade de emergência e seus respectivos coeficientes de variação, observadas 120 dias após a aplicação dos produtos (terceira época). Como se pode observar, o exame de sementes infestadas, o teste de envelhecimento acelerado, a emergência e a velocidade de emergência de plântulas no campo não revelaram diferenças significativas entre os nove tratamentos. Por outro lado, as sementes do tratamento 9 (EXPURGO) apresentaram maior massa de 100 sementes em relação aos demais tratamentos.

No teste de germinação verificou-se superioridade estatística dos tratamentos 6 (INSECTO) e 7 (KEEPDRY) em relação à maioria dos demais tratamentos.

Para o teste de frio, as sementes do tratamento 4 (DELT + CLOR1) apresentaram maior vigor em relação ao das sementes dos tratamentos 1 (DELT) e 2 (CLOR1), não tendo sido observada diferenças estatísticas entre os demais tratamentos.

Por outro lado, o teste de condutividade elétrica acusou vigor mais baixo para a testemunha em relação aos tratamentos 6 (INSECTO), 7 (KEEPDRY) e 9 (EXPURGO). $O$ tratamento 9 (EXPURGO) foi superior aos tratamentos 2 (CLOR1) e 4 (DELT + CLORl), havendo comportamento semelhante entre os demais tratamentos.

$\mathrm{Na}$ Tabela 10 são apresentadas as médias relativas ao exame de sementes infestadas, massa de 100 sementes, teste de germinação, primeira contagem de germinação, teste de frio, envelhecimento acelerado, condutividade elétrica, emergência de plântulas em campo, velocidade de emergência e seus respectivos coeficientes de variação, observadas 180 dias após a aplicação dos produtos (quarta época). Como se pode observar, o tratamento 8 (TESTEMUNHA) apresentou infestação superior aos 
demais tratamentos. Por outro lado, o tratamento 9 (EXPURGO) apresentou maior massa de 100 sementes em relação aos demais tratamentos.

Tabela 9. Híbrido AG 303- Terceira época: médias relativas ao exame de sementes infestadas (SI), massa de 100 sementes (M100S), teste de germinação (TG), teste de frio (TF), envelhecimento acelerado (EA), condutividade elétrica (CE), emergência de plântulas em campo (EC), velocidade de emergência (VE) e respectivos coeficientes de variação (C.V., \%).

\begin{tabular}{|c|c|c|c|c|c|c|c|c|}
\hline TRATAMENTOS & $S I^{1}$ & $M 100 S^{2}$ & $\mathrm{TG}^{1}$ & $\mathrm{TF}^{1}$ & $E A^{1}$ & $C E^{3}$ & $E C^{1}$ & $V E^{4}$ \\
\hline 1. DELT & $2,0 a^{*}$ & $28,4 b$ & $95 c$ & $44,3 b$ & $59,5 a$ & $14,2 a b c$ & $93,5 a$ & $15,24 a$ \\
\hline 2. CLOR1 & $2,0 a$ & $28,2 b$ & $97 \mathrm{bc}$ & $42,8 b$ & $67,0 a$ & $14,9 a b$ & $93,0 a$ & $14,87 a$ \\
\hline 3. CLOR2 & $4,0 a$ & $28,1 b$ & $97 \mathrm{bc}$ & $53,3 a b$ & $69,8 a$ & $14,4 a b c$ & $92,3 a$ & $14,72 a$ \\
\hline 4. DELT + CLOR1 & $2,0 a$ & $28,3 b$ & $98 a b$ & $57,5 a$ & $61,8 a$ & $15,2 a b$ & $91,5 a$ & $14,39 a$ \\
\hline 5. DELT + CLOR2 & $3,5 a$ & $28,4 b$ & $97 \mathrm{bc}$ & $51,5 a b$ & $61,8 a$ & $14,6 a b c$ & $88,0 a$ & $13,91 a$ \\
\hline 6. INSECTO & $2,0 a$ & $28,2 b$ & $99 a$ & $50,3 a b$ & $71,8 a$ & $14,1 b c$ & $92,8 a$ & $14,96 a$ \\
\hline 7. KEEPDRY & $2,3 a$ & $28,5 b$ & $99 a$ & $53,3 a b$ & $70,3 a$ & $14,2 \mathrm{bc}$ & $92,3 a$ & $14,95 a$ \\
\hline 8. TESTEMUNHA & $8,0 a$ & $28,5 b$ & $97 \mathrm{bc}$ & $50,0 a b$ & $59,3 a$ & $15,9 a$ & $91,0 a$ & $14,24 a$ \\
\hline 9. EXPURGO & $1,5 a$ & $29,7 a$ & $98 a b$ & $51,5 a b$ & $64,3 a$ & $13,0 \mathrm{c}$ & $91,3 a$ & $13,63 a$ \\
\hline č. & 26,4 & 1,7 & 2,3 & 6,9 & 9,2 & $5,0^{-}$ & 3,1 & 3,8 \\
\hline
\end{tabular}

\footnotetext{
Na coluna médias seguidas por letras distintas diferem entre si pelo teste de Tukey ao nível de $5 \%$ de probabilidade ${ }^{1}$ Dados em porcentagem

${ }^{2}$ Dados em gramas

${ }^{3}$ Dados em $\mu \mathrm{mho} / \mathrm{cm}$

${ }^{4}$ Dados na forma de índice
}

Nos testes de germinação, envelhecimento acelerado, emergência de plântulas em campo e velocidade de emergência, não foram constatadas diferenças significativas entre os nove tratamentos.

No teste de frio, as sementes dos tratamentos 6 (INSECTO) e 7 (KEEPDRY), apresentaram vigor superior ao apresentado pelas sementes do tratamento 
1 (DELT), não sendo observadas diferenças significativas entre os demais tratamentos.

Por outro lado, para leitura de condutividade elétrica, o tratamento 8 (TESTEMUNHA) foi maior do que os demais tratamentos, portanto, apresentando sementes menos vigorosas. Por sua vez, as sementes dos tratamentos 1 (DELT) e 9 (EXPURGO) apresentaram maior vigor em relação ao tratamento 5 (DELT + CLOR2).

Tabela 10. Híbrido AG 303- Quarta época: médias relativas ao exame de sementes infestadas (SI), massa de 100 sementes (M100S), teste de germinação (TG), teste de frio (TF), envelhecimento acelerado (EA), condutividade elétrica (CE), emergência de plântulas em campo (EC), velocidade de emergência (VE) e respectivos coeficientes de variação (C.V., \%).

$\begin{array}{lllllllll}\text { TRATAMENTOS } & \mathrm{SI}^{1} & \mathrm{M}_{100 S^{2}} & \mathrm{TG}^{1} & \mathrm{TF}^{1} & \mathrm{EA}^{1} & \mathrm{CE}^{3} & \mathrm{EC}^{1} & \mathrm{VE}^{4}\end{array}$

$\begin{array}{lcccccccc}\text { 1. DELT } & 2,3 b^{*} & 28,5 b & 96 a & 74,0 b & 54,3 a & 12,8 \mathrm{c} & 92,5 a & 17,90 a \\ \text { 2. CLOR1 } & 2,3 \mathrm{~b} & 28,6 \mathrm{~b} & 97 \mathrm{a} & 81,3 \mathrm{ab} & 61,8 \mathrm{a} & 14,1 \mathrm{bc} & 91,5 \mathrm{a} & 17,68 \mathrm{a} \\ \text { 3. CLOR2 } & \text { 2,0b } & 28,5 \mathrm{~b} & 97 \mathrm{a} & 80,8 \mathrm{ab} & 66,8 \mathrm{a} & 14,5 \mathrm{bc} & 92,5 \mathrm{a} & 17,85 \mathrm{a} \\ \text { 4. DELT + CLOR1 } & 2,3 \mathrm{~b} & 28,6 \mathrm{~b} & 98 \mathrm{a} & 82,3 \mathrm{ab} & 64,3 \mathrm{a} & 13,5 \mathrm{bc} & 94,5 \mathrm{a} & 18,39 \mathrm{a} \\ \text { 5. DELT + CLOR2 } & 1,5 \mathrm{~b} & 28,8 \mathrm{~b} & 97 \mathrm{a} & 80,5 \mathrm{ab} & 66,5 \mathrm{a} & 15,2 \mathrm{~b} & 93,8 \mathrm{a} & 18,06 \mathrm{a} \\ \text { 6. INSECTO } & 2,5 \mathrm{~b} & 28,6 \mathrm{~b} & 98 \mathrm{a} & 85,3 \mathrm{a} & 59,3 \mathrm{a} & 13,5 \mathrm{bc} & 94,0 \mathrm{a} & 18,22 \mathrm{a} \\ \text { 7. KEEPDRY } & 2,0 \mathrm{~b} & 28,5 \mathrm{~b} & 98 \mathrm{a} & 85,0 \mathrm{a} & 63,3 \mathrm{a} & 13,6 \mathrm{bc} & 92,5 \mathrm{a} & 18,42 \mathrm{a} \\ \text { 8. TESTEMUNHA } & 9,0 \mathrm{a} & 28,8 \mathrm{~b} & 94 \mathrm{a} & 82,0 \mathrm{ab} & 54,0 \mathrm{a} & 17,7 \mathrm{a} & 77,5 \mathrm{a} & 14,76 \mathrm{a} \\ \text { 9. EXPURGO } & 2,8 \mathrm{~b} & 30,2 \mathrm{a} & 96 \mathrm{a} & 81,3 \mathrm{ab} & 67,0 \mathrm{a} & 13,0 \mathrm{c} & 92,8 \mathrm{a} & 18,72 \mathrm{a} \\ \text { C.V. } & 28,0^{-}-1,9 & \mathbf{3 , 7} & 4,1 & 6,4 & 5,6 & 5,8 & 8,3\end{array}$

Na coluna, médias seguidas por letras distintas diferem entre si pelo teste de Tukey ao nível de $5 \%$ de probabilidade

${ }^{1}$ Dados em porcentagem

2 Dados em gramas

${ }^{3}$ Dados em $\mu \mathrm{mho} / \mathrm{cm}$

${ }^{4}$ Dados na forma de índice

Na Tabela 11, são apresentadas as médias relativas ao exame de sementes infestadas, massa de 100 sementes, teste de germinação, teste de frio, envelhecimento 
acelerado, condutividade elétrica, emergência de plântulas em campo, velocidade de emergência e seus respectivos coeficientes de variação, observados 240 dias após a aplicação dos produtos (quinta época). Como se pode observar, o tratamento 8 (TESTEMUNHA) apresentou porcentagem de infestação superior aos demais tratamentos. Esse mesmo tratamento apresentou também menor massa de 100 sementes quando comparado ao tratamento 9 (EXPURGO) porém, seu comportamento foi semelhante aos demais tratamentos.

Tabela 11. Híbrido AG 303- Quinta época: médias relativas ao exame de sementes infestadas (SI), massa de 100 sementes (M100S), teste de germinação (TG), teste de frio (TF), envelhecimento acelerado (EA), condutividade elétrica (CE), emergência de plântulas em campo (EC), velocidade de emergência (VE) e respectivos coeficientes de variação (C.V., \%).

TRATAMENTOS $\quad \mathrm{SI}^{1} \quad \mathrm{M}_{100 \mathrm{~S}^{2}} \quad \mathrm{TG}^{1} \quad \mathrm{TF}^{1} \quad \mathrm{EA}^{1} \quad \mathrm{CE}^{3} \quad \mathrm{EC}^{1} \quad \mathrm{VE}^{4}$

\begin{tabular}{lcccccccc}
\hline 1. DELT & $3,5 \mathrm{~b}^{*}$ & $28,9 \mathrm{ab}$ & $92 \mathrm{a}$ & $34,5 \mathrm{ab}$ & $30,5 \mathrm{c}$ & $16,2 \mathrm{~b}$ & $81,5 \mathrm{a}$ & $13,11 \mathrm{a}$ \\
2. CLOR1 & $3,3 \mathrm{~b}$ & $28,6 \mathrm{ab}$ & $94 \mathrm{a}$ & $32,0 \mathrm{~b}$ & $38,0 \mathrm{abc}$ & $16,0 \mathrm{~b}$ & $82,8 \mathrm{a}$ & $13,76 \mathrm{a}$ \\
3. CLOR2 & $3,0 \mathrm{~b}$ & $28,3 \mathrm{ab}$ & $96 \mathrm{a}$ & $32,5 \mathrm{~b}$ & $33,8 \mathrm{bc}$ & $15,3 \mathrm{~b}$ & $78,0 \mathrm{a}$ & $13,14 \mathrm{a}$ \\
4. DELT + CLOR1 & $3,0 \mathrm{~b}$ & $28,6 \mathrm{ab}$ & $94 \mathrm{a}$ & $32,5 \mathrm{~b}$ & $35,5 \mathrm{bc}$ & $16,5 \mathrm{~b}$ & $79,0 \mathrm{a}$ & $13,06 \mathrm{a}$ \\
5. DELT + CLOR2 & $4,0 \mathrm{~b}$ & $28,9 \mathrm{ab}$ & $95 \mathrm{a}$ & $34,5 \mathrm{ab}$ & $27,0 \mathrm{c}$ & $15,8 \mathrm{~b}$ & $84,3 \mathrm{a}$ & $14,02 \mathrm{a}$ \\
6. INSECTO & $2,0 \mathrm{~b}$ & $28,5 \mathrm{ab}$ & $97 \mathrm{a}$ & $47,5 \mathrm{a}$ & $49,3 \mathrm{a}$ & $15,4 \mathrm{~b}$ & $88,3 \mathrm{a}$ & $14,54 \mathrm{a}$ \\
7. KEEPDRY & $2,0 \mathrm{~b}$ & $28,7 \mathrm{ab}$ & $97 \mathrm{a}$ & $48,0 \mathrm{a}$ & $49,0 \mathrm{a}$ & $14,2 \mathrm{~b}$ & $85,8 \mathrm{a}$ & $13,96 \mathrm{a}$ \\
8. TESTEMUNHA & $46,5 \mathrm{a}$ & $28,2 \mathrm{~b}$ & $75 \mathrm{~b}$ & $18,5 \mathrm{c}$ & $9,0 \mathrm{~d}$ & $34,7 \mathrm{a}$ & $62,0 \mathrm{~b}$ & $9,40 \mathrm{~b}$ \\
9. EXPURGO & $3,3 \mathrm{~b}$ & $30,3 \mathrm{a}$ & $95 \mathrm{a}$ & $38,5 \mathrm{ab}$ & $44,5 \mathrm{ab}$ & $15,4 \mathrm{~b}$ & $84,5 \mathrm{a}$ & $13,61 \mathrm{a}$ \\
\hline C.V. & 24,3 & 2,1 & 3,4 & 9,4 & 8,3 & 8,1 & 12,4 & 11,8 \\
\hline
\end{tabular}

\footnotetext{
Na coluna, médias seguidas por letras distintas diferem entre si pelo teste de Tukey ao nível de $5 \%$ de probabilidade

${ }^{1}$ Dados em porcentagem

${ }^{2}$ Dados em gramas

${ }^{3}$ Dados em $\mu \mathrm{mho} / \mathrm{cm}$

${ }^{4}$ Dados na forma de índice
} 
Nos testes de germinação, condutividade elétrica, emergência de plântulas em campo e velocidade de emergência, foi observado para o tratamento testemunha, menor qualidade fisiológica em relação aos demais tratamentos.

No teste de frio, as sementes do tratamento 8 (TESTEMUNHA) apresentaram menor vigor em relação ao apresentado pelas sementes dos demais tratamentos. Os tratamentos 6 (INSECTO) e 7 (KEEPDRY) apresentaram maior vigor do que o observado para os tratamentos 2 (CLOR1), 3 (CLOR2) e 4 (DELT + CLOR1) não diferindo dos tratamentos 1 (DELT), 5 (DELT + CLOR2) e 9 (EXPURGO).

No teste de envelhecimento acelerado, as sementes do tratamento 8 (TETEMUNHA) apresentaram vigor mais baixo em relação aos demais tratamentos, ao passo que os tratamentos 6 (INSECTO) e 7 (KEEPDRY) apresentaram valores superiores aos observados para os tratamentos 1 (DELT), 3 (CLOR2), 4 (DELT + CLOR1) e 5 (DELT + CLOR2).

Na Tabela 12, são apresentadas as médias relativas ao exame de sementes infestadas, massa de 100 sementes, teste de germinação, teste de frio, envelhecimento acelerado, condutividade elétrica, emergência de plântulas em campo, velocidade de emergência e seus respectivos coeficientes de variação, observadas 300 dias após a aplicação dos produtos (sexta época). Como se pode observar, o tratamento testemunha apresentou maior porcentagem de infestação e menor massa de 100 sementes quando comparado aos demais tratamentos.

Nos resultados obtidos nos testes de germinação, de frio, envelhecimento acelerado, condutividade elétrica, emergência de plântulas em campo e velocidade de emergência foi observada qualidade fisiológica mais baixa para as sementes do tratamento 8 (TESTEMUNHA) em relação aos demais tratamentos.

Na Tabela 13, são apresentadas as médias relativas ao exame de sementes infestadas, massa de 100 sementes, teste de germinação, teste de frio, envelhecimento acelerado, condutividade elétrica, emergência de plântulas em campo, velocidade de emergência e seus respectivos coeficientes de variação, observadas 360 dias após a aplicação dos produtos (sétima época). Como se pode observar, o tratamento 8 (TESTEMUNHA) apresentou porcentagem de infestação superior e massa de 100 
sementes inferior quando comparado aos demais tratamentos, ocorrência já observada na sexta época de avaliação.

Tabela 12. Hibrido AG 303- Sexta época: médias relativas ao exame de sementes infestadas (SI), massa de 100 sementes (M100S), teste de germinação (TG), teste de frio (TF), envelhecimento acelerado (EA), condutividade elétrica (CE), emergência de plântulas em campo (EC), velocidade de emergência (VE) e respectivos coeficientes de variação (C.V., \%).

\begin{tabular}{|c|c|c|c|c|c|c|c|c|}
\hline TRATAMENTOS & $\mathrm{Sl}^{1}$ & $\mathrm{M}_{100 \mathrm{~S}^{2}}$ & $\mathrm{TG}^{1}$ & $\mathrm{TF}^{1}$ & $\mathrm{EA}^{1}$ & $C E^{3}$ & $\mathrm{EC}^{1}$ & $V E^{4}$ \\
\hline 1. DELT & $3,8 b^{*}$ & $26,6 a$ & $94 a$ & $28,8 a$ & $33,5 a$ & $19,3 b$ & $80,8 a$ & $12,95 a$ \\
\hline 2. CLOR1 & $1,5 b$ & $28,4 a$ & $96 a$ & $27,5 a$ & $43,8 a$ & $16,1 b$ & $86,0 a$ & $13,68 a$ \\
\hline 3. CLOR2 & $1,8 b$ & $28,4 a$ & $95 a$ & $27,3 a$ & $41,5 a$ & $17,6 b$ & $87,5 a$ & $13,98 \mathbf{a}$ \\
\hline 4. DELT + CLOR1 & $1,8 b$ & $28,4 a$ & $95 a$ & $36,8 a$ & $34,5 a$ & $16,7 b$ & $84,5 a$ & $14,24 a$ \\
\hline 5. DELT + CLOR2 & $3,5 b$ & $28,8 a$ & $95 a$ & $25,0 a$ & $40,3 a$ & $17,3 b$ & $84,3 a$ & $13,84 a$ \\
\hline 6. INSECTO & $1,8 b$ & $28,6 a$ & $96 a$ & $32,8 a$ & $51,0 a$ & $16,3 b$ & $84,8 a$ & $14,39 a$ \\
\hline 7. KEEPDRY & $1,3 b$ & $28,6 a$ & $95 a$ & $34,5 a$ & $54,0 a$ & $17,3 b$ & $85,5 a$ & $14,59 a$ \\
\hline 8. TESTEMUNHA & $95,8 a$ & $25,2 b$ & $24 b$ & $2,5 b$ & $2,3 b$ & $68,4 a$ & $5,0 b$ & $0,79 b$ \\
\hline 9. EXPURGO & $1,3 b$ & $30,2 a$ & $95 a$ & $31,3 a$ & $45,5 a$ & $17,5 b$ & $81,5 a$ & $13,30 a$ \\
\hline C.V. & 24,7 & 4,7 & 5,7 & 10,5 & 14,5 & 20,8 & 29,4 & 24,2 \\
\hline
\end{tabular}

Na coluna, médias seguidas por letras distintas diferem entre si pelo teste de Tukey ao nivel de 5\% de probabilidade

${ }^{1}$ Dados em porcentagem

2 Dados em gramas

${ }^{3}$ Dados em $\mu \mathrm{mho} / \mathrm{cm}$

${ }^{4}$ Dados na forma de índice

No teste de germinação, foi observado para o tratamento testemunha menor porcentagem de germinação em relação aos demais tratamentos, ao passo que o tratamento 7 (KEEPDRY) apresentou valores superiores aos observados para os tratamento 1 (DELT) e 9 (EXPURGO), não sendo observadas diferenças entre esses e os demais tratamentos, excluído o tratamento 8 (TESTEMUNHA). 
Nos testes de frio, envelhecimento acelerado, condutividade elétrica, emergência de plântulas em campo e velocidade de emergência de plântulas em campo, 0 tratamento 8 (TESTEMUNHA) apresentou sementes com vigor mais baixo em relação aos demais tratamentos.

Tabela 13. Híbrido AG 303- Sétima época: médias relativas ao exame de sementes infestadas (SI), massa de 100 sementes (M100S), teste de geminação (TG), teste de frio (TF), envelhecimento acelerado (EA), condutividade elétrica (CE), emergência de plântulas em campo (EC), velocidade de emergência (VE) e respectivos coeficientes de variação (C.V., \%).

\begin{tabular}{|c|c|c|c|c|c|c|c|c|}
\hline TRATAMENTOS & $S I^{1}$ & $\mathrm{M}_{100 S^{2}}$ & $\mathrm{TG}^{1}$ & $\mathrm{TF}^{1}$ & $E A^{1}$ & $C E^{3}$ & $E C^{1}$ & $V E^{4}$ \\
\hline 1. DELT & $5,5 b^{*}$ & $28,7 a$ & $88 b$ & $9,3 a$ & $15,8 \mathbf{a}$ & $18,5 b$ & $88,5 a$ & $15,31 a$ \\
\hline 2. CLOR1 & $2,3 b$ & $28,6 a$ & $91 a b$ & $10,3 a$ & $16,5 a$ & $18,0 b$ & $93,3 a$ & $16,30 a$ \\
\hline 3. CLOR2 & $2,8 b$ & $28,4 a$ & $92 a b$ & $10,0 a$ & $21,5 a$ & $17,3 b$ & $92,0 a$ & $16,29 a$ \\
\hline 4. DELT + CLOR1 & $1,5 b$ & $28,7 a$ & $91 \mathrm{ab}$ & $10,0 a$ & $22,0 a$ & $18,2 b$ & $92,3 a$ & $16,27 a$ \\
\hline 5. DELT + CLOR2 & $2,5 b$ & $28,7 a$ & $89 a b$ & $8,5 a$ & $16,8 a$ & $17,1 b$ & $89,8 a$ & $14,73 a$ \\
\hline 6. INSECTO & $1,0 b$ & $28,6 a$ & $93 a b$ & $10,8 a$ & $20,5 a$ & $17,6 b$ & $91,5 a$ & $16,78 a$ \\
\hline 7. KEEPDRY & $1,0 b$ & $28,7 a$ & $96 a$ & $9,8 a$ & $22,0 a$ & $17,2 b$ & $93,5 a$ & $17,09 a$ \\
\hline 8. TESTEMUNHA & $98,0 a$ & $22,8 b$ & $8 c$ & $0,0 b$ & $0,0 \mathrm{~b}$ & $94,6 a$ & $5,5 b$ & $0,67 b$ \\
\hline 9. EXPURGO & $2,3 b$ & $30,2 a$ & $89 b$ & $8,3 a$ & $19,3 a$ & $17,4 b$ & $89,3 a$ & $15,44 a$ \\
\hline c. v. & 24,6 & 7,3 & 4,2 & 15,4 & 9,8 & 9,2 & 28,6 & 26,4 \\
\hline
\end{tabular}

\footnotetext{
Na coluna, médias seguidas por letras distintas diferem entre si pelo teste de Tukey ao nível de $5 \%$ de probabilidade

${ }^{1}$ Dados em porcentagem

${ }^{2}$ Dados em gramas

${ }^{3}$ Dados em $\mu \mathrm{mho} / \mathrm{cm}$

${ }^{4}$ Dados na forma de índice
} 


\subsection{Hibrido BR 205}

Os dados relativos aos teores de água das sementes (Tabela 14), permitem verificar que os valores obtidos para os tratamentos nas diferentes épocas, ficaram entre $10,0 \%$ e $11,8 \%$, valores esses considerados como normais para o armazenamento de sementes de milho em ambiente não controlado na região de Piracicaba- SP (Figura 1).

Tabela 14. Híbrido BR 205: teores médios de água (\%) das sementes, observados nos tratamentos nas sete épocas de avaliação, durante 12 meses de armazenamento.

\begin{tabular}{lccccccc}
\hline & \multicolumn{7}{c}{ PERIODO DE ARMAZENAMENTO (MESES) } \\
\cline { 2 - 8 } TRATAMENTOS & 0 & 2 & 4 & 6 & 8 & 10 & 12 \\
\hline 1. DELT & 10,7 & 11,8 & 10,2 & 10,5 & 11,0 & 10,7 & 11,5 \\
2. CLOR1 & 11,0 & 11,8 & 10,2 & 10,6 & 10,8 & 10,7 & 11,4 \\
3. CLOR2 & 10,9 & 11,8 & 10,2 & 10,6 & 11,0 & 10,7 & 11,4 \\
4. DELT + CLOR1 & 10,7 & 11,7 & 10,2 & 10,7 & 10,6 & 10,8 & 11,4 \\
5. DELT + CLOR2 & 10,9 & 11,5 & 10,1 & 10,7 & 10,7 & 10,6 & 11,3 \\
6. INSECTO & 10,3 & 11,3 & 10,0 & 10,6 & 10,4 & 10,6 & 11,2 \\
7. KEEPDRY & 10,3 & 11,1 & 10,0 & 10,7 & 10,7 & 10,5 & 11,1 \\
8. TESTEMUNHA & 10,3 & 11,0 & 10,1 & 10,8 & 10,7 & 10,6 & 11,7 \\
9. EXPURGO & 10,5 & 11,0 & 10,0 & 10,6 & 10,8 & 10,6 & 11,1 \\
\hline
\end{tabular}

Por outro lado, os valores de $\mathrm{F}$ para as demais determinações de laboratório e de campo, calculados para as sete épocas, estão contidos na Tabela 15. 
Tabela 15. Híbrido BR 205: valores de F, para as determinações de laboratório (sementes infestadas-SI, massa de 100 sementes-M100S, teste de germinação-TG, teste de frio-TF, envelhecimento acelerado-EA e condutividade elétrica-CE) e de campo (emergência de plântulas em campo-EC e velocidade de emergência-VE), calculados para as sete épocas.

\begin{tabular}{|c|c|c|c|c|c|c|c|}
\hline \multirow{2}{*}{$\begin{array}{l}\text { DETERMI- } \\
\text { NAÇŌES }\end{array}$} & \multicolumn{7}{|c|}{ PERIODOS DE ARMAZENAMENTO (MESES) } \\
\hline & $\mathbf{0}$ & 2 & 4 & 6 & 8 & 10 & 12 \\
\hline SI & 2,16 & 5,22 & 4,34 & 9,90 & $69,59^{\star \star}$ & $160,10^{* *}$ & $103,41^{* \star}$ \\
\hline M100s & 6,17 & 2,89 & 0,01 & 1,84 & 2,19 & $11,71^{\star *}$ & $91,13^{\star *}$ \\
\hline TG & 1,54 & 1,34 & $2,96^{*}$ & $2,90^{*}$ & $8,90^{\star *}$ & $3,02^{\star \star}$ & $118,31^{* \star}$ \\
\hline TF & 0,52 & $3,31^{\star *}$ & $5,13^{\star *}$ & $2,48^{\star}$ & $8,13^{\star \star}$ & $7,11^{\star \star}$ & $12,11^{* \star}$ \\
\hline EA & 0,85 & $4,34^{* *}$ & $1,87^{* *}$ & $2,85^{\star}$ & $38,60^{\star *}$ & $8,02^{\star \star}$ & $54,35^{\star *}$ \\
\hline CE & $37,70^{\star \star *}$ & 2,01 & $8,00^{* *}$ & $5,75^{\star \star}$ & $41,27^{\star *}$ & $47,67^{\star \star}$ & $830,03^{* \star}$ \\
\hline EC & 2,08 & 1,49 & 1,70 & 1,80 & 4,43 & $54,26^{* \star}$ & $69,18^{* *}$ \\
\hline VE & 1,34 & 1,34 & 1,10 & 4,50 & $10,01^{* *}$ & $26,40^{\star \star}$ & $80,20^{* *}$ \\
\hline
\end{tabular}

* Significativo ao nível de $5 \%$ de probabilidade

** Significativo ao nivel de $1 \%$ de probabilidade

$\mathrm{Na}$ Tabela 16 são apresentadas as médias relativas ao exame de sementes infestadas, massa de 100 sementes, teste de germinação, teste de frio, envelhecimento acelerado, condutividade elétrica, emergência de plântulas em campo, velocidade de emergência e seus respectivos coeficientes de variação, observadas na primeira época. Como se pode observar, as sementes dos nove tratamentos apresentaram porcentagem de infestação semelhantes. A maior infestação observada, em termos numéricos, foi de 3\%; o referido valor é admitido nos padrões de Sementes Certificadas e de Sementes Fiscalizadas (Brasil, 1991). Por sua vez, todos os tratamentos apresentaram massa de 100 sementes semelhante.

Nos testes de germinação, de frio, de envelhecimento acelerado, de emergência de plântulas e de velocidade de emergência de plântulas em campo não foram constatadas diferenças significativas entre os nove tratamentos. 
Tabela 16. Híbrido BR 205- Primeira época: médias relativas ao exame de sementes infestadas (SI), massa de 100 sementes (M100S), teste de germinação (TG), teste de frio (TF), envelhecimento acelerado (EA), condutividade elétrica (CE), emergência de plântulas em campo (EC) e velocidade de emergência (VE) e respectivos coeficientes de variação (C.V., \%).

TRATAMENTOS $\quad \mathrm{SI}^{1} \quad \mathrm{M}_{100 \mathrm{~S}^{2}} \mathrm{TG}^{1} \quad \mathrm{TF}^{1} \quad \mathrm{EA}^{1} \quad \mathrm{CE}^{3} \quad \mathrm{EC}^{1} \quad \mathrm{VE}^{4}$

$\begin{array}{lllllllll}\text { 1. DELT } & 2,0 a^{*} & 27,3 a & 98 a & 78,0 a & 84,3 a & 14,1 a b & 87,0 a & 14,14 a \\ \text { 2. CLOR1 } & 2,0 a & 27,5 a & 98 a & 82,0 a & 87,3 a & 13,8 b & 92,5 a & 14,76 a \\ \text { 3. CLOR2 } & 3,0 a & 27,1 a & 95 a & 82,0 a & 84,0 a & 13,6 b & 90,5 a & 14,41 a \\ \text { 4. DELT+ CLOR1 } & 2,0 a & 27,4 a & 96 a & 79,5 a & 81,8 a & 14,5 a & 92,0 a & 14,30 a \\ \text { 5. DELT+ CLOR2 } & 3,0 a & 27,3 a & 98 a & 76,5 a & 82,5 a & 13,9 b & 88,3 a & 14,08 a \\ \text { 6. INSECTO } & 2,0 a & 27,3 a & 96 a & 81,0 a & 82,0 a & 12,4 c & 90,8 a & 14,39 a \\ \text { 7. KEEPDRY } & 3,0 a & 27,3 a & 97 a & 81,0 a & 86,3 a & 12,8 c & 92,5 a & 14,71 a \\ \text { 8. TESTEMUNHA } & 3,0 a & 27,2 a & 99 a & 82,3 a & 83,8 a & 12,4 c & 94,0 a & 14,80 a \\ \text { 9. EXPURGO } & 3,0 a & 26,9 a & 95 a & 84,5 a & 84,5 a & 13,6 b & 92,0 a & 14,72 a\end{array}$

$\begin{array}{lllllllllll}\text { C..v. } & 8,3 & 0,6 & 5,5 & 6,9 & 5,1 & 1,8 & 2,9 & 3,3\end{array}$

\footnotetext{
Na coluna, médias seguidas por letras distintas diferem entre si pelo teste de Tukey ao nivel de $5 \%$ de probabilidade

${ }^{1}$ Dados em porcentagem

${ }^{2}$ Dados em gramas

${ }^{3}$ Dados em $\mu \mathrm{mho} / \mathrm{cm}$

${ }^{4}$ Dados na forma de índice
}

Por outro lado, no teste de condutividade elétrica, as sementes do tratamento 4 (DELT + CLOR1) apresentaram menor qualidade fisiológica em relação à maioria dos demais tratamentos, sendo os melhores resultados obtidos nos tratamentos 6 (INSECTO), 7 (KEEPDRY) e 8 (TESTEMUNHA).

Na Tabela 17 são apresentadas as médias relativas ao exame de sementes infestadas, massa de 100 sementes, teste de germinação, teste de frio, envelhecimento acelerado, condutividade elétrica, emergência de plântulas em campo, velocidade de emergência e seus respectivos coeficientes de variação observadas na segunda época. Como se pode observar, no exame de sementes infestadas, massa de 100 sementes, teste 
de germinação, condutividade elétrica, emergência de plântulas e velocidade de emergência de plântulas em campo não foram constatadas diferenças significativas entre os nove tratamentos.

No teste de frio, no tratamento 9 (EXPURGO) as sementes apresentaram maior vigor do que o observado para as sementes do tratamento 3 (CLOR2), não sendo constatadas diferenças estatísticas em relação aos demais tratamentos.

Tabela 17. Híbrido BR 205- Segunda época: médias relativas ao exame de sementes infestadas (SI), massa de 100 sementes (M100S), teste de germinação (TG), teste de frio (TF), envelhecimento acelerado (EA), condutividade elétrica (CE), emergência de plântulas em campo (EC), velocidade de emergência (VE) e respectivos coeficientes de variação (C.V., \%).

TRATAMENTOS $\quad \mathrm{SI}^{1} \quad \mathrm{M}_{100 \mathrm{~S}^{2}} \mathrm{TG}^{1} \quad \mathrm{TF}^{1} \quad \mathrm{EA}^{1} \quad \mathrm{CE}^{3} \quad \mathrm{EC}^{1} \quad \mathrm{VE}^{4}$

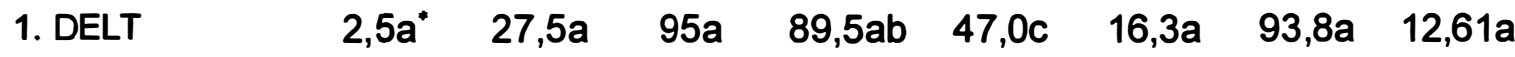

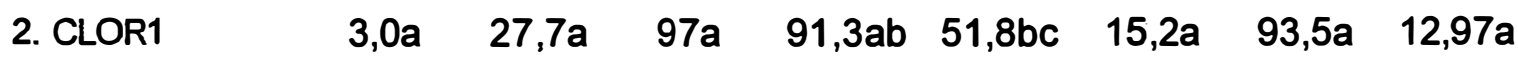

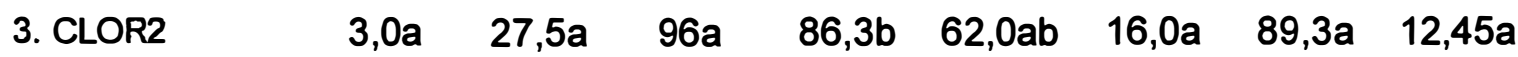

4. DELT+CLOR1 $\quad 2,5 a \quad 27,9 a \quad 96 a \quad 90,3 a b \quad 56,8 a b c \quad 16,1 a \quad 92,3 a \quad 12,77 a$

5. DELT+CLOR2 $\quad 2,0 a \quad 27,4 a \quad 95 a \quad 88,5 a b \quad 60,5 a b \quad 15,8 a \quad 90,3 a \quad 12,34 a$

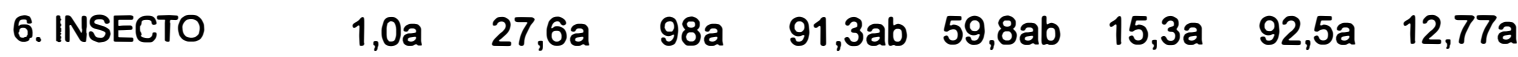

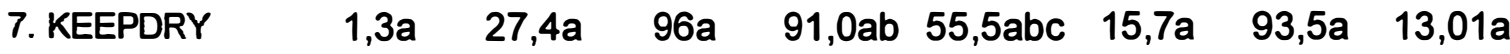

8. TESTEMUNHA $\quad 4,5 a \quad 27,4 a \quad 96 a \quad 89,0 a b \quad 54,5 a b c \quad 16,6 a \quad 93,5 a \quad 12,68 a$

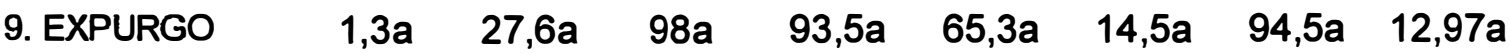

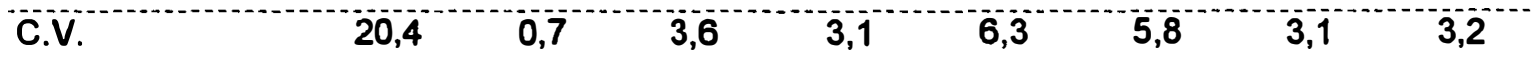

Na coluna, médias seguidas por letras distintas diferem entre si pelo teste de Tukey ao nível de $5 \%$ de probabilidade

${ }^{1}$ Dados em porcentagem

2 Dados em gramas

${ }^{3}$ Dados em $\mu \mathrm{mho} / \mathrm{cm}$

${ }^{4}$ Dados na forma de índice

Por outro lado, no teste de envelhecimento acelerado as sementes do tratamento 1 (DELT) apresentaram menor vigor em relação ao apresentado pelas 
sementes dos tratamentos 3 (CLOR2), 5 (DELT + CLOR2), 6 (INSECTO) e 9 (EXPURGO), não diferindo significativamente dos demais tratamentos. Houve, também, superioridade estatística do tratamento 9 (EXPURGO) em relação ao tratamento 2 (CLOR1).

$\mathrm{Na}$ Tabela 18 são apresentadas as médias relativas ao exame de sementes infestadas, massa de 100 sementes, teste de germinação, teste de frio, envelhecimento acelerado, condutividade elétrica, emergência de plântulas em campo, velocidade de emergência e seus respectivos coeficientes de variação, observadas na terceira época. Como se pode verificar, o exame de sementes infestadas, a massa de 100 sementes, a emergência de plântulas e a velocidade de emergência de plântulas em campo não revelaram diferenças significativas entre os nove tratamentos.

No teste de gemninação verificou-se superioridade estatística do tratamento 9 (EXPURGO) em relação ao tratamento 2 (CLOR1), não sendo constatadas diferenças em relação aos demais tratamentos.

Pelos resultados apresentados no teste de frio, foi observado maior vigor do tratamento 9 (EXPURGO) em relação aos tratamentos 1 (DELT), 2 (CLOR1), 3 (CLOR2), 4 (DELT + CLOR1) e 5 (DELT + CLOR2) e comportamento semelhante em relação aos demais tratamentos.

Os resultados observados no teste de envelhecimento acelerado apresentaram diferenças apenas entre as sementes do tratamento 9 (EXPURGO) e as dos tratamentos 8 (TESTEMUNHA) e 4 (DELT + CLOR1), as quais apresentaram menor vigor.

Por outro lado, no teste de condutividade elétrica as sementes dos tratamentos 3 (CLOR2), 4 (DELT + CLOR1) e 8 (TESTEMUNHA) não apresentaram diferenças significativas entre si, porém apresentaram valor de condutividade elétrica superior aos das sementes dos tratamentos 1 (DELT), 2 (CLOR1) e 6 (INSECTO), tratamentos esses que apresentaram maior qualidade fisiológica em relação à maioria dos demais tratamentos.

$\mathrm{Na}$ Tabela 19 são apresentadas as médias relativas ao exame de sementes infestadas, massa de 100 sementes, teste de germinação, teste de frio, envelhecimento 
acelerado, condutividade elétrica, emergência de plântulas em campo, velocidade de emergência e seus respectivos coeficientes de variação, observadas na quarta época. Como se pode verificar, o exame de sementes infestadas, a massa de 100 sementes, a emergência de plântulas e a velocidade de emergência de plântulas em campo não revelaram diferenças significativas entre os nove tratamentos. Em termos numéricos as sementes do tratamento 8 (TESTEMUNHA) apresentaram porcentagem de infestação superior ao permitido nos padrões de sementes (Brasil, 1991).

Tabela 18. Híbrido BR 205- Terceira época: médias relativas ao exame de sementes infestadas (SI), massa de 100 sementes (M100S), teste de germinação (TG), teste de frio $(\mathrm{TF})$, envelhecimento acelerado (EA), condutividade elétrica (CE), emergência de plântulas em campo (EC), velocidade de emergência (VE) e respectivos coeficientes de variação (C.V., \%).

\begin{tabular}{|c|c|c|c|c|c|c|c|c|}
\hline TRATAMENTOS & $S I^{1}$ & $M 100 S^{2}$ & $\mathrm{TG}^{1}$ & $T^{1}$ & $\mathrm{EA}^{1}$ & $C E^{3}$ & $E C^{1}$ & $V E^{4}$ \\
\hline 1. DELT & $2,5 a^{*}$ & $27,0 a$ & $97 a b$ & $23,3 b$ & $62,8 a b$ & $15,6 c$ & $85,5 a$ & $12,84 a$ \\
\hline 2. CLOR1 & $3,0 a$ & $27,1 a$ & $94 b$ & $25,3 b$ & $58,8 a b$ & $15,6 c$ & $89,8 a$ & $13,42 a$ \\
\hline 3. CLOR2 & $4,0 a$ & $27,1 \mathrm{a}$ & $97 a b$ & $21,0 b$ & $64,3 a b$ & $17,1 \mathrm{a}$ & $89,8 a$ & $13,48 a$ \\
\hline 4. DELT + CLOR1 & $2,5 a$ & $27,2 a$ & $95 a b$ & $23,0 b$ & $57,8 b$ & $16,8 a b$ & $88,0 a$ & $13,02 a$ \\
\hline 5. DELT + CLOR2 & $2,5 a$ & $26,9 a$ & $96 a b$ & $23,0 b$ & $62,3 a b$ & $16,5 a b c$ & $88,5 a$ & $13,13 a$ \\
\hline 6. INSECTO & $1,8 a$ & $27,1 a$ & $98 a b$ & $28,3 a b$ & $62,0 a b$ & $15,2 c$ & $91,8 a$ & $14,21 a$ \\
\hline 7. KEEPDRY & $1,3 a$ & $26,9 a$ & $98 a b$ & $28,5 a b$ & $62,5 a b$ & $15,9 b c$ & $90,3 a$ & $13,93 a$ \\
\hline 8. TESTEMUNHA & $6,5 a$ & $26,9 a$ & $95 a b$ & $28,0 a b$ & $52,3 b$ & $17,7 a$ & $86,0 a$ & $12,57 a$ \\
\hline 9. EXPURGO & $1,3 a$ & $26,9 a$ & $98 a$ & $36,0 a$ & $74,0 a$ & $16,0 \mathrm{bc}$ & $91,3 a$ & $14,02 a$ \\
\hline c.v. & 18,7 & 0,4 & $2,9^{-}$ & 8,4 & 10,0 & 3,6 & 3,9 & 7,6 \\
\hline
\end{tabular}

Na coluna, médias seguidas por letras distintas diferem entre si pelo teste de Tukey ao nivel de $5 \%$ de probabilidade

${ }^{1}$ Dados em porcentagem

2 Dados em gramas

${ }^{3}$ Dados em $\mu \mathrm{mho} / \mathrm{cm}$

${ }^{4}$ Dados na forma de indice 
No teste de germinação verificou-se para os tratamentos 9 (EXPURGO) e 4 (DELT + CLOR1) maior porcentagem de germinação, sendo significativamente superiores ao tratamento 8 (TESTEMUNHA), não havendo diferenças estatísticas em relação aos demais tratamentos.

Os testes de frio e de envelhecimento acelerado, mostraram comportamento semelhante; foi verificado que no tratamento 9 (EXPURGO) as sementes apresentaram maior vigor em relação ao observado para as sementes do tratamento 8 (TESTEMUNHA), não sendo constatadas diferenças significativas entre os demais tratamentos.

Tabela 19. Híbrido BR 205- Quarta época: médias relativas ao exame de sementes infestadas (SI), massa de 100 sementes (M100S), teste de germinação (TG), teste de frio (TF), envelhecimento acelerado (EA), condutividade elétrica (CE), emergência de plântulas em campo (EC), velocidade de emergência (VE) e respectivos coeficientes de variação (C.V., \%).

\begin{tabular}{|c|c|c|c|c|c|c|c|c|}
\hline TRATAMENTOS & $S I^{1}$ & $\mathrm{M100S}^{2}$ & $\mathrm{TG}^{1}$ & $\mathrm{TF}^{1}$ & $\mathrm{EA}^{1}$ & $C E^{3}$ & $\mathrm{EC}^{1}$ & $V E^{4}$ \\
\hline 1. DELT & $3,0 a^{*}$ & $27,2 a$ & $96 a b$ & $73,8 a b$ & $60,0 a b$ & $14,8 a b$ & $86,3 a$ & $17,49 a$ \\
\hline 2. CLOR1 & $3,0 a$ & $27,4 a$ & $95 a b$ & $75,0 a b$ & $70,0 a b$ & $13,8 a b c$ & $91,0 a$ & $18,40 a$ \\
\hline 3. CLOR2 & $2,5 a$ & $27,1 a$ & $96 a b$ & $74,5 a b$ & $69,8 a b$ & $14,4 a b c$ & $89,3 a$ & $17,88 \mathrm{a}$ \\
\hline 4. DELT + CLOR1 & $3,3 a$ & $27,4 a$ & $98 a$ & $71,8 a b$ & $67,3 a b$ & $14,2 a b c$ & $90,3 a$ & $17,70 \mathrm{a}$ \\
\hline 5. DELT + CLOR2 & $2,8 a$ & $27,2 a$ & $96 a b$ & $72,0 a b$ & $64,8 a b$ & 13,1bc & $87,5 a$ & $16,71 a$ \\
\hline 6. INSECTO & $1,8 a$ & $27,2 a$ & $96 a b$ & $76,5 a b$ & $70,8 a b$ & $12,4 \mathrm{C}$ & $92,5 a$ & $18,68 a$ \\
\hline 7. KEEPDRY & $2,0 \mathrm{a}$ & $27,3 a$ & $95 a b$ & $70,5 a b$ & $63,5 a b$ & $13,2 b c$ & $91,5 a$ & $18,32 a$ \\
\hline 8. TESTEMUNHA & $11,8 a$ & $27,0 a$ & $93 b$ & $64,5 b$ & $52,3 b$ & $15,7 a$ & $87,0 a$ & $16,29 a$ \\
\hline 9. EXPURGO & $2,0 a$ & $27,2 a$ & $98 a$ & $78,3 a$ & $75,0 a$ & $13,1 b c$ & $92,0 a$ & $18,36 a$ \\
\hline c.v. & 31,5 & 0,5 & 3,9 & 5,6 & 9,0 & 6,5 & 3,8 & 4,6 \\
\hline
\end{tabular}

\footnotetext{
Na coluna, médias seguidas por letras distintas diferem entre si pelo teste de Tukey ao nível de $5 \%$ de probabilidade

${ }^{1}$ Dados em porcentagem

${ }^{2}$ Dados em gramas

${ }^{3}$ Dados em $\mu \mathrm{mho} / \mathrm{cm}$

${ }^{4}$ Dados na forma de índice
} 
Por outro lado, no teste de condutividade elétrica as sementes do tratamento 8 (TESTEMUNHA) apresentaram qualidade fisiológica inferior ao dos tratamentos 9 (EXPURGO), 7 (KEEPDRY), 6 (INSECTO) e 5 (DELT + CLOR2) e semelhante aos demais tratamentos. $O$ tratamento 6 (INSECTO) apresentou maior qualidade fisiológica em relação aos tratamentos 1 (DELT) e 8 (TESTEMUNHA).

$\mathrm{Na}$ Tabela 20 são apresentadas as médias relativas ao exame de sementes infestadas, massa de 100 sementes, teste de germinação, teste de frio, envelhecimento acelerado, condutividade elétrica, emergência de plântulas em campo, velocidade de emergência e seus respectivos coeficientes de variação, observadas na quinta época. Como se pode observar, as sementes do tratamento 8 (TESTEMUNHA) apresentaram porcentagem de infestação superior e menor massa de 100 sementes quando comparado aos obtidos para as sementes dos demais tratamentos.

Nos testes de germinação e condutividade elétrica verificou-se, para o tratamento testemunha, menor qualidade fisiológica em relação aos demais tratamentos.

No teste de frio foi observada semelhança de vigor entre os tratamentos 7 (KEEPDRY) e 9 (EXPURGO), sendo que ambos apresentaram vigor superior ao apresentado pelas sementes do tratamento 8 (TESTEMUNHA). O tratamento 9 (EXPURGO) foi também superior estatisticamente em relação à maioria dos demais tratamentos.

Para o vigor das sementes avaliado pelo teste de envelhecimento acelerado, foi constatado comportamento semelhante entre as sementes dos tratamentos 6 (INSECTO), 7 (KEEPDRY) e 9 (EXPURGO), sendo as mesmas mais vigorosas em relação às sementes dos tratamentos 1 (DELT), 4 (DELT + CLOR1), 5 (DELT + CLOR2) e 8 (TESTEMUNHA) e as do último tratamento apresentaram menor vigor em relação aos demais tratamentos.

Por outro lado, no teste de emergência de plântulas em campo não foram constatadas diferenças significativas entre os nove tratamentos.

Finalizando a análise da Tabela 20, para a velocidade de emergência de plântulas, o tratamento 7 (KEEPDRY) resultou em índice superior ao apresentado pelos tratamentos 1 (DELT) e 8 (TESTEMUNHA). As sementes do tratamento 8 
(TESTEMUNHA) apresentaram menor velocidade de emergência do que a dos tratamentos com terra diatomácea (6- INSECTO e 7- KEEPDRY) não diferindo significativamente dos demais.

Tabela 20. Hibrido BR 205- Quinta época: médias relativas ao exame de sementes infestadas (SI), massa de 100 sementes (M100S), teste de germinação (TG), teste de frio (TF), envelhecimento acelerado (EA), condutividade elétrica (CE), emergência de plântulas em campo (EC), velocidade de emergência (VE) e respectivos coeficientes de variação (C.V., \%).

TRATAMENTOS $\quad \mathrm{Sl}^{1} \quad \mathrm{M}_{100 \mathrm{~S}^{2}} \mathrm{TG}^{1} \quad \mathrm{TF}^{1} \quad \mathrm{EA}^{1} \quad \mathrm{CE}^{3} \quad \mathrm{EC}^{1} \quad \mathrm{VE}^{4}$

\begin{tabular}{lcccccccc} 
1. DELT & $4,5 b^{*}$ & $27,4 a$ & $94 a$ & $24,0 b c$ & $35,5 c$ & $17,1 b c$ & $82,0 a$ & $13,25 b c$ \\
2. CLOR1 & $2,8 b$ & $27,4 a$ & $94 a$ & $22,5 b c$ & $40,3 b c$ & $17,2 b c$ & $88,5 a$ & $14,78 a b c$ \\
3. CLOR2 & $3,0 b$ & $27,3 a$ & $94 a$ & $26,5 b$ & $40,0 b c$ & $18,9 b$ & $84,8 a$ & $14,36 a b c$ \\
4. DELT + CLOR1 & $3,5 b$ & $27,4 a$ & $94 a$ & $24,5 b c$ & $37,8 \mathrm{c}$ & $17,3 \mathrm{bc}$ & $83,5 \mathrm{a}$ & $14,11 \mathrm{abc}$ \\
5. DELT + CLOR2 & $3,3 \mathrm{~b}$ & $27,2 \mathrm{a}$ & $93 \mathrm{a}$ & $25,5 \mathrm{bc}$ & $36,8 \mathrm{c}$ & $17,9 \mathrm{bc}$ & $84,8 \mathrm{a}$ & $14,71 \mathrm{abc}$ \\
6. INSECTO & $2,3 \mathrm{~b}$ & $27,5 \mathrm{a}$ & $95 \mathrm{a}$ & $27,5 \mathrm{~b}$ & $55,0 \mathrm{a}$ & $16,7 \mathrm{bc}$ & $88,3 \mathrm{a}$ & $16,88 \mathrm{ab}$ \\
7. KEEPDRY & $2,0 \mathrm{~b}$ & $27,3 \mathrm{a}$ & $96 \mathrm{a}$ & $29,5 \mathrm{ab}$ & $51,8 \mathrm{a}$ & $16,8 \mathrm{bc}$ & $91,8 \mathrm{a}$ & $17,51 \mathrm{a}$ \\
8. TESTEMUNHA & $29,0 \mathrm{a}$ & $26,9 \mathrm{~b}$ & $80 \mathrm{~b}$ & $17,5 \mathrm{c}$ & $14,3 \mathrm{~d}$ & $27,5 \mathrm{a}$ & $72,5 \mathrm{a}$ & $12,97 \mathrm{c}$ \\
9. EXPURGO & $2,5 \mathrm{~b}$ & $27,3 \mathrm{a}$ & $97 \mathrm{a}$ & $38,5 \mathrm{a}$ & $49,8 \mathrm{ab}$ & $16,3 \mathrm{c}$ & $89,5 \mathrm{a}$ & $16,30 \mathrm{abc}$ \\
C.V. & 24,1 & 0,7 & 4,1 & 8,5 & 6,2 & 5,9 & 6,3 & 10,6 \\
\hline
\end{tabular}

$\mathrm{Na}$ coluna, médias seguidas por letras distintas diferem entre si pelo teste de Tukey ao nível de $5 \%$ de probabilidade

${ }^{1}$ Dados em porcentagem

${ }^{2}$ Dados em gramas

${ }^{3}$ Dados em $\mu \mathrm{mho} / \mathrm{cm}$

${ }^{4}$ Dados na forma de índice

$\mathrm{Na}$ Tabela 21 são apresentadas as médias relativas ao exame de sementes infestadas, massa de 100 sementes, teste de germinação, teste de frio, envelhecimento acelerado, condutividade elétrica, emergência de plântulas em campo, velocidade de emergência e seus respectivos coeficientes de variação, observadas na sexta época. Como se pode verificar, as sementes do tratamento 8 (TESTEMUNHA) apresentaram 
porcentagem de infestação superior e menor massa de 100 sementes quando comparado aos obtidos para as sementes dos demais tratamentos.

Tabela 21. Híbrido BR 205- Sexta época: médias relativas ao exame de sementes infestadas (SI), massa de 100 sementes (M100S), teste de germinação (TG), teste de frio (TF), envelhecimento acelerado (EA), condutividade elétrica (CE), emergência de plântulas em campo (EC), velocidade de emergência (VE) e respectivos coeficientes de variação (C.V., \%).

TRATAMENTOS $\quad \mathrm{SI}^{1} \quad{\mathrm{M} 100 \mathrm{~S}^{2}}^{\mathrm{T}} \mathrm{TG}^{1} \quad \mathrm{TF}^{1} \quad \mathrm{EA}^{1} \quad \mathrm{CE}^{3} \quad \mathrm{EC}^{1} \quad \mathrm{VE}^{4}$

\begin{tabular}{|c|c|c|c|c|c|c|c|c|}
\hline 1. DELT & $6,5 \mathrm{~b}^{*}$ & $27,3 a$ & $92 \mathrm{ab}$ & $12,8 a$ & $51,0 a$ & $19,8 b$ & $70,0 a$ & $10,01 a$ \\
\hline 2. CLOR1 & $3,0 \mathrm{~b}$ & $27,5 a$ & $96 a$ & $17,5 a$ & $48,8 a$ & $18,5 b$ & $79,3 a$ & $11,43 a$ \\
\hline 3. CLOR2 & $3,3 b$ & $27,4 a$ & $93 a b$ & $14,0 a$ & $49,3 a$ & $19,8 b$ & $75,8 a$ & $10,82 a$ \\
\hline DELT + CLOR1 & $2,5 b$ & $27,5 a$ & $94 a b$ & $17,0 a$ & $45,8 a$ & $20,0 b$ & $81,8 a$ & $12,01 a$ \\
\hline 5. DELT + CLOR2 & $1,3 b$ & $27,3 a$ & $95 a b$ & $16,0 a$ & $54,8 a$ & $20,1 b$ & $86,5 a$ & $12,13 a$ \\
\hline 3. INSECTO & $1,5 b$ & $27,4 a$ & $95 a b$ & $17,0 a$ & $53,3 a$ & $20,1 b$ & $82,8 a$ & $12,14 a$ \\
\hline 7. KEEPDRY & $1,8 b$ & $27,3 a$ & $96 a$ & $18,0 a$ & $64,3 a$ & $19,8 b$ & $75,3 a$ & $10,76 a$ \\
\hline 8. TESTEMUNHA & $69,8 a$ & $26,2 b$ & $68 b$ & $5,0 \mathrm{~b}$ & $12,5 b$ & $38,6 a$ & $25,0 \mathrm{~b}$ & $3,88 b$ \\
\hline 9. EXPURGO & $1,0 \mathrm{~b}$ & $27,3 a$ & $95 a b$ & $19,8 a$ & $64,0 a$ & $18,8 b$ & $78,5 a$ & $10,96 a$ \\
\hline c.v. & 26,3 & 1,5 & 13,5 & 13,5 & 15,6 & 8,5 & 18,3 & 29,0 \\
\hline
\end{tabular}

Na coluna médias seguidas por letras distintas diferem entre si pelo teste de Tukey ao nível de $5 \%$ de probabilidade

${ }^{1}$ Dados em porcentagem

${ }^{2}$ Dados em gramas

${ }^{3}$ Dados em $\mu \mathrm{mho} / \mathrm{cm}$

${ }^{4}$ Dados na forma de índice

Nos testes de frio, de envelhecimento acelerado, condutividade elétrica, emergência de plântulas e velocidade de emergência de plântulas em campo, foi observado para o tratamento 8 (TESTEMUNHA) menor qualidade fisiológica em relação aos demais tratamentos.

Por outro lado, no teste de germinação foi constatada inferioridade estatística do tratamento 8 (TESTEMUNHA) apenas em relação aos tratamentos 2 
(CLOR1) e 7 (KEEPDRY).

Na Tabela 22 são apresentadas as médias relativas ao exame de sementes infestadas, massa de 100 sementes, teste de germinação, teste de frio, envelhecimento acelerado, condutividade elétrica, emergência de plântulas em campo, velocidade de emergência e seus respectivos coeficientes de variação, observadas na sétima época. Como se pode observar, as sementes do tratamento 8 (TESTEMUNHA) apresentaram porcentagem de infestação superior e massa de 100 sementes inferior quando comparado aos obtidos para as sementes dos demais tratamentos, conforme ocorrência verificada a partir da quinta época de avaliação (Tabela 20).

Tabela 22. Híbrido BR 205- Sétima época: médias relativas ao exame de sementes infestadas (SI), massa de 100 sementes (M100S), teste de germinação (TG), teste de frio (TF), envelhecimento acelerado (EA), condutividade elétrica (CE), emergência de plântulas em campo (EC), velocidade de emergência (VE) e respectivos coeficientes de variação (C.V., \%).

\begin{tabular}{lcccccccc}
\hline TRATAMENTOS & $\mathrm{SI}^{1}$ & $\mathrm{M}^{100 \mathrm{~S}^{2}}$ & $\mathrm{TG}^{1}$ & $\mathrm{TF}^{1}$ & $\mathrm{EA}^{1}$ & $\mathrm{CE}^{3}$ & $\mathrm{EC}^{1}$ & $\mathrm{VE}^{4}$ \\
\hline 1. DELT & $5,0 \mathrm{~b}^{*}$ & $27,4 \mathrm{a}$ & $87 \mathrm{c}$ & $3,3 \mathrm{a}$ & $28,8 \mathrm{a}$ & $22,6 \mathrm{~b}$ & $83,0 \mathrm{a}$ & $14,60 \mathrm{a}$ \\
2. CLOR1 & $2,0 \mathrm{~b}$ & $27,5 \mathrm{a}$ & $90 \mathrm{bc}$ & $3,3 \mathrm{a}$ & $30,0 \mathrm{a}$ & $21,4 \mathrm{~b}$ & $87,0 \mathrm{a}$ & $16,01 \mathrm{a}$ \\
3. CLOR2 & $2,0 \mathrm{~b}$ & $27,5 \mathrm{a}$ & $91 \mathrm{bc}$ & $3,8 \mathrm{a}$ & $30,3 \mathrm{a}$ & $20,6 \mathrm{~b}$ & $90,8 \mathrm{a}$ & $15,86 \mathrm{a}$ \\
4. DELT + CLOR1 & $2,0 \mathrm{~b}$ & $27,5 \mathrm{a}$ & $89 \mathrm{bc}$ & $5,0 \mathrm{a}$ & $30,3 \mathrm{a}$ & $21,6 \mathrm{~b}$ & $87,8 \mathrm{a}$ & $15,23 \mathrm{a}$ \\
5. DELT + CLOR2 & $2,5 \mathrm{~b}$ & $27,4 \mathrm{a}$ & $93 \mathrm{ab}$ & $4,0 \mathrm{a}$ & $30,5 \mathrm{a}$ & $21,9 \mathrm{~b}$ & $86,8 \mathrm{a}$ & $15,12 \mathrm{a}$ \\
6. INSECTO & $1,3 \mathrm{~b}$ & $27,5 \mathrm{a}$ & $95 \mathrm{ab}$ & $4,0 \mathrm{a}$ & $33,8 \mathrm{a}$ & $20,1 \mathrm{~b}$ & $92,0 \mathrm{a}$ & $16,75 \mathrm{a}$ \\
7. KEEPDRY & $1,5 \mathrm{~b}$ & $27,5 \mathrm{a}$ & $96 \mathrm{a}$ & $4,5 \mathrm{a}$ & $33,5 \mathrm{a}$ & $20,2 \mathrm{~b}$ & $92,5 \mathrm{a}$ & $16,49 \mathrm{a}$ \\
8. TESTEMUNHA & $97,5 \mathrm{a}$ & $23,3 \mathrm{~b}$ & $12 \mathrm{~d}$ & $0,3 \mathrm{~b}$ & $0,3 \mathrm{~b}$ & $78,4 \mathrm{a}$ & $16,8 \mathrm{~b}$ & $2,70 \mathrm{~b}$ \\
9. EXPURGO & $1,8 \mathrm{~b}$ & $27,5 \mathrm{a}$ & $92 \mathrm{ab}$ & $4,8 \mathrm{a}$ & $39,0 \mathrm{a}$ & $19,8 \mathrm{~b}$ & $82,5 \mathrm{a}$ & $14,53 \mathrm{a}$ \\
C.V. & $24, \ldots+\cdots$ & 5,1 & 4,9 & 19,2 & 9,8 & 4,8 & 23,1 & 28,3 \\
\hline
\end{tabular}

\footnotetext{
$\mathrm{Na}$ coluna, médias seguidas por letras distintas diferem entre si pelo teste de Tukey ao nível de $5 \%$ de probabilidade

${ }^{1}$ Dados em porcentagem

${ }^{2}$ Dados em gramas

${ }^{3}$ Dados em $\mu \mathrm{mho} / \mathrm{cm}$

${ }^{4}$ Dados na forma de índice
} 


\subsection{Híbrido Z 8392}

Os dados relativos aos teores de água das sementes (Tabela 23), permitem verificar que os valores obtidos para os tratamentos nas diferentes épocas, ficaram entre 9,9\% e 12,2\%, valores esses considerados como normais para o armazenamento de sementes de milho em ambiente não controlado na região de Piracicaba- SP (Figura 1).

Tabela 23. Híbrido Z 8392: teores médios de água (\%) das sementes, observados nos tratamentos nas sete épocas de avaliação, durante 12 meses de armazenamento.

\begin{tabular}{lccccccc}
\hline & \multicolumn{7}{c}{ PERIODO DE ARMAZENAMENTO (MESES) } \\
\cline { 2 - 8 } TRATAMENTOS & 0 & 2 & 4 & 6 & 8 & 10 & 12 \\
\hline \multirow{2}{*}{ 1. DELT } & 10,4 & 11,8 & 10,5 & 10,3 & 10,8 & 11,1 & 11,6 \\
2. CLOR1 & 10,6 & 11,8 & 10,5 & 10,4 & 10,7 & 11,1 & 11,6 \\
3. CLOR2 & 10,5 & 11,7 & 10,4 & 10,4 & 10,7 & 11,0 & 11,7 \\
4. DELT + CLOR1 & 10,5 & 11,7 & 10,4 & 10,5 & 10,5 & 11,0 & 11,5 \\
5. DELT + CLOR2 & 10,4 & 11,3 & 10,0 & 10,3 & 10,3 & 10,7 & 11,0 \\
6. INSECTO & 10,0 & 11,2 & 10,2 & 10,4 & 10,4 & 10,7 & 11,0 \\
7. KEEPDRY & 10,0 & 11,0 & 10,1 & 10,5 & 10,3 & 10,7 & 11,1 \\
8. TESTEMUNHA & 9,9 & 10,9 & 10,2 & 10,6 & 10,8 & 11,3 & 12,2 \\
9. EXPURGO & 10,0 & 11,1 & 10,5 & 10,8 & 10,5 & 10,7 & 11,2 \\
\hline
\end{tabular}

Por outro lado, os valores de $\mathrm{F}$ para as demais determinações de laboratório e de campo, calculados para as sete épocas, estão contidos na Tabela 24. 
Tabela 24. Híbrido $Z$ 8392: valores de F, para as determinações de laboratório (sementes infestadas-SI, massa de 100 sementes-M100S, teste de germinação-TG, teste de frio-TF, envelhecimento acelerado-EA e condutividade elétrica-CE) e de campo (emergência de plântulas em campo-EC e velocidade de emergênciaVE), calculados para as sete épocas.

\begin{tabular}{|c|c|c|c|c|c|c|c|}
\hline \multirow{2}{*}{$\begin{array}{l}\text { DETERMI- } \\
\text { NAÇŐES }\end{array}$} & \multicolumn{7}{|c|}{ PERIODO DE ARMAZENAMENTO (MESES) } \\
\hline & 0 & 2 & 4 & 6 & 8 & 10 & 12 \\
\hline SI & 0,53 & 1,69 & $10,41^{\star \star}$ & $42,29^{\star \star}$ & $151,42^{* *}$ & $184,81^{\text {** }}$ & $134,57^{\star *}$ \\
\hline M100S & 3,38 & 0,96 & 1,85 & $5,26^{* *}$ & $36,62^{* *}$ & $103,55^{\text {** }}$ & $173,44^{\text {** }}$ \\
\hline TG & 1,46 & 0,87 & $5,22^{\star \star *}$ & $15,21^{\star \star}$ & $56,63^{* *}$ & $92,27^{\star \star}$ & $167,35^{\star \star}$ \\
\hline TF & 1,96 & 2,08 & 2,10 & $7,68^{* *}$ & $19,06^{* *}$ & $108,06^{* *}$ & $195,08^{* *}$ \\
\hline EA & 1,16 & 1,75 & $2,14^{\star \star *}$ & $5,18^{\star \star *}$ & $45,88^{* \star}$ & $55,50^{* \star}$ & $134,79^{* *}$ \\
\hline CE & $23,68^{\star \star}$ & $2,67^{\star}$ & $3,23^{\star \star \star}$ & $38,57^{* \star}$ & $427,37^{\star \star}$ & $38,13^{\star *}$ & $3533,7^{\star \star}$ \\
\hline EC & 0,53 & $2,21^{*}$ & 2,13 & 3,24 & $36,10^{* *}$ & $472,48^{\text {t* }}$ & $982,57^{\text {** }}$ \\
\hline VE & 1,83 & 1,43 & 3,59 & $8,58^{* \star}$ & $34,62^{* \star}$ & $74,47^{\star \star *}$ & $418,54^{\star \star *}$ \\
\hline
\end{tabular}

* Significativo ao nível de $5 \%$ de probabilidade

** Significativo ao nivel de $1 \%$ de probabilidade

Na Tabela 25 são apresentadas as médias relativas ao exame de sementes infestadas, massa de 100 sementes, teste de germinação, teste de frio, envelhecimento acelerado, condutividade elétrica, emergência de plântulas em campo, velocidade de emergência e seus respectivos coeficientes de variação, observadas na primeira época. Como se pode verificar, as sementes, dos nove tratamentos apresentaram porcentagens de infestação semelhantes. A maior infestação observada, em termos numéricos, foi de $1 \%$ nos tratamentos 7 (KEEPDRY), 8 (TESTEMUNHA) e 9 (EXPURGO); o referido valor é admitido nos padrões de Sementes Certificadas e de Sementes Fiscalizadas (Brasil, 1991). Com exceção do teste de condutividade elétrica, resultados semelhantes entre os tratamentos também foram obtidos em relação às demais determinações.

No teste de condutividade elétrica, os tratamentos 1 (DELT) e 2 (CLOR1) apresentaram qualidade fisiológica inferior a maioria dos demais tratamentos. 
Tabela 25. Hibrido Z 8392- Primeira época: médias relativas ao exame de sementes infestadas (SI), massa de 100 sementes (M100S), teste de germinação (TG), teste de frio $(\mathrm{TF})$, envelhecimento acelerado (EA), condutividade elétrica (CE), emergência de plântulas em campo (EC), velocidade de emergência (VE) e respectivos coeficientes de variação (C.V., \%).

\begin{tabular}{|c|c|c|c|c|c|c|c|c|}
\hline TRATAMENTOS & $S I^{1}$ & $\mathrm{M}_{100 \mathrm{~S}^{2}}$ & $\mathrm{TG}^{1}$ & $\mathrm{TF}^{1}$ & $E A^{1}$ & $\mathrm{CE}^{3}$ & $E C^{1}$ & $V E^{4}$ \\
\hline 1. DELT & $0,5 a^{*}$ & $32,7 a$ & $98 a$ & $97,0 a$ & $93,8 a$ & $11,4 a$ & $93,8 a$ & $14,98 a$ \\
\hline 2. CLOR1 & $0,5 a$ & $32,6 a$ & $96 a$ & $96,0 a$ & $94,5 a$ & $11,6 a$ & $94,5 a$ & $15,53 a$ \\
\hline 3. CLOR2 & $0,5 a$ & $32,4 a$ & $94 a$ & $95,3 a$ & $91,8 a$ & $10,1 \mathrm{c}$ & $93,8 a$ & $15,52 a$ \\
\hline 4. DELT + CLOR1 & $0,5 a$ & $32,3 a$ & $97 a$ & $93,3 a$ & $94,5 a$ & $9,7 \mathrm{~cd}$ & $95,0 a$ & $15,65 a$ \\
\hline 5. DELT + CLOR2 & $0,5 a$ & $32,5 a$ & $98 a$ & $95,0 a$ & $91,5 a$ & $10,3 b c$ & $93,0 a$ & $15,47 a$ \\
\hline 6. INSECTO & $0,5 a$ & $32,6 a$ & $97 a$ & $96,0 \mathrm{a}$ & $91,3 a$ & $9,4 d$ & $92,8 a$ & $15,35 a$ \\
\hline 7. KEEPDRY & $1,0 a$ & $32,8 a$ & $98 a$ & $93,5 a$ & $93,5 a$ & $10,4 b c$ & $94,5 a$ & $15,44 a$ \\
\hline 8. TESTEMUNHA & $1,0 a$ & $32,3 a$ & $97 a$ & $92,0 a$ & $95,5 a$ & $10,3 b c$ & $93,0 a$ & $15,21 a$ \\
\hline 9. EXPURGO & $1,0 a$ & $32,4 a$ & $97 a$ & $94,8 a$ & $93,3 a$ & $10,9 a b$ & $92,5 a$ & $14,97 a$ \\
\hline c.v. & 11,7 & 0,5 & 4,6 & 3,7 & 4,3 & 2,9 & 2,5 & 2,3 \\
\hline
\end{tabular}

Na coluna, médias seguidas por letras distintas diferem entre si pelo teste de Tukey ao nível de $5 \%$ de probabilidade

${ }^{1}$ Dados em porcentagem

${ }^{2}$ Dados em gramas

${ }^{3}$ Dados em $\mu \mathrm{mho} / \mathrm{cm}$

${ }^{4}$ Dados na forma de indice

Na Tabela 26 são apresentadas as médias relativas ao exame de sementes infestadas, massa de 100 sementes, teste de germinação, teste de frio, envelhecimento acelerado, condutividade elétrica, emergência de plântulas em campo, velocidade de emergência e seus respectivos coeficientes de variação, observadas na segunda época. Como se pode verificar no exame de sementes infestadas, massa de 100 sementes, testes de germinação, de frio, de envelhecimento acelerado e velocidade de emergência de plântulas em campo não foram constatadas diferenças significativas entre os nove tratamentos.

Por outro lado, no teste de condutividade elétrica as sementes do 
tratamento 5 (DELT + CLOR2) apresentaram menor qualidade fisiológica em relação às do tratamento 7 (KEEPDRY), não havendo diferenças significativas em relação aos demais tratamentos.

Tabela 26. Híbrido Z 8392- Segunda época: médias relativas ao exame de sementes infestadas (SI), massa de 100 sementes (M100S), teste de germinação (TG), teste de frio (TF), envelhecimento acelerado (EA), condutividade elétrica (CE), emergência de plântulas em campo (EC), velocidade de emergência (VE) e respectivos coeficientes de variação (C.V., \%).

\begin{tabular}{|c|c|c|c|c|c|c|c|c|}
\hline TRATAMENTOS & $S 1^{1}$ & $M 100 S^{2}$ & $T G^{1}$ & $\mathrm{TF}^{1}$ & $E A^{1}$ & $C E^{3}$ & $E C^{1}$ & $V E^{4}$ \\
\hline 1. DELT & $2,0 a^{*}$ & $33,1 a$ & $96 a$ & $94,5 a$ & $62,5 a$ & $10,7 a b$ & $96,0 a b$ & $13,93 a$ \\
\hline 2. CLOR1 & $2,3 a$ & $32,9 a$ & $97 a$ & $93,5 a$ & $65,3 a$ & $11,6 a b$ & $95,5 a b$ & $13,72 a$ \\
\hline 3. CLOR2 & $2,5 a$ & $33,0 a$ & $97 a$ & $94,8 a$ & $61,3 a$ & $11,0 a b$ & $93,5 b$ & $13,43 a$ \\
\hline 4. DELT + CLOR1 & $2,0 a$ & $33,0 a$ & $96 a$ & $92,3 a$ & $68,3 a$ & $11,2 a b$ & $97,5 a b$ & $13,83 a$ \\
\hline 5. DELT + CLOR2 & $2,0 a$ & $32,8 a$ & $97 a$ & $95,8 a$ & $62,5 a$ & $11,8 a$ & $96,5 a b$ & $13,71 a$ \\
\hline 6. INSECTO & $1,3 a$ & $33,0 a$ & $97 a$ & $95,5 a$ & $66,5 a$ & $10,8 a b$ & $97,0 a b$ & $13,91 a$ \\
\hline 7. KEEPDRY & $1,3 a$ & $33,1 a$ & $97 a$ & $96,3 a$ & $67,8 a$ & $10,3 b$ & $95,0 a b$ & $13,49 a$ \\
\hline 8. TESTEMUNHA & $3,5 a$ & $32,9 a$ & $97 a$ & $95,0 a$ & $60,5 a$ & $11,7 a b$ & $96,3 a b$ & $13,63 a$ \\
\hline 9. EXPURGO & $1,3 a$ & $33,0 a$ & $98 a$ & $96,0 a$ & $69,8 a$ & $11,4 a b$ & $98,0 a$ & $13,41 a$ \\
\hline C. V. & 13,5 & 0,3 & 3,0 & 2,9 & 5,8 & 5,4 & 2,5 & 3,1 \\
\hline
\end{tabular}

Na coluna, médias seguidas por letras distintas diferem entre si pelo teste de Tukey ao nível de 5\% de probabilidade

${ }^{1}$ Dados em porcentagem

2 Dados em gramas

${ }^{3}$ Dados em $\mu \mathrm{mho} / \mathrm{cm}$

${ }^{4}$ Dados na forma de índice

Para finalizar a análise da Tabela 26, no teste de emergência de plântulas em campo, as sementes do tratamento 9 (EXPURGO) apresentaram maior desempenho em relação ao observado nas sementes do tratamento 3 (CLOR2), não sendo constatadas diferenças estatísticas entre os demais tratamentos.

Na Tabela 27 são apresentadas as médias relativas ao exame de sementes 
infestadas, massa de 100 sementes, teste de germinação, teste de frio, envelhecimento acelerado, condutividade elétrica, emergência de plântulas em campo, velocidade de emergência e seus respectivos coeficientes de variação, observadas na terceira época. Como se pode verificar, as sementes do tratamento 8 (TESTEMUNHA) apresentaram porcentagem de infestação superior em relação aos demais tratamentos.

Tabela 27. Híbrido Z 8392- Terceira época: médias relativas ao exame de sementes infestadas (SI), massa de 100 sementes (M100S), teste de germinação (TG), teste de frio (TF), envelhecimento acelerado (EA), condutividade elétrica (CE), emergência de plântulas em campo (EC), velocidade de emergência (VE) e respectivos coeficientes de variação (C.V., \%).

\begin{tabular}{|c|c|c|c|c|c|c|c|c|}
\hline TRATAMENTOS & $S I^{1}$ & $M 100 S^{2}$ & $\mathrm{TG}^{1}$ & $\mathrm{TF}^{1}$ & $E A^{1}$ & $C E^{3}$ & $E C^{1}$ & $V^{4}$ \\
\hline 1. DELT & $1,5 b^{*}$ & $32,3 a$ & $97 a b$ & $72,0 a$ & $61,0 a b$ & $13,7 a b$ & $93,8 a$ & $15,34 a$ \\
\hline 2. CLOR1 & $2,0 b$ & $32,5 a$ & $96 b$ & $67,5 a$ & $65,8 a b$ & $13,0 a b$ & $94,5 a$ & $15,43 a$ \\
\hline 3. CLOR2 & $2,5 b$ & $32,5 a$ & $97 a b$ & $72,8 a$ & $66,3 a b$ & $13,7 a b$ & $96,0 a$ & $15,61 a$ \\
\hline 4. DELT + CLOR1 & $1,8 b$ & $32,4 a$ & $97 a b$ & $66,3 a$ & $62,8 a b$ & $13,1 a b$ & $93,5 a$ & $15,12 a$ \\
\hline 5. DELT + CLOR2 & $1,5 b$ & $32,2 a$ & $96 b$ & $70,3 a$ & $66,5 a b$ & $13,0 a b$ & $94,5 a$ & $15,39 a$ \\
\hline 6. INSECTO & $1,5 b$ & $32,6 a$ & $99 a$ & $72,0 a$ & $61,5 a b$ & $13,1 a b$ & $93,3 a$ & $15,08 a$ \\
\hline 7. KEEPDRY & $1,3 b$ & $32,4 a$ & $97 a b$ & $71,8 a$ & $63,3 a b$ & $12,0 b$ & $93,3 a$ & $15,49 a$ \\
\hline 8. TESTEMUNHA & $12,3 a$ & $32,3 a$ & $94 b$ & $67,3 a$ & $58,0 b$ & $15,2 a$ & $90,3 a$ & $14,50 a$ \\
\hline 9. EXPURGO & $1,3 b$ & $32,5 a$ & $99 a$ & $77,3 a$ & $74,5 a$ & $12,7 b$ & $95,3 a$ & $15,68 a$ \\
\hline c.v. & 35,6 & 0,4 & 3,2 & 5,2 & 7,5 & 7,3 & 2,4 & 2,5 \\
\hline
\end{tabular}

$\mathrm{Na}$ coluna, médias seguidas por letras distintas diferem entre si pelo teste de Tukey ao nivel de $5 \%$ de probabilidade

1 Dados em porcentagem

${ }^{2}$ Dados em gramas

${ }^{3}$ Dados em $\mu$ mho/cm

${ }^{4}$ Dados na forma de indice

Para os parâmetros massa de 100 sementes, teste de frio, emergência de plântulas em campo e índice de velocidade de emergência não foram constatadas diferenças significativas entre os tratamentos. 
No teste de germinação verificou-se para os tratamentos 2 (CLOR1), 5 (DELT + CLOR2) e 8 (TESTEMUNHA) menor porcentagem de germinação em relação aos obtidos para as sementes dos tratamentos 6 (INSECTO) e 9 (EXPURGO), não havendo diferenças significativas em relação aos demais tratamentos.

Por outro lado, no teste de envelhecimento acelerado, as sementes do tratamento 8 (TESTEMUNHA) apresentaram menor vigor em relação às sementes do tratamento 9 (EXPURGO).

No teste de condutividade elétrica, as sementes dos tratamentos 7 (KEEPDRY) e 9 (EXPURGO) apresentaram maior qualidade fisiológica em relação às sementes do tratamento 8 (TESTEMUNHA), não sendo constatadas diferenças significativas entre os demais tratamentos.

$\mathrm{Na}$ Tabela 28 são apresentadas as médias relativas ao exame de sementes infestadas, massa de 100 sementes, teste de germinação, teste de frio, envelhecimento acelerado, condutividade elétrica, emergência de plântulas em campo, velocidade de emergência e seus respectivos coeficientes de variação, observadas na quarta época. Como se pode verificar, as sementes do tratamento 8 (TESTEMUNHA) apresentaram maior porcentagem de infestação e menor massa de 100 sementes em relação aos demais tratamentos.

Nos testes de germinação, de frio, de envelhecimento acelerado e condutividade elétrica foi observada menor qualidade fisiológica das sementes do tratamento 8 (TESTEMUNHA) em relação aos demais tratamentos.

Finalizando a análise da Tabela 28, os resultados obtidos na emergência de plântulas em campo e índice de velocidade de emergência não apresentaram diferenças significativas entre os nove tratamentos.

$\mathrm{Na}$ Tabela 29 são apresentadas as médias relativas ao exame de sementes infestadas, massa de 100 sementes, teste de germinação, teste de frio, envelhecimento acelerado, condutividade elétrica, emergência de plântulas em campo, velocidade de emergência e seus respectivos coeficientes de variação, observadas na quinta época. Como se pode verificar, as sementes do tratamento 8 (TESTEMUNHA) apresentaram porcentagem de infestação superior e massa de 100 sementes inferior aos demais 
tratamentos, não sendo obtidas diferenças significativas em relação aos demais tratamentos.

Tabela 28. Híbrido $Z$ 8392- Quarta época: médias relativas ao exame de sementes infestadas (SI), massa de 100 sementes (M100S), teste de germinação (TG), teste de frio (TF), envelhecimento acelerado (EA), condutividade elétrica (CE), emergência de plântulas em campo (EC), velocidade de emergência (VE) e respectivos coeficientes de variação (C.V., \%).

\begin{tabular}{|c|c|c|c|c|c|c|c|c|}
\hline TRATAMENTOS & $S l^{1}$ & $\mathrm{M100S}^{2}$ & $\mathrm{TG}^{1}$ & $\mathrm{TF}^{1}$ & $E A^{1}$ & $\mathrm{CE}^{3}$ & $E C^{1}$ & $V^{4}$ \\
\hline 1. DELT & $3,5 b^{*}$ & $32,6 a$ & $97 a$ & $89,8 a$ & $63,5 a$ & $12,4 b$ & $88,3 a$ & $16,99 a$ \\
\hline 2. CLOR1 & $2,3 b$ & $32,6 a$ & $95 a$ & $87,5 a$ & $68,8 a$ & $10,7 b$ & $84,3 a$ & $16,56 a$ \\
\hline 3. CLOR2 & $1,8 b$ & $32,4 a$ & $97 a$ & $90,0 a$ & $67,8 a$ & $11,5 b$ & $87,0 a$ & $17,20 a$ \\
\hline 4. $\mathrm{DELT}+\mathrm{CLOR} 1$ & $2,0 b$ & $32,5 a$ & $96 a$ & $88,5 a$ & $65,3 a$ & $12,3 b$ & $87,3 a$ & $17,17 a$ \\
\hline 5. DELT + CLOR2 & $3,5 b$ & $32,5 a$ & $97 a$ & $90,5 a$ & $74,0 a$ & $11,5 b$ & $88,3 a$ & $17,74 a$ \\
\hline 6. INSECTO & $3,0 b$ & $32,6 a$ & $97 a$ & $86,5 a$ & $65,0 a$ & $11,2 b$ & $89,3 a$ & $18,63 a$ \\
\hline 7. KEEPDRY & $1,5 b$ & $32,5 a$ & $98 a$ & $88,3 a$ & $64,8 a$ & $11,4 b$ & $94,8 a$ & $20,30 a$ \\
\hline 8. TESTEMUNHA & $41,8 a$ & $31,5 b$ & $83 b$ & $68,3 b$ & $43,3 b$ & $22,3 a$ & $86,8 a$ & $17,38 \mathbf{a}$ \\
\hline 9. EXPURGO & $4,5 b$ & $32,4 a$ & $96 a$ & $87,8 a$ & $67,8 a$ & $11,3 b$ & $89,0 a$ & $17,59 a$ \\
\hline c. & 23,9 & 1,1 & $3,0^{-}$ & 5,3 & 8,3 & 9,2 & 3,7 & 15,9 \\
\hline
\end{tabular}

Nos testes de germinação, teste de frio, emergência de plântulas em campo e índice de velocidade de emergência, verificou-se para o tratamento 8 (TESTEMUNHA) valores inferiores aos constatados para os demais tratamentos, não sendo observadas diferenças significativas entre os demais tratamentos.

No teste de envelhecimento acelerado, verificou-se maior vigor para as sementes do tratamento 7 (KEEPDRY) em relação à maioria dos demais tratamentos. As 
sementes do tratamento 8 (TESTEMUNHA) apresentaram vigor inferior ao apresentado pelas sementes dos demais tratamentos.

Tabela 29. Hibrido $Z$ 8392- Quinta época: médias relativas ao exame de sementes infestadas (SI), massa de 100 sementes (M100S), teste de germinação (TG), teste de frio (TF), envelhecimento acelerado (EA), condutividade elétrica (CE), emergência de plântulas em campo (EC), velocidade de emergência (VE) e respectivos coeficientes de variação (C.V., \%).

\begin{tabular}{|c|c|c|c|c|c|c|c|c|}
\hline TRATAMENTOS & $S I^{1}$ & $M 100 S^{2}$ & $\mathrm{TG}^{1}$ & $\mathrm{TF}^{1}$ & $E A^{1}$ & $C E^{3}$ & $E C^{1}$ & $V E^{4}$ \\
\hline 1. DELT & $3,5 b^{*}$ & $32,7 a$ & $97 a$ & $67,5 a$ & $48,5 b$ & $15,5 \mathrm{bcd}$ & $93,3 a$ & $17,11 a$ \\
\hline 2. CLOR1 & $2,3 b$ & $32,5 a$ & $96 a$ & $63,5 a$ & $49,5 b$ & $15,2 \mathrm{bcd}$ & $94,3 a$ & $17,62 a$ \\
\hline 3. CLOR2 & $2,8 b$ & $32,6 a$ & $97 a$ & $61,5 a$ & $51,8 a b$ & $16,6 b$ & $92,0 a$ & $17,20 a$ \\
\hline 4. DELT + CLOR1 & $2,5 b$ & $32,5 a$ & $96 a$ & $70,0 a$ & $49,8 b$ & $16,4 b c$ & $93,0 a$ & $16,95 a$ \\
\hline 5. DELT + CLOR2 & $2,8 b$ & $32,5 a$ & $96 a$ & $69,5 a$ & $51,0 \mathrm{~b}$ & $15,3 \mathrm{bcd}$ & $93,3 a$ & $16,77 a$ \\
\hline 6. INSECTO & $2,5 b$ & $32,9 a$ & $96 a$ & $70,0 a$ & $59,0 a b$ & $13,9 \mathrm{~cd}$ & $94,5 a$ & $18,13 a$ \\
\hline 7. KEEPDRY & $2,5 b$ & $32,7 a$ & $97 a$ & $73,0 a$ & $63,8 a$ & $13,8 d$ & $94,3 a$ & $19,63 a$ \\
\hline 8. TESTEMUNHA & $75,3 a$ & $30,3 b$ & $60 b$ & $18,5 b$ & $8,3 c$ & $47,4 a$ & $53,8 b$ & $9,91 b$ \\
\hline 9. EXPURGO & $4,0 b$ & $32,8 a$ & $94 a$ & $63,0 a$ & $55,5 a b$ & $15,1 \mathrm{bcd}$ & $95,0 a$ & $18,64 a$ \\
\hline c.v. & 25,7 & 2,5 & 3,2 & 9,1 & 7,1 & 5,6 & 12,6 & 15,5 \\
\hline
\end{tabular}

\footnotetext{
Na coluna, médias seguidas por letras distintas diferem entre si pelo teste de Tukey ao nível de $5 \%$ de probabilidade

${ }^{1}$ Dados em porcentagem

${ }^{2}$ Dados em gramas

${ }^{3}$ Dados em $\mu \mathrm{mho} / \mathrm{cm}$

${ }^{4}$ Dados na forma de índice
}

Por outro lado, no teste de condutividade elétrica as sementes dos tratamentos 6 (INSECTO) e 7 (KEEPDRY) apresentaram maior qualidade fisiológica em relação as sementes dos tratamentos 3 (CLOR2) e 8 (TESTEMUNHA). As sementes do tratamento 8 (TESTEMUNHA) mostraram menor qualidade em relação às dos demais tratamentos.

Na Tabela 30 são apresentadas as médias relativas ao exame de sementes infestadas, massa de 100 sementes, teste de germinação, teste de frio, envelhecimento 
acelerado, condutividade elétrica, emergência de plântulas em campo, velocidade de emergência e seus respectivos coeficientes de variação, observadas na sexta época. Como se pode verificar, as sementes do tratamento 8 (TESTEMUNHA) apresentaram porcentagem de infestação superior em relação às apresentadas pelas sementes dos demais tratamentos. As sementes do tratamento 8 , também apresentaram menor massa de 100 sementes em relação aos demais tratamentos.

Tabela 30. Híbrido Z 8392- Sexta época: médias relativas ao exame de sementes infestadas (SI), massa de 100 sementes (M100S), teste de germinação (TG), teste de frio $(\mathrm{TF})$, envelhecimento acelerado (EA), condutividade elétrica (CE), emergência de plântulas em campo (EC), velocidade de emergência (VE) e respectivos coeficientes de variação (C.V., \%).

TRATAMENTOS $\quad \mathrm{Sl}^{1} \quad \mathrm{M}_{100 \mathrm{~S}^{2}} \quad \mathrm{TG}^{1} \quad \mathrm{TF}^{1} \quad \mathrm{EA}^{1} \quad \mathrm{CE}^{3} \quad \mathrm{EC}^{1} \quad \mathrm{VE}^{4}$

\begin{tabular}{lcccccccc}
\hline 1. DELT & $5,8 b^{*}$ & $32,6 a$ & $95 a$ & $46,3 a$ & $43,0 a$ & $15,9 b$ & $89,3 a$ & $15,09 a$ \\
2. CLOR1 & $1,8 b$ & $32,6 a$ & $96 a$ & $48,5 a$ & $42,5 a$ & $15,2 b$ & $92,0 a$ & $15,18 a$ \\
3. CLOR2 & $2,8 b$ & $32,7 a$ & $96 a$ & $45,0 a$ & $41,5 a$ & $16,3 b$ & $91,8 a$ & $15,88 a$ \\
4. DELT + CLOR1 & $1,0 b$ & $32,6 a$ & $96 a$ & $41,5 a$ & $49,5 a$ & $15,3 b$ & $91,3 a$ & $15,52 a$ \\
5. DELT + CLOR2 & $1,8 b$ & $32,6 a$ & $97 a$ & $47,5 a$ & $50,8 a$ & $14,7 b$ & $92,8 a$ & $16,53 a$ \\
6. INSECTO & $1,5 b$ & $32,8 a$ & $98 a$ & $44,5 a$ & $50,5 a$ & $13,8 b$ & $92,0 a$ & $16,52 a$ \\
7. KEEPDRY & $1,8 b$ & $32,4 a$ & $98 a$ & $48,8 a$ & $56,3 a$ & $13,7 b$ & $93,5 a$ & $17,33 a$ \\
8. TESTEMUNHA & $99,8 a$ & $25,7 b$ & $12 b$ & $1,0 b$ & $0,8 b$ & $78,4 a$ & $2,3 b$ & $0,44 b$ \\
9. EXPURGO & $3,8 b$ & $32,6 a$ & $94 a$ & $48,3 a$ & $54,8 a$ & $14,7 b$ & $91,5 a$ & $16,07 a$ \\
C..V. & 17,6 & 7,2 & 5,7 & 6,5 & 11,4 & 17,8 & 21,2 & 24,7 \\
\hline
\end{tabular}

"Na coluna, médias seguidas por letras distintas diferem entre si pelo teste de Tukey ao nível de $5 \%$ de probabilidade

${ }^{1}$ Dados em porcentagem

${ }^{2}$ Dados em gramas

${ }^{3}$ Dados em $\mu \mathrm{mho} / \mathrm{cm}$

${ }^{4}$ Dados na forma de índice

Nos testes de germinação, de frio, de envelhecimento acelerado, de condutividade elétrica, de emergência de plântulas em campo e índice de velocidade de 
emergência foi observado para as sementes do tratamento 8 (TESTEMUNHA) menor qualidade fisiológica em relação aos demais tratamentos.

$\mathrm{Na}$ Tabela 31 são apresentadas as médias relativas ao exame de sementes infestadas, massa de 100 sementes, teste de germinação, teste de frio, envelhecimento acelerado, condutividade elétrica, emergência de plântulas em campo, velocidade de emergência e seus respectivos coeficientes de variação, observadas na sétima época. Como se pode verificar, as sementes do tratamento 8 (TESTEMUNHA) apresentaram porcentagem de infestação superior e massa de 100 sementes inferior em relação aos demais tratamentos.

Tabela 31. Híbrido Z 8392- Sétima época: médias relativas ao exame de sementes infestadas (SI), massa de 100 sementes (M100S), teste de germinação (TG), teste de frio (TF), envelhecimento acelerado (EA), condutividade elétrica (CE), emergência de plântulas em campo (EC), velocidade de emergência (VE) e respectivos coeficientes de variação (C.V., \%).

TRATAMENTOS. $\quad \mathrm{SI}^{1} \quad \mathrm{M}_{100 \mathrm{~S}^{2}} \mathrm{TG}^{1} \quad \mathrm{TF}^{1} \quad \mathrm{EA}^{1} \quad \mathrm{CE}^{3} \quad \mathrm{EC}^{1} \quad \mathrm{VE}^{4}$

\begin{tabular}{|c|c|c|c|c|c|c|c|c|}
\hline 1. DELT & $5,5 b^{*}$ & $32,9 a$ & $93 a$ & $18,5 a$ & $37,8 a$ & $17,7 b$ & $93,3 a$ & $16,15 a$ \\
\hline 2. CLOR1 & $2,3 b$ & $32,8 a$ & $93 a$ & $18,0 a$ & $37,3 a$ & $16,5 b$ & $94,8 a$ & $17,19 a$ \\
\hline 3. CLOR2 & $1,8 b$ & $33,0 a$ & $92 a$ & $17,5 a$ & $37,8 a$ & $16,9 b$ & $95,3 a$ & $18,07 a$ \\
\hline 4. DELT + CLOR1 & $1,8 b$ & $32,6 a$ & $93 a$ & $18,3 a$ & $36,5 a$ & $16,7 b$ & $91,0 a$ & $16,94 a$ \\
\hline 5. DELT + CLOR2 & $1,8 b$ & $32,8 a$ & $94 a$ & $19,3 \mathbf{a}$ & $43,5 a$ & $16,9 b$ & $92,8 a$ & $18,06 a$ \\
\hline 6. INSECTO & $1,5 b$ & $32,9 a$ & $94 a$ & $20,8 a$ & $43,5 a$ & $16,7 b$ & $95,8 a$ & $19,13 a$ \\
\hline 7. KEEPDRY & $2,3 b$ & $32,9 a$ & $96 a$ & $20,0 a$ & $45,8 a$ & $16,3 b$ & $95,8 a$ & $18,99 a$ \\
\hline 8. TESTEMUNHA & $99,5 a$ & $21,4 b$ & $0,0 b$ & $0,0 b$ & $0,0 b$ & $106,3 a$ & $1,3 b$ & $0,19 b$ \\
\hline 9. EXPURGO & $2,8 b$ & $32,6 a$ & $94 a$ & $20,5 a$ & $45,0 a$ & $15,4 b$ & $95,8 a$ & $18,28 a$ \\
\hline C. V. & 20,6 & 12,1 & 5,7 & 5,4 & 6,5 & 3,8 & 24,6 & 27,6 \\
\hline
\end{tabular}

Na coluna, médias seguidas por letras distintas diferem entre si pelo teste de Tukey ao nível de 5\% de probabilidade

${ }^{1}$ Dados em porcentagem

2 Dados em gramas

${ }^{3}$ Dados em $\mu \mathrm{mho} / \mathrm{cm}$

${ }^{4}$ Dados na forma de índice 
Nos testes de germinação, de frio, de envelhecimento acelerado, de condutividade elétrica, de emergência de plântulas em campo e índice de velocidade de emergência foi observado para as sementes do tratamento 8 (TESTEMUNHA) menor qualidade fisiológica em relação aos demais tratamentos.

\subsection{Persistência dos produtos aplicados nas sementes}

Os insetos utilizados na infestação artificial e os encontrados nas sementes do tratamento 8 (TESTEMUNHA) foram identificados, por meio da análise de genitálias de insetos adultos, conforme Pacheco \& Paula (1995), como sendo da espécie Sitophilus zeamais Motsch. Esta espécie de inseto é hábil em infestar sementes de milho não apenas no armazém mas, também, no campo, quando são trazidos para o armazém no interior dos grãos (Richter et al., 1998).

Na Tabela 32 são apresentados os dados médios em porcentagem, de controle de Sitophilus zeamais Motsch. proporcionado pelos produtos, 12 meses após a aplicação, em sementes de milho dos híbridos AG 303, BR 205 e Z 8392, infestadas

artificialmente por insetos. Como se pode observar, todos os produtos aplicados nas sementes do híbrido AG 303 foram eficazes no controle da espécie de inseto utilizada, resultando em controle igual ou maior que $99 \%$.

Por outro lado, para os híbridos BR 205 e Z 8392, observou-se menor eficiência do tratamento 1 (DELT) em relação aos demais tratamentos. 
Tabela 32. Dados médios, em porcentagem, de controle de Sitophilus zeamais Motsch. proporcionado pelos produtos, 12 meses após a aplicação, em sementes de milho dos híbridos (AG 303, BR 205 e Z 8392) e respectivos coeficientes de variação (C.V., \%).

\begin{tabular}{|c|c|c|c|}
\hline \multirow[b]{2}{*}{ TRATAMENTOS } & AG 303 & BR 205 & $\overline{Z 8392}$ \\
\hline & \multicolumn{3}{|c|}{ Mortalidade (\%) } \\
\hline 1. DELT & $99,7 \mathrm{a}^{\star}$ & 94,2 b & 89,0 b \\
\hline 2. CLOR1 & $100,0 a$ & 100,0 a & $100,0 a$ \\
\hline 3. CLOR2 & $100,0 a$ & $100,0 a$ & 100,0 a \\
\hline 4. DELT + CLOR1 & $100,0 a$ & $100,0 a$ & 100,0 a \\
\hline 5. DELT + CLOR2 & $100,0 a$ & $100,0 a$ & 100,0 a \\
\hline 6. INSECTO & 99,7 a & 99,0 a & $100,0 a$ \\
\hline 7. KEEPDRY & 99,0 a & 99,7 a & 100,0 \\
\hline 9. TESTEMUNHA (EXPURGO) & $0,0 \mathrm{~b}$ & $0,0 \mathrm{c}$ & $0,0 \mathrm{c}$ \\
\hline c.v. & 4,8 & 4,8 & 6,4 \\
\hline
\end{tabular}

Na coluna, médias seguidas por letras distintas diferem entre si pelo teste de Tukey ao nível de $5 \%$ de probabilidade 


\section{DISCUSSÃO}

\subsection{Qualidade fisica}

As condições sob as quais as sementes foram armazenadas revelaram variações de temperatura e UR normais para o local e região (Figura 2). Observou-se que nos primeiros quatro meses as condições de armazenamento (Figura 1) foram apropriadas para um armazenamento seguro, o que se refletiu nos resultados de qualidade fisiológica e de sementes infestadas por insetos. Essas condições determinaram, também, os teores de água das sementes durante o período de armazenamento, para os três híbridos (Tabelas 5, 14 e 23). Os teores de água constatados nas sementes podem ser considerados adequados para armazenamento em ambiente não controlado. Além disso, são considerados baixos para o desenvolvimento dos insetos, o que justifica a lenta proliferação da população nas sementes, verificada nos primeiros quatro meses de armazenamento, como pode ser observado no tratamento 8 (TESTEMUNHA), nas três primeiras épocas de avaliação, para os três híbridos. A multiplicação dos insetos se torna lenta quando as condições para o seu desenvolvimento não são apropriadas; o teor de água observado nas sementes ao longo do período esteve compreendida entre 9,9\% e $12,1 \%$, valores esses que dificultam a multiplicação rápida dos insetos, de acordo com Faroni (1988) e Sedlacek et al. (1991).

A proliferação de insetos observada na presente pesquisa foi lenta em relação aos dados obtidos por Takahashi (1985), que constatou infestação de 41,7\% e 98,2\%, respectivamente aos 90 e 180 dias de armazenamento, para sementes de milho. Os valores de infestação, constatados no presente trabalho, para o tratamento 8 
(TESTEMUNHA), aos seis meses, foram de $9 \%, 11,8 \%$ e 41,8\%, respectivamente para os hibridos AG 303, BR 205 e Z 8392 (Tabelas 10, 19 e 28).

O aumento da infestação das sementes do tratamento 8 (TESTEMUNHA) verificado para o híbrido AG 303, a partir dos dois meses de armazenamento, mostraram a necessidade de aplicação de produtos visando o controle dos insetos, concordando com resultado obtido por Bitran et al. (1980).

As sementes do tratamento 8 (TESTEMUNHA), já aos dois meses de armazenamento para o híbrido AG 303 e aos quatro meses para os outros dois híbridos, não poderiam ser comercializadas por apresentarem percentuais de sementes infestadas superiores ao estabelecido nos padrões de sementes (Brasil, 1991). Após seis meses de armazenamento foi observado crescimento acentuado da porcentagem de sementes infestadas no tratamento 8 (TESTEMUNHA), para os três híbridos.

Com relação aos produtos aplicados nas sementes foi verificado que, com exceção do deltametrina, os demais foram altamente eficientes no controle e na proteção (poder residual) contra os insetos-praga durante os 12 meses de armazenamento. $O$ inseticida deltametrina proporcionou menor controle em relação aos demais a partir de 10 meses de armazenamento, quando as sementes tratadas com o referido produto não poderiam ser comercializadas, por não atenderem aos padrões de sementes (Brasil, 1991).

A ação específica dos produtos INSECTO e KEEPDRY (terras diatomáceas) resultou na preservação eficiente das sementes de milho, não permitindo infestações superiores a 3\% durante os 12 meses de armazenamento. Esses resultados concordam com os obtidos por Pinto Junior et al. (1996), que conseguiram controle eficiente de gorgulhos em sementes de milho tratadas com terra diatomácea.

Com relação ao massa de 100 sementes, não foi constatada durante os 12 meses de armazenamento perda de massa das sementes tratadas; por outro lado, as sementes do tratamento 8 (TESTEMUNHA) tiveram perdas crescentes de massa de 100 sementes, corroborando os resultados obtidos por Smiderle et al. (1995), que verificaram reduções deste atributo, durante o armazenamento, no material sem tratamento inseticida. 
As sementes tratadas com terra diatomácea apresentaram teores de água $\mathrm{e}$ massa de 100 sementes semelhantes aos observados para as sementes dos demais tratamentos, diferindo dos resultados observados por Pinto Junior et al. (1996), que constataram aumento da massa de 100 sementes e no teor de água das sementes tratadas com terra diatomácea, durante o armazenamento.

\subsection{Qualidade fisiológica}

Os produtos aplicados contribuíram sobremaneira para preservar a germinação das sementes de milho dos três híbridos, as quais, após 12 meses de armazenamento apresentaram percentuais de germinação dentro dos padrões de sementes (Brasil, 1991), exigidos para comercialização. Observou-se também que, a queda do poder germinativo das sementes ao longo do período de armazenamento foi normal, ressaltando o efeito dos produtos aplicados sobre a preservação do poder germinativo em relação à TESTEMUNHA que, a partir de oito meses, passou a decrescer drasticamente. Esta redução do poder germinativo está diretamente relacionada com a porcentagem de sementes infestadas que, também, a partir do oitavo mês de armazenamento aumentou consideravelmente e atingiu ao final do trabalho índices superiores a $97,5 \%$ de infestação, dependendo do híbrido.

Conforme relatos de Howe (1973), a germinação de sementes de milho sem tratamento inseticida é prejudicada pela presença crescente de insetos durante o armazenamento das sementes e, assim sendo, a proteção oferecida pelos produtos inseticidas, certamente contribuiu para preservar a integridade do embrião e do endosperma das sementes de milho, embora, algumas vezes, a destruição parcial do endosperma não cause redução de germinação.

Durante o armazenamento, foi observado que as sementes não tratadas (TESTEMUNHA) apresentaram vigor inferior ao das sementes tratadas. Desta forma, grande vantagem da aplicação dos produtos foi constatada para o híbrido Z 8392, já aos seis meses de armazenamento (Tabela 28) e aos oito meses de armazenamento para os 
híbridos AG 303 e BR 205 (Tabelas 11 e 20). Aos oito meses, as sementes tratadas com todos os produtos apresentaram qualidade fisiológica visivelmente superior às do tratamento TESTEMUNHA.

Não foi observado efeito negativo dos produtos sobre o vigor das sementes, mesmo para os tratamentos em que foi aplicado chlorpirifos usando o dobro da dose comercial, diferindo do observado por Silva et al. (1996) que constataram redução na porcentagem de emergência em campo para sementes de milho tratadas com o referido produto.

A aplicação de deltametrina isolada ou associada com chlorpirifos nas sementes de milho não provocou efeitos negativos sobre a qualidade fisiológica das sementes, diferindo do observado por Godoy et al. (1990), que constataram menores porcentagem e velocidade de emergência quando as sementes foram tratadas com inseticidas sistêmicos e por La Hue (1976) que verificou declínio na germinação das sementes.

Da mesma forma, não houve efeito negativo da fumigação, com fosfina, na qualidade fisiológica das sementes concordando com os relatos de Andrade \& Nascimento (1984), Komatsu (1985), Puzzi (1986) e Gallo et al. (1988) que verificaram que a aplicação de fosfina não altera a capacidade germinativa das sementes, mesmo quando em doses elevadas (Coelho et al., 1980). Foi, também, observado comportamento semelhante para os três híbridos, diferindo do constatado por Yadav \& Mookherjee (1975) que obtiveram resposta diferenciada para cultivares.

Por outro lado, a aplicação das terras diatomáceas (INSECTO e KEEPDRY), também não provocou qualquer efeito fitotóxico para as sementes durante o armazenamento, concordando com os resultados obtidos por Rupp et al. (1996), Lazzari et al. (1996), Dupchak et al. (1996) e Gionédis et al. (1996), os quais observaram efeitos benéficos do tratamento de sementes de milho no controle de insetos e no poder germinativo das sementes armazenadas por períodos de até 120 dias.

Os resultados obtidos no teste de condutividade elétrica demonstraram que as sementes do tratamento 8 (TESTEMUNHA), já aos quatro meses, apresentavam 
maior quantidade de solutos lixiviados e, aos seis meses, para os três híbridos, foram constatadas diferenças significativas entre a TESTEMUNHA e os demais tratamentos.

Já na emergência e na velocidade de emergência de plântulas em campo, as condições ambientais ocorridas (Figura 2) no período foram variadas, mas não adversas para a condução desse teste e confirmou os resultados obtidos para as demais avaliações realizadas para as sementes dos três híbridos. As sementes da TESTEMUNHA apresentaram menores porcentagem de emergência e velocidade de emergência de plântulas em relação aos demais tratamentos, principalmente a partir dos 10 meses de armazenamento.

Os efeitos prejudiciais resultantes da presença de insetos obtidos nesse trabalho corroboram as afirmações relatadas por Carvalho \& Nakagawa (1988), de que os insetos causam diversos danos às sementes, com maior ou menor severidade dependendo das condições de armazenamento. Conforme Faroni (1988), Sedlacek et al. (1991) e Gilbert \& Raworth (1996), a redução do vigor ocorre devido aos insetos causarem danos no tegumento, aumentando a atividade respiratória e provocando deterioração das sementes.

Os produtos inseticidas aplicados nas sementes de milho, nas condições de condução do presente trabalho, foram importantes para a preservação do vigor, por evitar a ação negativa dos insetos durante o armazenamento, conforme destacado por Carvalho \& Nakagawa (1988). A redução de vigor apresentada pelas sementes do tratamento 8 (TESTEMUNHA) em relação as sementes tratadas foi constatada pelos diversos testes realizados. Redução de vigor de sementes durante o armazenamento provocado pela presença de insetos, também, foi observado por Smiderle et al. (1997).

\subsection{Persistência dos produtos aplicados nas sementes}

O controle dos insetos com os produtos utilizados no presente trabalho foi satisfatório e semelhante aos obtidos em trabalhos realizados por Rupp et al. (1996), Lazzari et al. (1996), Dupchak et al. (1996) e Gionédis et al. (1996), ao utilizarem terra 
diatomácea, bem como, aos trabalhos realizados com vários inseticidas quimicos isolados ou em misturas, como os de Takahashi (1985), Komatsu (1985), Giga \& Zvoutete (1990), Arthur et al. (1990), Bitran et al. (1991), Deglish et al. (1995) e Arthur (1992, 1994, 1995a, 1995b, 1995c).

O produto deltametrina, na dose aplicada, proporcionou menor proteção às sementes. Esta baixa dose (Tabela 1), é indicada para uma proteção por até seis meses. Desta forma, os resultados verificados são concordantes com os obtidos nos trabalhos de Pinto (1991), Arthur (1994) e Von Pinho et al. (1995). Para os demais produtos aplicados nas sementes de milho, inclusive as terras diatomáceas, foi obtida eficiência superior a $99 \%$ no controle da população de insetos. Estes resultados corroboram os observados por Rupp et al. (1996), Lazzari et al. (1996), Dupchak et al. (1996) e Gionédis et al. (1996).

A infestação artificial das sementes com Sitophilus zeamais adultos mostrou que os produtos aplicados nas sementes podem manter proteção contra essa espécie durante o armazenamento por 12 meses.

O produto chlorpirifos (Clorsan 500CE), nas duas doses empregadas, isolado ou associado com deltametrina (K-Obiol 25CE) e fosfina (Gastoxin), preservam as sementes por 12 meses, de forma semelhante à deltametrina isolada, na dose utilizada, conforme observado pelos resultados obtidos no presente trabalho.

As terras diatomáceas não proporcionaram $100 \%$ de mortalidade aos 15 dias após o contato dos insetos com as sementes tratadas. No entanto, não foi obtida população originada por estes insetos, que não estavam mortos na ocasião da avaliação. Este fato, sugere que os produtos, mesmo não tendo eficiência de $100 \%$ de mortalidade, impediram que os insetos tivessem a capacidade de provocar danos ou mesmo postura nas sementes. Desta forma, as perspectivas de uso da terra diatomácea no tratamento das sementes de milho são promissoras, tendo em vista que não foram constatados prejuizos, provocados pelos produtos aplicados nas sementes. Constatou-se, assim, que a aplicação destes dois produtos naturais apresenta vantagem sobre a aplicação dos produtos químicos por não apresentarem riscos de poluição ambiental e possibilitarem o reaproveitamento das sementes para consumo humano e animal. 


\section{CONCLUSÕES}

Os resultados obtidos, no presente trabalho, permitiram concluir que:

a) os inseticidas químicos deltametrina e chlorpirifos, isolados ou associados, fosfina e as terras diatomáceas promovem, de maneira similar, o controle de insetos-praga que ocorrem no armazenamento e não causam toxicidade às sementes de milho;

b) a qualidade fisiológica das sementes de milho é preservada pelos tratamentos com produtos químicos e terra diatomácea. 


\section{REFERÊNCIAS BIBLIOGRÁFICAS}

ALDRYHIM, Y.N. Efficacy of the amorphous silica dusts, Dryacide ${ }^{\circledR}$, against Tribolium confusum Duv. and Sitophilus granarius (L.). Journal of Stored Products Research, v.26, n.3, p.207-210, 1990.

ALDRYHIM, Y.N. Combination of classes of wheat and environmental factors affecting the efficacy of amorphous silica dusts, Dryacide ${ }^{\circledR}$, against Rhyzopertha dominica (F.). Journal of Stored Products Research, v.29, n.3, p.271-275, 1993.

ANDERSON, J.D.; BAKER, J.E. Deterioration of seeds during aging. Phytopathology, v.73, n.2, p.321-325, 1983.

ANDRADE, R.V.; NASCIMENTO, T.F. Efeito do expurgo com fosfina (Gastoxin) sobre a qualidade fisiológica de sementes de milho e sorgo. Revista Brasileira de Sementes, v.6, n.2, p.9-16, 1984.

ARTHUR, F.H. Efficacy of chlorpyrifos-methyl for control of maize weevils (Coleoptera: Curculionidae) and red flour beetles (Tenebrionidae) in mixtures of treated and untreated corn. Journal of Economic Entomology, v.85, n.2, p.554$560,1992$.

ARTHUR, F.H. Efficacy of unsynergised deltamethrin and deltamethrim + chlorpyrifosmethyl combinations as protectantes of stored wheat and stored corn (maize). Journal of Stored Products Research, v.30, n.1, p.87-94, 1994. 
ARTHUR, F.H. Aeration alone versus chlorpyrifos-methyl treatment followed by aeration for wheat stored in Georgia: simulated field test. Journal of Economic Entomology, v.88, n.6, p.1764-1770, 1995a.

ARTHUR, F.H. Degradation and efficacy of deltamethrin + chlorpyrifos-methyl and cyfluthrin + chlorpyrifos-methyl as protectants of wheat stored in Southeast Georgia. Journal of Entomological Science, v.30, n.3, p.397-405, 1995 b.

ARTHUR, F.H. Efficacy of three insecticides to control insect pests of stored seed corn. Journal of Agricultural Entomology, v.12, n.1, p.45-53, 1995c.

ARTHUR, F.H.; THRONE, J.E.; SIMONAITIS, R.A. et al. Evaluated of chlorpyrifosmethyl and chlorpyrifos-methyl plus metoprene as protectants of stored corn: small bin tests. Journal of Economic Entomology, v.83, n.3, p.1114-1121, 1990.

ASSOCIATION OF OFFICIAL SEED ANALISTS. Seed vigour testing handbook. Lansing, 1983. 88p. (AOSA. Contribution, 32)

BANKS, H.J.; FIELDS, P.G. Physical methods for insect control in stored-grain ecosystems. In: JAYAS, D.S.; WHITE, N.D.G.; MUIR, W.E. (Ed.) Stored-grain ecosystems. New York: Marcel Dekker, 1994. p.353-409.

BANZATTO, D.A; KRONKA, S.N. Experimentação agrícola. Jaboticabal: FUNEP, 1994. 247p.

BARNEY, J.; SEDLACEK, J.D.; SIDDIQUI, M. et al. Quality of stored corn (maize) as influenced by Sitophilus zeamais Motsch. and several management practices. Journal of Stored Products Research, v.27, n.4, p.225-237, 1991.

BARNEY, R.J.; PRICE, B.D.; SEDLACEK, J.D. et al. Fungal species composition and abundance on stored corn as influenced by several management pratices and Maize Weevil (Coleoptera: Curculionidae). Crop Protection, v.14, n.2, p.159-164, 1995. 
BARROS, A.S.R. Maturação e colheita de sementes. In: SEMANA DE ATUALIZAÇÃO EM PRODUÇÃO DE SEMENTES, 1., Piracicaba 1986. Trabalhos apresentados. Campinas: Fundação Cargill, 1986. p.107-134.

BETI, J.A.; PHILLIPS, T.W.; SMALLEY, E.B. Effects of Maize Weevils (Coleoptera: Curculionidae) on production of aflatoxin B1 by Aspergillus flavus in stored corn. Journal of Economic Entomology, v.88, n.6, p.1776-1782, 1995.

BITRAN, E.A. Controle químico dos grãos armazenados. In: SEMINÁRIOS SOBRE CONTROLE DE INSETOS, Campinas, 1989. Campinas: Fundação Cargill, 1989. p.1-15.

BITRAN, E.A.; MELLO, E.J.R. Prejuízos causados pelo gorgulho Sitophilus zeamais Motsch. em milho armazenado. In: REUNIÃO BRASILEIRA DE MILHO, 9., Recife, 1972. Anais. Recife: UFP, 1972. p.102-105.

BITRAN, E.A.; CAMPOS, T.B.; OLIVEIRA, A. Avaliação da persistência residual de inseticidas na proteção de milho e café durante o armazenamento. Biológico, v.46, n.3/4, p. 45-57, 1980.

BITRAN, E.A.; CAMPOS, T.B.; SUPLICY FILHO, N. et al. Evaluation of the residual action of some insecticides on the protection of maize, wheat and rice graisn against stored products pests. Arquivos do Instituto Biológico, v.58, n.1/2, p.43-50, 1991.

BRACCINI, A.L.; PICANÇO, M. Manejo integrado de pragas do feijoeiro no armazenamento. Revista Brasileira de Armazenamento, v.20, n.1/2, p.37-43, 1995. 
BRAGA, G.C.; GUEDES, R.N.C.; SILVA, F.A.P. et al. Avaliação da eficiência de inseticidas isolados e em misturas, no controle de Sitophilus zeamais Motsch. em milho armazenado. Revista Ceres, v.38, p.522-528, 1992.

BRASIL. Leis, Decretos, etc. Portaria do Diretor do Departamento de Sementes, Mudas e Matrizes de 13 de dez. 1991. Diário Oficial do Estado de São Paulo, 18 dez. 1991. Seção 1, p.17.

BRASIL. Ministério da Agricultura, do Abastecimento e da Reforma Agrária. Departamento Nacional de Produção Vegetal. Divisão de Sementes e Mudas. Regras para análise de sementes. Brasilia, 1992. 365p.

BRIDGEMAN, B.W. Structural treatment with amorphus silica slury: na integral component of GRAINCO's IPM strategy. In: INTERNATIONAL CONFERENCE ON STORED-PRODUCT PROTECTION, 6., Canberra, 1994, Proceedings. London: CABI, 1994. p.628-630.

CALDWELL, R.W.; TUITE, J.; CARTON, W.W. Pathogenicity of Penicillium to corn ears. Phytopathology, v.71 p.175-180, 1981.

CARVALHO, R.P.L. Pragas do milho. In: PATERNIANI, E. (Coord.) Melhoramento e produção do milho no Brasil. Campinas: Fundação Cargill, 1978. p.505-561.

CARVALHO, N.M.; NAKAGAWA, J. Sementes: ciência, tecnologia e produção. 3.ed. Campinas: Fundação Cargill, 1988. 429p.

COELHO, R.C.; LIBERAL, O.H.T.; ARRUDA, M.L.R. et al. Efeito de inseticidas na conservação de sementes de milho. Revista Brasileira de Sementes, v.2, n.1, p.53$65,1980$. 
CHRISTENSEN, C.M. Some changes in corn stored two years at moisture contents of $14,5 \%$ and $15,2 \%$ and temperatures of $12^{\circ} \mathrm{C}, 20^{\circ} \mathrm{C}$ and $25^{\circ} \mathrm{C}$. Cereal Chemestry, v.44, n.1, p.95-99, 1966.

DEGLISH, G.J.; EELKEMA, M.; HARRINSON, L.M. Chlorpyrifos-methyl plus methoprene or synergized phenothrin for control of Coleoptera in maize in Queensland, Australia. Meiers Road, Indooropilly, Brisbane, Austrália. Journal of Stored Products Research, v.31, n.3, p.235-241, 1995.

DELOUCHE, J.C.; BASKIN, C.C. Accelerated aging techniques for predicting the relative storability of seed lots. Seed Science and Technology, v.1, n.2, p.427-452, 1973.

DESMARCHELIER, J.M.; DINES, J.C. Dryacide ${ }^{\circledR}$ treament of stored wheat: its efficacy against insects, and after processing. Australian Journal of Experimental Agriculture, v.27, p.309-312, 1987.

DESMARCHELIER, J.M.; WRIGHT, E.J.; ALLEN, S.E. Dryacide ${ }^{\circledR}$ : a structural treatment for stored-product insects. In: AUSTRALIAN APPLIED ENTOMOLOGICAL RESEARCH CONFERENCE, Canberra, 1994. Pest control and sustainable agriculture. Canberra: CSIRO, 1993. p.483-485.

DHINGRA, O.D.; MUCHOVEJ, J.J.; CRUZ FILHO, J. Tratamento de sementes (Controle de patógenos), Viçosa: Imprensa Universitária, 1980. 121p.

DUPCHAK, L.M.; LAZZARI, S.M.N.; LAZZARI, F.A. et al. Efeito de diferentes dosagens de pós inertes no controle de Sitophilus spp. (Col.: Curculionidae) e Rhizopertha dominica (Col.: Bostrichidae) em sementes de milho armazenadas. In: CONGRESSO NACIONAL DE MILHO E SORGO, 21., Londrina, 1996. Resumos. Londrina: IAPAR, 1996. p.284 
EBELING, W. Sorptive dusts for pests control. Annual Review of Entomology, v.16, p.123-158, 1971.

FARONI, L.R.D. Fatores que influenciam a qualidade dos grãos ammazenados. Postcosecha, v.5, n.8, p.34-41, 1988.

FARONI, L.R.D. Manejo das pragas dos grãos armazenados e sua influência na qualidade do produto final. Viçosa. Revista Brasileira de Armazenamento, v.17, n.1/2, p.36-43, 1992.

FLOYD, E.H. Relationship between maize weevil infestation in corn at harvest and progressive infestation during storage. Journal of Economic Entomology, v.64, p.408-411, 1971.

GALLO, D.; NAKANO, O.; SILVEIRA NETO, S. et al. Manual de entomologia agrícola. 2. ed. São Paulo: CERES, 1988. 649p.

GIGA, D.P.; ZVOUTETE, P. The evaluation of different insecticides for the protection of maize against some stored product pests. International Pest Control, v.32, n.1, p.10-13, 1990.

GILBERT, N.; RAWORTH, D.A. Insects and temperature- a general theory. The Canadian Entomologist, v.128, p.1-13, 1996.

GIONÉDIS, M.A.; RUPP, M.M.M.; DUPCHAK, L.M. et al. Efeito do uso de pós inertes em Rhizopertha dominica (Col.: Bostrichidae) e Sitophilus spp. (Col.; Curculionidae) em sementes de milho híbrido C-805 armazenados. In: CONGRESSO NACIONAL DE MILHO E SORGO, 21., Londrina, 1996. Resumos. Londrina: IAPAR, 1996. p.285. 
GOLOB, P. Current status and future perspectives for inert dusts for control of stored product insects. Journal of Stored Products Research, v.33, n.1, p.69-79, 1997.

GODOY, J.R. de ; CROCOMO, W.B.; NAKAGAWA, J. et al. Efeito do armazenamento sobre a qualidade fisiológica de sementes tratadas com inseticidas sistêmicos. Científica, v.18, n.1, p.81-93, 1990.

GUEDES, R.N.C.; LIMA, J.O.G.; SANTOS, J.P. et al. Inheritance of deltametrin resistance in a Brazilian strain of maize weevil (Sitophilus zeamais Mots.). International Journal of Pest Management, v.40, n.1, p.103-106, 1994.

HAREIN, P.H.; LAS CASAS, E. Chemical control of stored-grain insects and associated micro and macro-organisms. In: CRISTENSEN, C.M. (Ed.). Storage of cereal grains and their products. St. Paul: American Association of Cereal Chemists, 1974. p.232-291.

HARMAN, G.E. Mechanisms of seed infection and pathogenesis. Phytopathology, v.73, n.2, p.326-329, 1983.

HOWE, R.W. Loss of viability of seed in storage attributable to infestation of insect and mites. Seed Science and Technology, n.1, p.563-586, 1973.

IBARRA, R.M.R.; MARKHAM, R.H.; ARRIAGA, J.T. Porcentage de pérdida de peso en maíz almacenado causado por insectos. Chapingo: Instituto Nacional de Investigaciones Forestales y Agropecuárias. 1990. 18p.

KATZ, H. Desiccants: dry a dust means insect's death. Pest Control Technology, v.82, p.84, 1991. 
KOMATSU, Y.H. Tratamento inseticida e as qualidades fisiológicas de sementes de milho (Zea mays L.). Piracicaba, 1985. 87p. Dissertação (Mestrado)- Escola Superior de Agricultura “Luiz de Queiroz”, Universidade de São Paulo.

KORUNIC, Z. Rapid assessment of the insecticidal value of diatomaceous earths without conducting bioassays. Journal of Stored Products Research, v.33, n.3, p.219-229, 1997.

KORUNIC, Z. Review diatomaceous earths, a group of natural insecticides. Journal of Stored Products Research, v.34, n.2/3, p.87-97, 1998.

KORUNIC, Z.; CENKOWSKI, S.; FIELDS, P. Grain bulk density as affected by diatomaceous earth and application method. Postharvest Biology and Technology, v.13, n.1, p.81-89. 1998.

KORUNIC, Z.; FIELDS, P.G.; KOVACS, M.I.P. et al. The effect of diatomaceous earth on grain quality. Postharvest Biology and Technology, v.9, p.373-387, 1996.

KRZYZANOWSKI, F.C.; FRANÇA NETO, J.B.; HENNING, A.A. Relato dos testes de vigor disponíveis para grandes culturas. Informativo ABRATES, v.1, n.2, p.15-50, 1991.

LA HUE, D.W. Evaluation of malathion, diazinon, a silica aerogel, and a diatomaceous earth as protectants on wheat against lesser grain borer attack in small bins. Washington:USDA, Agricultural Research Service, Marketing Research, 1970. 12p. (Report, 860).

LA HUE, D.W. Grain protectans for seed corn. Journal of Economic Entomology, v.69. p.652-654, 1976.

LAZZARI, F. Contaminação fúngica de sementes, grãos e rações. In: SIMPÓSIO DE PROTEÇÃO DE GRÃOS ARMAZENADOS. Passo Fundo, 1993. Anais. Passo Fundo: EMBRAPA, CNPT, 1993. p.59-61. 
LAZZARI, F.A.; GIONÉDIS, M.A.; RUPP, M.M.M. et al. Avaliação da eficácia de terra diatomácea sobre populações de insetos em sementes armazenadas de milho híbrido. In: CONGRESSO NACIONAL DE MLHO E SORGO, 21., Londrina, 1996. Resumos. Londrina: IAPAR, 1996. p.283.

LE PATOUREL, G.N.J. The effect of grain moisture content on the toxicity of a sorptive silica dust to four species of grain beetle. Journal of Stored Products Research, v.22, n.1, p.63-69, 1986.

MACHADO, J.C. Patologia de sementes: fundamentos e aplicações. Brasilia: MEC; ESAL; FAEPE, 1988. 107p.

MATIOLI, J.C.; ALMEIDA, A.A. de.; MATIOLI, C.H. Efeitos da infestação do Sitophilus oryzae (L., 1763) sobre a germinação de sementes de milho armazenado. Revista Brasileira de Armazenamento, v.3, n.4, p.15-18, 1978.

MATIOLI, J.J.; ALMEIDA, A.A. Alterações nas caractenísticas químicas dos grãos de milho causadas pela infestação de Sitophilus oryzae (L., 1973)- nitrogênio total e carboidratos. Revista Brasileira de Armazenamento, v.4, n.1, p.57-68, 1979.

McLAUGHLIN, A. Laboratory trials on desiccant dust insecticides. In: INTERNATIONAL CONFERENCE ON STORED-PRODUCT PROTECTION, 6., Canberra, 1994, Proceedings. London: CABI, 1994. p.638-645.

MLLS, J.T. Insect-fungus associations influencing seed deterioration. Phytopathology, v.73, p.330-335, 1983.

MORDUE, W.; GOLDSWORTH, G.J.; BRADY, J. et al. Insect physiology. Oxford, Blackwell, 1980. 108p. 
NIELSEN, P.S. The effect of a diatomaceous earth formulation on the larvae of Ephestia kuehniella Zeller. Journal of Stored Products Research, v.34, n.2/3, p.113-121, 1998.

NOVEMBRE, A.D.L.C.; MARCOS FILHO, J. Tratamento fungicida e conservação de sementes de feijão. Revista Brasileira de Sementes, v.13, n.2, p.105-112, 1991.

OLIVEIRA, A.M.; PACOVA, B.E.; SUDO, S. et al. Incidência de Zabrotes subfasciatus Bohemann, e Acanthoscelides obtectus Say, em diversos cultivares de feijão armazenado. Anais da Sociedade Entomológica do Brasil, v.8, n.1, p.47-55, 1979.

PACHECO, I.A.; PAULA, D.C. Insetos de grãos armazenados: Identificação e biologia. Campinas: Fundação Cargill, 1995. 228p.

PADILHA, L.; FARONI, L.R.D.A. Importância e forma de controle de Rhizopertha dominica em grãos armazenados. In: SIMPÓSIO DE PROTEÇÃO DE GRÃOS ARMAZENADOS. Passo Fundo, 1993. Anais. Passo Fundo: EMBRAPA, CNPT, 1993. p.52-58.

PESKE, S.T. Programa de sementes. In: SIMPÓSIO SOBRE ATUALIZAÇÃO DO PROGRAMA DE SEMENTES DO RS, Pelotas, 1988. Anais. Pelotas: UFPel, 1988. p.21-29.

PINTO JUNIOR, A.R; PEREIRA, P.R.V.S.; LAZZARI, F.A. Avaliação de pós inertes na manutenção da qualidade de grãos de milho armazenado por 270 dias. In: CONGRESSO NACIONAL DE MILHO E SORGO, 21., Londrina, 1996. Resumos. Londrina: IAPAR, 1996. p.302.

PINTO, N. F. J. A. Tratamento de sementes. Sete Lagoas: EMBRAPA, CNPMS, 1991. 10p. 
POPINIGIS, F. Fisiologia da semente. Brasilia: AGIPLAN, 1985. 289p.

PUZZI, D. Abastecimento e armazenagem de grãos. Campinas: Instituto Campineiro de Ensino Agrícola, 1986. 605p.

QUARLES, W. Diatomaceous earth for pest control. The Integrated Pest Management Practitioner, v.14, n.7, p.1-11, 1992.

QUARLES, W.; WINN, P.S. Diatomaceous earth and stored products. The Integrated Pest Management Practitioner. v.18, n.5/6, p.1-10, 1996.

RICHTER, J.; BILIWA, A.; HELBIG, S.H. Efficacy of dust formulated insecticides in traditional maize stores in west África. Journal of Stored Products Research, v.34, n.2/3, p.181-187, 1998.

RUPP, M.M.M.; DUPCHAK, L.M.; LAZZARI, S.M.N. et al. O uso de pós inertes no controle de insetos em sementes de sorgo armazenadas. In: CONGRESSO NACIONAL DE MILHO E SORGO, 21., Londrina, 1996. Resumos. Londrina: IAPAR, 1996. p.280.

SANTOS, J.P.; FONTES, R.A.; CAJUEIRO, I.V.M. et al. Levantamento de perdas causadas por insetos no milho armazenado em pequenas propriedades do Estado do Paraná. In:CONGRESSO NACIONAL DE MILHO E SORGO, 16., Belo Horizonte, 1986. Anais. Sete Lagoas: EMBRAPA, CNPMS, 1988a. p.254-275. (EMBRAPA CNPMS. Documentos, 6).

SANTOS, J.P.; FONTES, R.A.; CAJUEIRO, I.V.M. et al. Situação do armazenamento de milho a nível de propriedade no Estado do Espírito Santo. In: CONGRESSO NACIONAL DE MILHO E SORGO, 16., Belo Horizonte, 1986. Anais. Sete 
Lagoas: EMBRAPA, CNPMS, 1988b. p.237-247. (EMBRAPA. CNPMS. Documentos, 6).

SANTOS, J.P.; MAIA, J.D.G.; CRUZ, I. Efeito da infestação pelo gorgulho (Sitophilus zeamais) e traça (Sitotroga cerealella) sobre a germinação de sementes de milho. Pesquisa Agropecuária Brasileira, v.25, n.12, p.1687-1692, 1990.

SANTOS, J.P; OLIVEIRA, A.C. Perda de peso em grãos armazenados devido ao ataque de insetos. Sete Lagoas: EMBRAPA, CNPMS. 1991. 6p. (Comunicado Técnico, 6)

SANTOS, J.P. Controle de pragas de grãos ammazenados. In: CONGRESSO NACIONAL DE MILHO E SORGO, 19., Porto Alegre, 1992. Anais. Porto Alegre: SAA; ABMS; EMATER-RS; EMBRAPA, CNPMS; CIENTEC, 1992. p.191-209.

SANTOS. J.P. Recomendações para o controle de pragas de grãos e de sementes armazenadas. In: BÜLL, L.T.; CANTARELLA, H. Cultura do milho: fatores que afetam a produtividade. Piracicaba: POTAFOS, 1993. p.197-248.

SEDLACEK, J.D.; BARNEY, R.J.; PRICE, B.D. et al. Effect of several management tactics on adult mortality and progeny production of Sitophilus zeamais (Coleoptera: Curculionidae) on stored corn in the laboratory. Journal of Economic Entomology, v.84, p.100-105, 1991.

SILVA, F.M.A; MELO, P.C.; CARVALHO, R.L. Efeito de inseticidas na germinação e vigor de sementes de milho (Zea mays L.) em duas épocas de armazenamento. In: CONGRESSO NACIONAL DE MLHO E SORGO, 21., Londrina, 1996. Resumos. Londrina: IAPAR, 1996. p.276. 
SIMPÓSIO DE PROTEÇÃO DE GRÃOS ARMAZENADOS, Passo Fundo, 1993. Anais. Passo Fundo: EMBRAPA,CNPT, 1993. 147p.

SINCLAIR, E.R.; ALDER, J. Migration of stored-grain insect pests from a small wheat bulk. Australian Journal of Experimental Agriculture and Animal Husbandry, v.24, n.125, p.260-266, 1984.

SINHA, A.K.; SINHA, K.K. Insect pests, Aspergillus flavus and aflatoxin contamination in stored wheat: a survey at North Bihar (Índia). Journal of Stored Products Research, v.26, p.223-226, 1990.

SINHA, K.K.; SINHA, A.K. Impact of stored grain pests on seed deterioration and aflatoxin contamination in maize. Journal of Stored Products Research, v.28, n.3, p.211-219, 1992.

SMIDERLE, O.J.; BELARMINO, L.C. Danos provocados por Rhizopertha dominica Fabricius, 1792 em sementes de arroz irrigado armazenadas. In: REUNIÃO DA CULTURA DO ARROZ IRRIGADO, 20., Pelotas, 1993. Anais. Pelotas: EMBRAPA, CPACT, 1993. p.205. (EMBRAPA. CPACT. Documentos, 1)

SMIDERLE, O.J. Qualidade fisica e fisiológica de sementes de arroz irrigado, submetidas ao ataque de insetos durante o armazenamento. Pelotas, 1994. 61p. Dissertação (Mestrado) - Faculdade de Agronomia "Eliseu Maciel", Universidade Federal de Pelotas.

SMIDERLE, O.J.; SANTOS FILHO, B.G.; SANTOS, D.S.B.; LOECK, A.E.; SILVA, J.B. Qualidade fisica e fisiológica de sementes de arroz irrigado (Oryza sativa L.), submetidas ao ataque de Rhizopertha dominica e Sitophilus sp. durante o armazenamento. Revista Brasileira de Sementes, v.19, n.1, p.1-8, 1997. 
SMIDERLE, O.J.; SANTOS FILHO, B.G.; SANTOS, D.S.B.; LOECK, A.E.; SILVA, J.B. Qualidade fisica de sementes de arroz irrigado, submetidas ao ataque de insetos durante o armazenamento. Revista Brasileira de Armazenamento, v.20, n.1/2, p.26-32, 1995.

SUBRAMANYAM, B.; SWANSON, C.L.; MADAMANCHI, N. et al. Effectiveness of Insecto $^{\circledast}$, a new diatomaceous earth formulation, in supressing several stored-grain insect species. In: INTERNATIONAL CONFERENCE ON STORED-PRODUCT PROTECTION, 6., Canberra, 1994, Proceedings. London: CABI, 1994. p.650-659.

SUBRAMANYAM, B. Resistance measurement and management. In: Subramanyam, B.; Hagstrum, D.W. (ed.), Integrated management of insects in stored products. Marcel Dekker: New York, p.331-338, 1995.

TAKAHASHI, L.S.A. Efeitos da aplicação de inseticidas, fungicidas e suas associações na qualidade das sementes de milho (Zea mays L.). Piracicaba, $1985.73 p$. Dissertação (Mestrado)- Escola Superior de Agricultura "Luiz de Queiroz", Universidade de São Paulo.

TAKAHASHI, L.S.A.; CICERO, S.M. Efeito da aplicação de inseticidas e fungicidas e suas associações na qualidade de sementes de milho. Revista Brasileira de Sementes, v.8, n.1, p.85-100, 1986.

VERNALHA, M.M.; SOARES, S.G.; ROCHA, M.A.L.; GABARDO, J.C. 0 expurgo. Curitiba: Instituto de Biologia e Pesquisas Tecnológicas, 1966. 131p. (Boletim, 43) VON PINHO, E.V.R.; SILVEIRA, J.F.; VIEIRA, M.G.G.C. et al. Influência do tamanho e do tratamento de sementes de milho na preservação da qualidade durante o armazenamento e posterior comportamento na campo. Lavras-MG. Ciência e Prática, v.19, n.1, p.30-36, 1995. 
WETZEL, M.M.V.S. Fungos de armazenamento. In: SOAVE, J.; WETZEL, M.M.V.S. Patologia de sementes. Campinas: Fundação Cargill, 1987. cap.9, p.260-275.

WRIGLEY, C.W.; GRAS, P.W.; BASON, M.L. Maintenance of grain quality during storage- prediction of the conditions and period of "safe" storage. In: INTERNATIONAL CONFERENCE ON STORED-PRODUCT PROTECTION, 6. Canberra, 1994, Proceedings. London: CABI, 1994. p.666-670.

YADAV, T.D.; MOOKHERJEE, P.B. Tolerance of different hybrids and composites of maize seeds to fumigants. Seed Research, v.2, p.51-55, 1975.

YAMADA, H. Pre and post-harvest control for the production of quality seed of vegetable. In: Textbook Vegetable Seed, Tsukuba. Japan, 1989. 133p.

ZONTA, E.P.; MACHADO, A.A. Sistema de análise estatística para microcomputadores - SANEST. Pelotas, UFPel, 1984. (Disquete) 